\title{
GALLIUM CONTAINING ZINC BORATE BIOACTIVE GLASSES FOR BONE GRAFT APPLICATIONS
}

\author{
by
}

\author{
Alireza Rahimnejad Yazdi
}

BSc, Materials Engineering, Sahand University of Technology, Iran, 2007

MSc, Composite Materials Engineering, Malek Ashtar University of Technology, Iran, 2009

\author{
A dissertation \\ presented to Ryerson University \\ in partial fulfillment of the \\ requirements for the degree of \\ Doctor of Philosophy \\ in the Program of \\ Mechanical Engineering
}

Toronto, Ontario, Canada, 2017

(C)Alireza Rahimnejad Yazdi 2017 


\section{Author's Declaration}

\section{AUTHOR'S DECLARATION FOR ELECTRONIC SUBMISSION OF A DISSERTATION}

I hereby declare that I am the sole author of this dissertation. This is a true copy of the dissertation, including any required final revisions, as accepted by my examiners.

I authorize Ryerson University to lend this dissertation to other institutions or individuals for the purpose of scholarly research.

I further authorize Ryerson University to reproduce this dissertation by photocopying or by other means, in total or in part, at the request of other institutions or individuals for the purpose of scholarly research.

I understand that my dissertation may be made electronically available to the public. 


\title{
Abstract \\ GALLIUM CONTAINING ZINC BORATE BIOACTIVE GLASSES FOR BONE GRAFT APPLICATIONS
}

\author{
Doctor of Philosophy, 2017 \\ Alireza Rahimnejad Yazdi \\ Department of Mechanical \& Industrial Engineering \\ Faculty of Engineering \& Architectural Science \\ Ryerson University
}

Zinc borate glasses with increasing gallium (Ga) content $(0,2.5,5,10$, and 15 wt.\% Ga) were synthesized with Ga replacing boron. X-ray diffraction (XRD) verified their amorphous state. Thermal analysis recorded a steady decline in both glass transition and crystallization temperatures with the addition of $\mathrm{Ga} .{ }^{11} \mathrm{~B}$ magic angle spinning nuclear magnetic resonance spectroscopy showed incremental addition of Ga reduced the $\mathrm{BO}_{4} / \mathrm{BO}_{3}$ ratio.

Next, Bioactivity and antibacterial properties were investigated. Ion release profiles showed that increased Ga content in the glass resulted in increased Ga ion release, but decreased the release of other ions. The formation of amorphous Ca-P on the surface of all the glasses after 24 hours of incubation in simulated body fluid was confirmed by scanning electron microscopyenergy dispersive spectroscopy, XRD and Fourier transform infrared spectroscopy analyses. Antibacterial evaluation of the glasses demonstrated that the addition of $\mathrm{Ga}$ increased the antibacterial potency of the glasses against $P$. aeruginosa (Gram-negative bacteria) while decreasing it against $S$. epidermidis (Gram-positive bacteria).

Finally, the effect of glass composition on the viability and proliferation of preosteoblast and osteosarcoma cancer cells was investigated. Methyl Thiazolyl Tetrazolium (MTT) cell viability assays using glass degradation extracts revealed that the extracts from glasses with 0 , 2.5 and 5 wt. \% Ga did not lower the viability of preosteoblasts; however, extracts from glasses with 0 and $2.5 \%$ Ga increased the viability of cancer cells. Therefore, glass with 5 wt.\% Ga (G3) was selected for further analyses. The viability of preosteoblasts and osteosarcoma cells in contact with the G3 glass powders were also investigated using MTT assays. G3 powders could enhance the viability of preosteoblasts while decreasing the viability of osteosarcoma cells. According to Live/Dead assays, suppression of proliferation appeared to be the mechanism causing the reductions in the viability of osteosarcoma cells exposed to G3 powders.

In conclusion, the performed in vitro characterizations confirmed the bioactivity and antibacterial activity of all glasses. However, G3 was selected as the most suitable composition for osteosarcoma-related graft operations as it could improve the viability of preosteoblasts without increasing the viability of cancer cells. 


\section{Acknowledgements}

Firstly, I would like to thank my supervisor, Dr. Mark Towler for giving me the chance to be part of his great group, and for being a very supportive, knowledgeable, and friendly supervisor. I would also like to thank my family: Ali, Mahnaz, Narges, Nastaran, and Mojtaba, for always giving me their unconditional love and support. I would like to seize this opportunity to acknowledge the support I have received from my lab-mates (Adel, Omar, Mike, Li, Saad, Faizan and Basel) and the following Ryerson technicians: Alan Machin, Joe Amankrah, Shawn McFadden, Qiang Li, Robert Denning, Roy Churaman and Grace He. Dr. Stephen Waldman, Dr. Declan Curran, Dr. Daniel Boyd, Dr. Glenn A. Facey, Warren Tang, Lawrence Torkan, Warren Tang, and Dr. Wendy Stone also assisted with aspects of data collection and provided technical and analytical support for some of the experiments performed for this dissertation.

I respectfully acknowledge the funding from Collaborative Health Research Project (\#315694-DAN) for financing this research. 


\section{Dedication}

I dedicate this work to my beloved parents for their unconditional love and support in every step of my life. I also dedicate this work to my brother and my sisters and their lovely children.

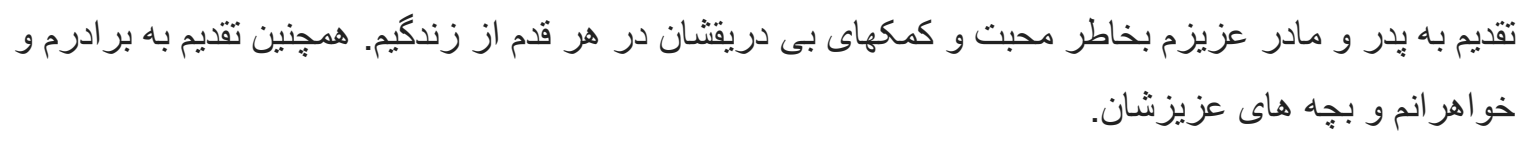




\section{Tables of Contents}

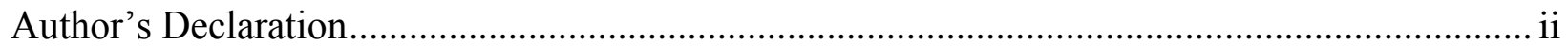

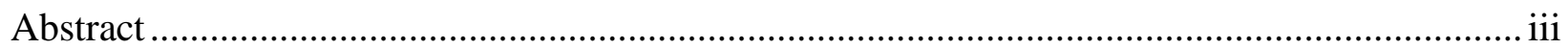

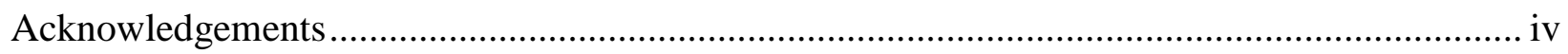

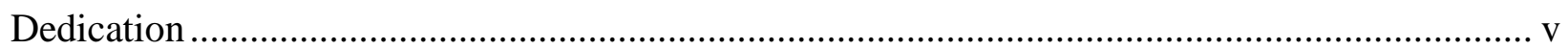

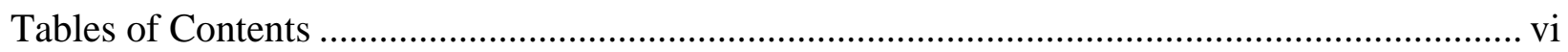

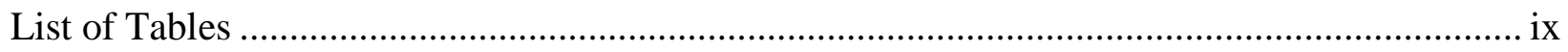

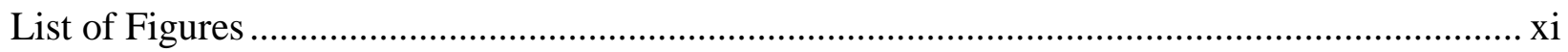

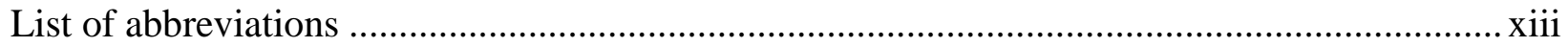

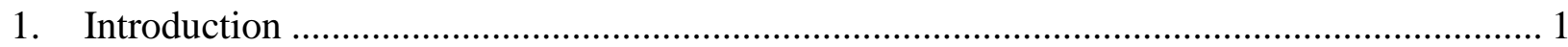

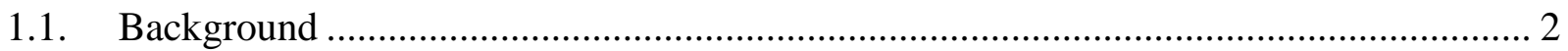

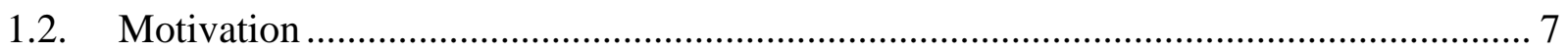

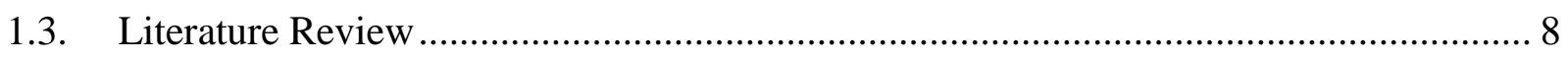

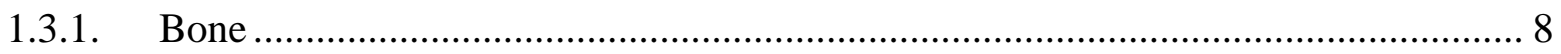

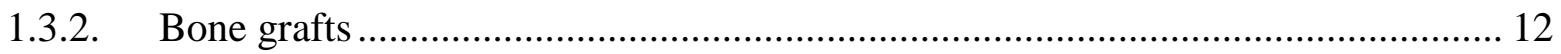

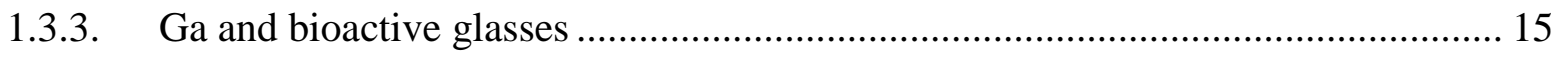

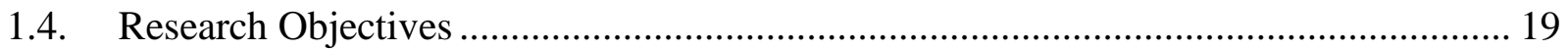

1.5. Author's Contribution in the Context of Collaboration ........................................... 20

2. The effect of the addition of gallium on the structure of zinc borate glass with controlled

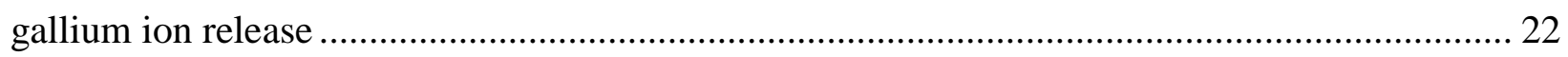

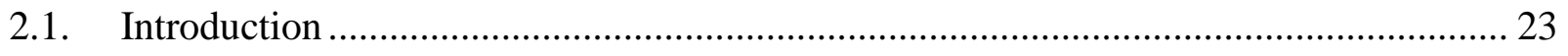

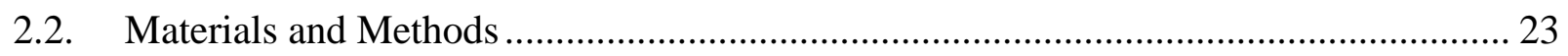

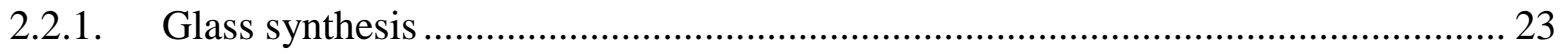

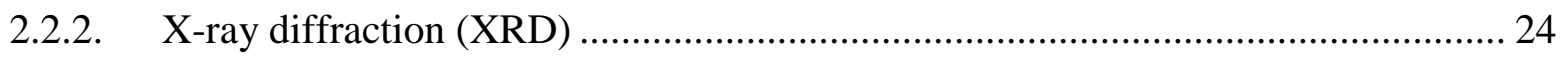

2.2.3. Scanning Electron Microscopy-Energy Dispersive Spectroscopy (SEM-EDS).... 24 


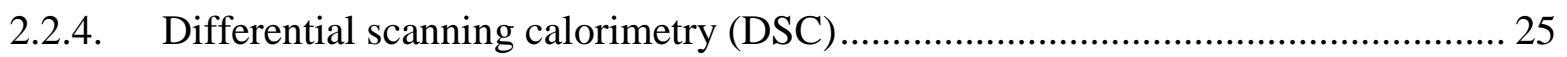

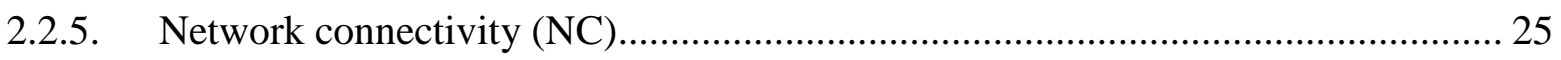

2.2.6. Fourier transform infrared spectroscopy (FTIR) ................................................ 26

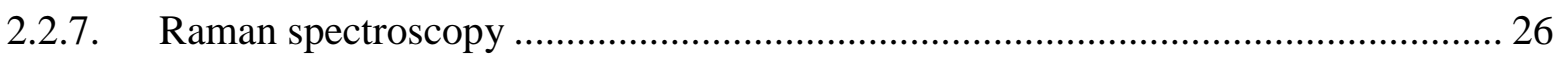

2.2.8. Magic-angle spinning- Nuclear magnetic resonance spectroscopy (MAS-NMR) . 27

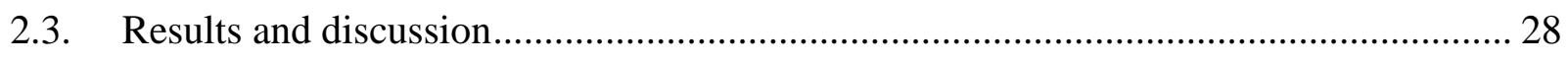

The DSC curves of the synthesized glasses are similar (Figure 2- 3); however, as it can be seen

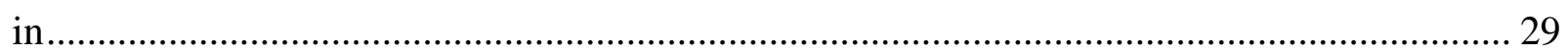

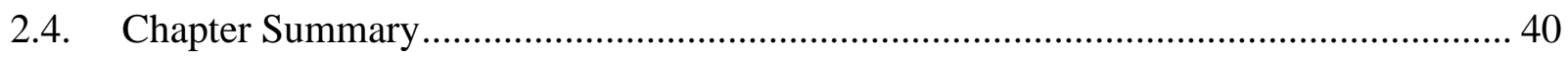

3. The impact of gallium content on degradation, bioactivity and antibacterial potency of zinc borate bioactive glass ....................................................................................................... 42

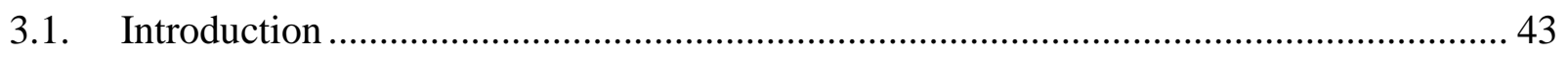

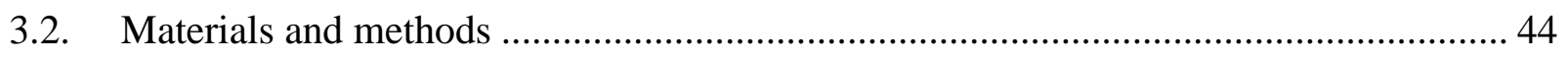

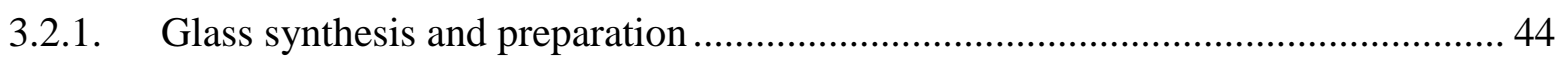

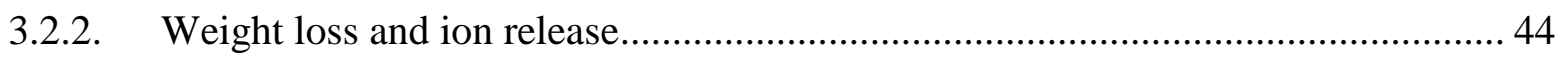

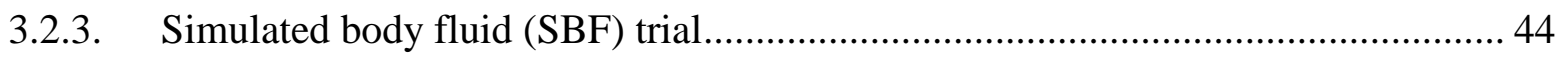

3.2.3.1. SBF preparation and incubation ...................................................................... 44

3.2.3.2. Scanning electron microscopy- energy dispersive spectroscopy ……................. 45

3.2.3.3. Fourier transform infrared spectroscopy (FTIR) ................................................ 45

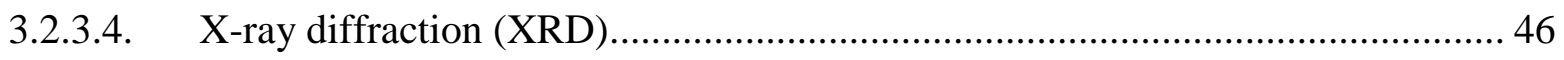

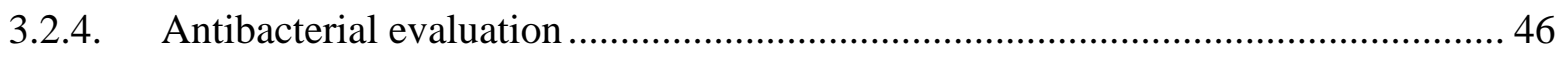

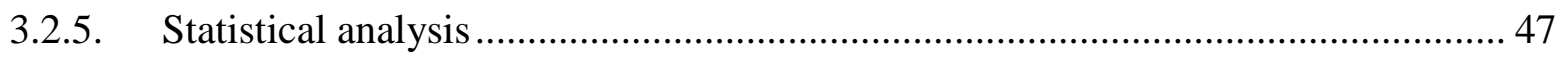

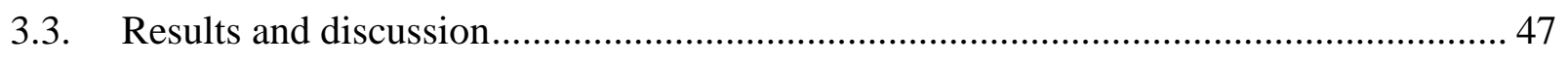

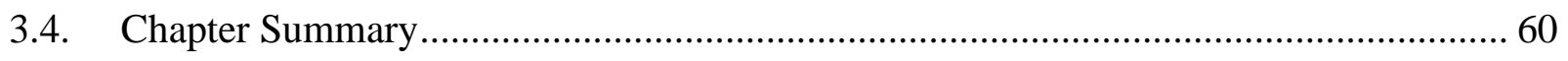

4. Development of a novel bioactive glass suitable for osteosarcoma-related bone grafting applications 


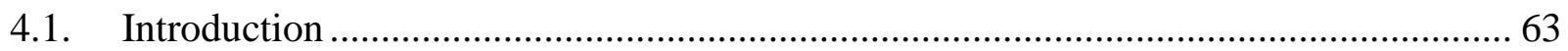

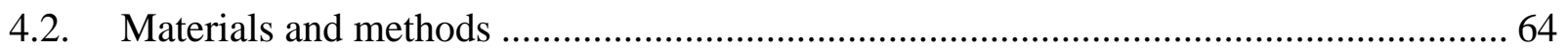

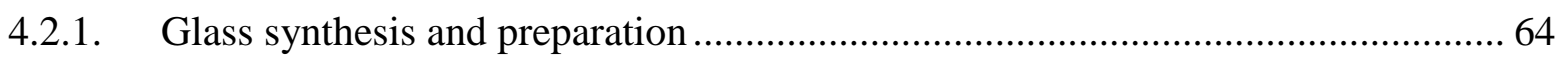

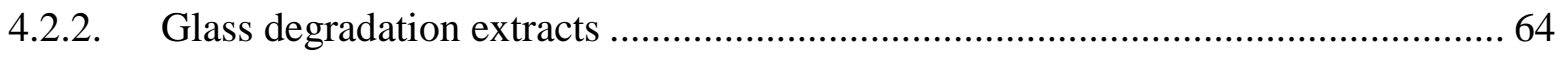

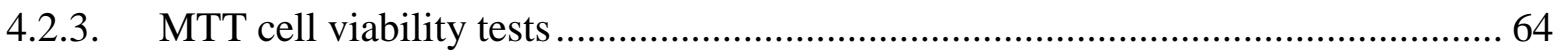

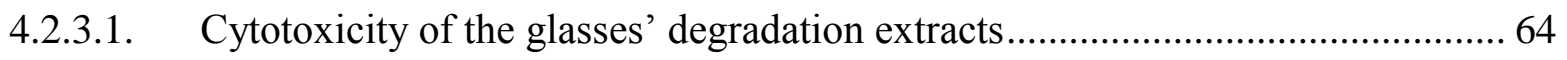

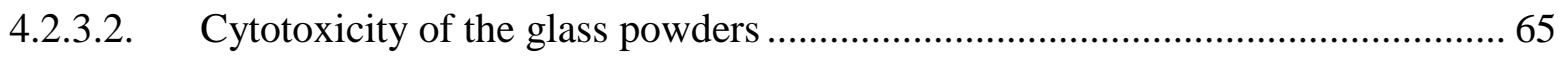

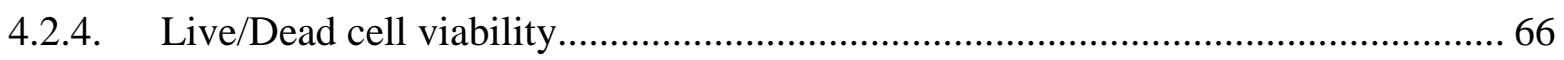

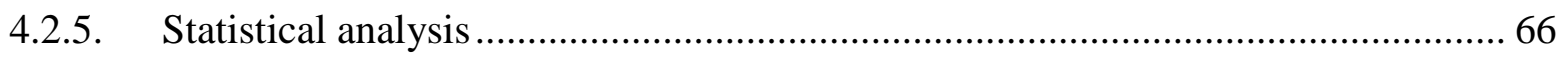

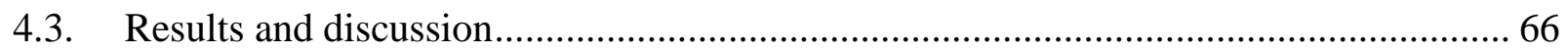

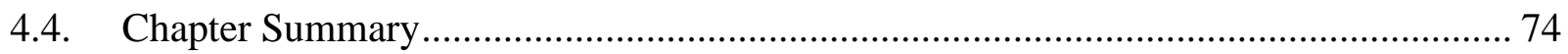

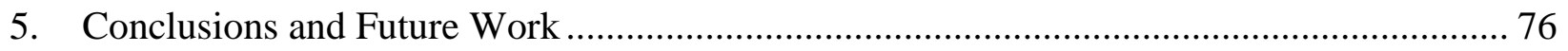

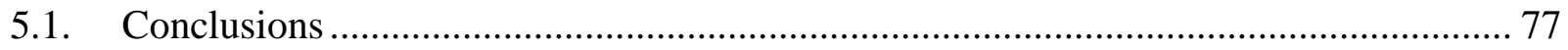

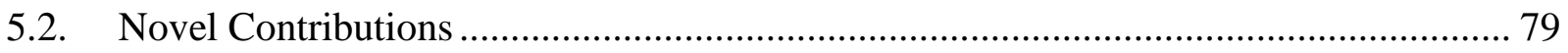

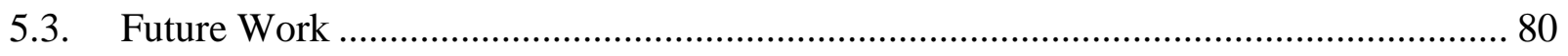

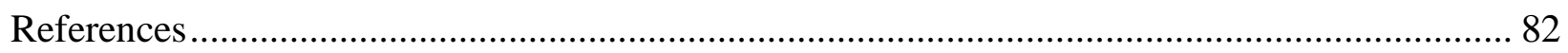




\section{List of Tables}

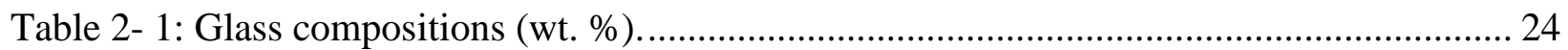

Table 2- 2: D10, D50 and D90 values in micrometers for the glass powders............................. 25

Table 2- 3: The assumed role of the elements in the glass network. ............................................ 26

Table 2- 4: Glass transition temperature $\left(\mathrm{T}_{\mathrm{g}}\right)$ and first crystallization temperature $\left(\mathrm{T}_{\mathrm{C} 1}\right)$ of the

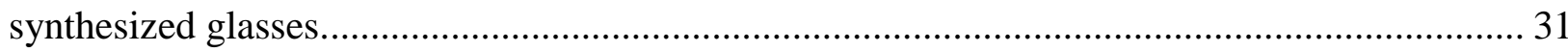

Table 2- 5: The calculated values of network connectivity of the synthesized glass compositions.

Table 2- 6: FTIR peak assignments of the synthesized glasses. ......................................... 31

Table 2- 7: Raman peak assignments of the synthesized glasses. ......................................... 34

Table 2- 8: The peak centers and peak area percentages from the fitted ${ }^{11} \mathrm{~B}$ NMR MAS lineshape

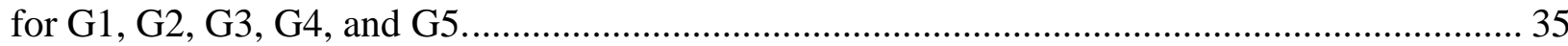

Table 2- 9: The peak centers and peak area percentages from the fitted ${ }^{31} \mathrm{P}$ NMR MAS lineshape

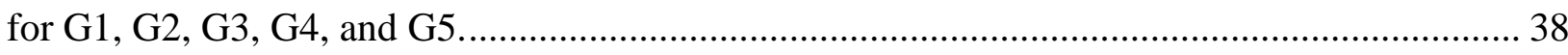

Table 3- 1: Order and amounts of reagents for preparing $1000 \mathrm{ml}$ of SBF.............................45 Table 3- 2: The p-values for degradability measurements of the glasses according to the Kruskal-

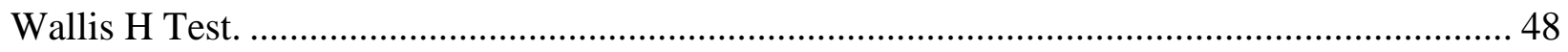

Table 3- 3: The p-values for ion release measurements of the glasses according to Kruskal-Wallis H Test.

Table 3- 4: The p-values for inhibition zone measurements of the glasses according to KruskalWallis H Test. 58

Table 4- 1: The p-values for the PO cell viability measurements of the glass extracts and control

(C) according to Mann-Whitney $U$ test: Those with $\mathrm{P}>0.05$ are underlined. 69

Table 4- 2: The concentration ( $\mathrm{ppm}$ ) of the released ions from glass powder after soaking in DI water for 1,7 , and 28 days at $37^{\circ} \mathrm{C}$.

Table 4- 3: The p-values for the OS cell viability measurements of the glass extracts and control

(C) according to Mann-Whitney $\mathrm{U}$ test: Those with $\mathrm{P} \leq 0.05$ are underlined. 70 
Table 4- 4: The p-values for the PO \& OS cell viability measurements of the glass powders and

control (C) according to Mann-Whitney $\mathrm{U}$ test: Those with $\mathrm{P} \leq 0.05$ are underlined................. 72 


\section{List of Figures}

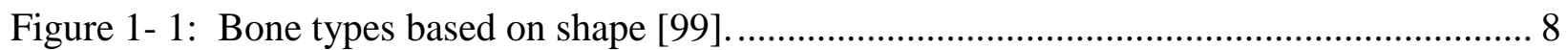

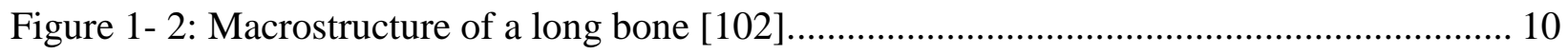

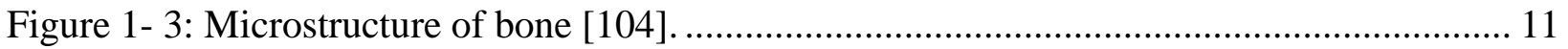

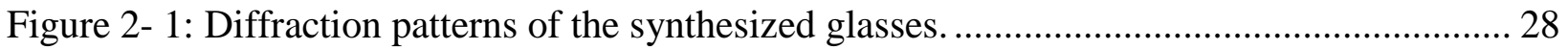

Figure 2- 2: The EDS spectra of the synthesized glasses with normalized counts....................... 29

Figure 2- 3: DSC curves of the synthesized glasses; (a) G1, (b) G2, (c) G3, (d) G4, (e) G5...... 30

Figure 2- 4: FTIR spectra of the synthesized glasses. ............................................................... 32

Figure 2- 5: Raman spectra of the synthesized glasses........................................................... 33

Figure 2- 6: The ${ }^{11}$ B NMR MAS spectra for the synthesized glasses. ........................................ 35

Figure 2- 7: The fit of ${ }^{11}$ B NMR MAS lineshape for (a) G1, (b) G2, (c) G3, (d) G4, and (e) G5.36

Figure 2- 8: The ${ }^{31}$ P NMR MAS spectra for the synthesized glasses ........................................... 38

Figure 2- 9: The fit of ${ }^{31}$ P NMR MAS lineshape for (a) G1, (b) G2, (c) G3, (d) G4, and (e) G5. 39

Figure 3- 1: The weight loss percentages of the synthesized glasses in deionized water and SBF after (a) 1, (b) 7 and (c) 28 days of incubation at $37^{\circ} \mathrm{C}$; error bars represent standard deviation.49 Figure 3- 2: The concentration of the ions released from G1, G2, G3, G4, and G5 after soaking in DI water for 1,7 , and 28 days at $37^{\circ} \mathrm{C}$; (a) $\mathrm{Ga}$, (b) $\mathrm{Zn}$, (c) $\mathrm{Na}$, (d) P, (e) B, (f) Ca; error bars represent standard deviation.

Figure 3-3: SEM image of the precipitations on the surface of a G1 glass particle; (a) before immersion in SBF, and after immersion in SBF for: (b) 1 day, (c) 7 days, and (d) 28 days........ 53 Figure 3- 4: The normalized EDS spectra of G3 glass particles after incubation in SBF for (a) 1,

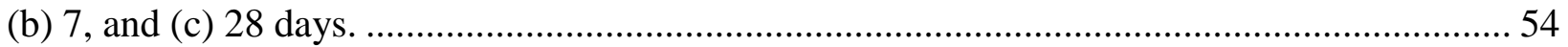

Figure 3- 5: X-ray Diffraction pattern of G5 particles after immersion in SBF for 28 days........ 55 Figure 3- 6: The FTIR spectra of the synthesized glasses before and after immersion in SBF for 1, 7 and 28 days; (a) G1, (b) G2, (c) G3, (d) G4, (e) G5 ....................................................... 56 
Figure 3- 7: Inhibition zone diameters of the synthesized glasses against $S$. epidermidis after 1, 7, and 28 days of incubation (irregular growth of bacteria in the inhibition zone was observed in 7 and 28 day samples); error bars represent standard deviation. ............................................. 58 Figure 3- 8: Inhibition zone diameters of the synthesized glasses against P. aeruginosa after 1, 7, and 28 days of incubation (irregular growth of bacteria in the inhibition zone was observed in 28 day samples); error bars represent standard deviation..................................................... 59

Figure 4- 1: The viability of the preosteoblast cells in the presence of (a) 1 day, (b) 7 day, and (c) 28 day glass extracts; error bars represent standard deviation. 68 Figure 4- 2: The viability of the osteosarcoma cells in the presence of (a) 1 day, (b) 7 day, and (c) 28 day glass extracts; error bars represent standard deviation............................................. 71 Figure 4- 3: Cell viability of (a) PO and (b) OS cells in the presence of 1, 2 and $5 \mathrm{mg}$ of G3 glass powders; error bars represent standard deviation. 73 Figure 4- 4: Labeled live (green) and dead (red) OS cells after exposure to 1, 2, and 5 mg G3 glass powders. 


\section{List of abbreviations}

\begin{tabular}{ll} 
ATR & Attenuated total reflectance \\
BMPs & Bone morphogenetic proteins \\
BMU & Basic multicellular unit \\
Ca-P & Calcium phosphate \\
CPCs & Calcium phosphate cements \\
CW & Continuous wave \\
DBM & Demineralized bone matrix \\
DI & Deionized \\
DSC & Differential scanning calorimetry \\
FTIR & Fourier transform infrared spectroscopy \\
GICs & Glass ionomer cements \\
GPCs & Glass polyalkenoate cements \\
HA & Hydroxyapatite \\
HCA & Carbonated hydroxyapatite \\
ICDD & International Centre for Diffraction Data \\
ICP-AES & Inductively coupled plasma atomic emission spectroscopy \\
MAS NMR & Magic angle spinning nuclear magnetic resonance \\
MEM $\alpha$ & Minimum essential medium alpha \\
MTT & Methyl Thiazolyl Tetrazolium \\
NC & Network connectivity \\
OC & Osteocalcin \\
OS & Osteosarcoma \\
PO & Preosteoblast \\
ppm & Part per million \\
SBF & Simulated body fluid \\
SEM-EDS & Scanning electron microscopy-energy dispersive spectroscopy \\
TC1 & First crystallization temperature \\
TCP & Tricalcium phosphate \\
Tg & Glass transition temperature \\
TSA & Tryptic Soy Agar \\
UV & Ultra violet \\
XRD & X-ray diffraction \\
& \\
\hline &
\end{tabular}


1. Introduction 


\subsection{Background}

Since their development in the late 1960s, bioactive glasses have been used for bone tissue engineering applications [1,2]. The therapeutic properties of these glasses are a result of their degradation in the body and the subsequent release of ions into the surrounding tissue $[2,3$, 4]. Due to their biocompatibility and ability to bond to both bone and soft tissue, bioactive glasses have been utilized for bone augmentation [5, 6, 7, 8, 9]. Scaffolds and bone graft powders have been fabricated entirely from bioactive glass [10,11, 12, 13, 14, 15].

Early bioactive glasses were composed of silica $\left(\mathrm{SiO}_{2}\right)$, soda $\left(\mathrm{Na}_{2} \mathrm{O}\right)$, calcia $(\mathrm{CaO})$ and phosphorus pentoxide $\left(\mathrm{P}_{2} \mathrm{O}_{5}\right)$. However, other elements have been substituted into bioactive glasses in order to enhance their therapeutic performance and modify their physical and mechanical properties $[16,17,18,19]$. For example, borate based glasses have fast dissolution rates and the ability to facilitate tissue infiltration, cell proliferation and differentiation [9]; silver (Ag) is known for its oligodynamic effect and inducing antibacterial properties in glass; boron (B) and magnesium $(\mathrm{Mg})$ have been incorporated to modify the thermal coefficient temperature of the glass such that it matches that of metal substrates for coating applications $[19,20,21,22$, 23]; and zinc (Zn) is known to offer both antibacterial and anti-inflammatory effects [24, 25, 26, 27] and can enhance bone formation by stimulating osteoblast activity and retarding the formation of osteoclasts $[28,29]$.

Among those elements that can be added to a bioactive glass, $\mathrm{Ga}$ is a promising candidate due to its antibacterial and anti-inflammatory properties, ability to suppress bone resorption, and its antineoplastic properties in ionic form $[30,31,32]$. These therapeutic properties explain why Ga has been recently incorporated into bioactive glasses [33, 34, 35]. However, because of the concentration limits determined by its toxicity and minimum concentration needed for its 
effectiveness, one the most critical features of such Ga glasses is the quantity of the active ion that can be released from them $[36,32,37,38]$. The structure of the glass network is a major factor that determines ion release from a bioactive glass [19]; therefore, understanding how the structure of the glass is affected by the incorporation of $\mathrm{Ga}$ is of great importance in predicting and designing formulations that target specific ion release amounts. Ga is known as an intermediate element in the glass network that can act as both network former and modifier [39]. Franchini et al. (2012) studied the structural role of Ga in a series of phosphosilicate bioactive glasses with varying $\mathrm{Ga}$ content and reported that, at $\mathrm{Ga}$ concentrations above $3.2 \mathrm{~mol} \%, \mathrm{Ga}$ starts to significantly change the degradation behavior of the glass by acting as a network modifier [40]. Similar studies on Ga containing silica bioactive glasses further imply the network modifier role of $\mathrm{Ga}$ in the glass structure $[34,41]$. However, there are studies that have found that $\mathrm{Ga}$ incorporation can reduce the dissolution rate $[33,35]$ which could be indicative of the network forming ability of this intermediate element.

Another important feature of a bioactive glass is its osteoconductivity; defined as the ability of a material to encourage bone growth on a surface [42]. In vitro formation of calcium phosphate $(\mathrm{Ca}-\mathrm{P})$ on the surface of the glass upon its immersion in an acellular solution of simulated body fluid (SBF) containing ion concentrations nearly equal to that of human blood plasma can indicate its ability to integrate with hard tissue after implantation. A formula for a supersaturated SBF solution was initially described by Cho et al. [43]. The degree and rate of HA formation on the surface of bioactive glasses in SBF has been considered to predict the degree of in vivo bioactivity $[3,44,45]$. The silicate-derived bioactive glass designated 45S5 (Bioglass $\left.{ }^{\circledR}\right)$ was the first to demonstrate bone-bonding properties and its bioactivity has since been widely studied [46]. Hench et al. developed 45S5 Bioglass, a soda-lime-phosphosilicate 
$\left(\mathrm{SiO}_{2}-\mathrm{Na}_{2} \mathrm{O}-\mathrm{CaO}-\mathrm{P}_{2} \mathrm{O}_{5}\right)$ glass [47].The osteoconductivity of $45 \mathrm{~S} 5$ has been attributed to formation of HA on its surface after implantation [48, 14, 46, 49, 50, 51, 52]. Other bioactive glasses with varying compositions such as $13-93$ bioactive glass $\left(\mathrm{SiO}_{2}-\mathrm{CaO}-\mathrm{K}_{2} \mathrm{O}-\mathrm{Na} 2 \mathrm{O}-\mathrm{MgO}-\right.$ $\mathrm{P}_{2} \mathrm{O}_{5}$ ) have been developed in order to provide enhanced therapeutic performance and modify physical and mechanical properties [53].

Borate-based bioactive glasses have lower chemical durability compared to silicate-based ones and thus degrade faster $[53,9]$. They have the potential to convert more completely to HA than silicate glasses and can better match the rate of new tissue formation in the body [53,9]. The conversion mechanisms are similar to that of silicate glasses; however, a $\mathrm{SiO}_{2}$ gel-layer is absent during the degradation of borate glasses. Borate-based glasses offer support of cell differentiation, tissue infiltration $[54,55]$, and they are also able to serve as a carrier for drug delivery applications $[56,57,58]$.

The addition of inorganic components such as $\mathrm{Ga}$ and $\mathrm{Zn}$ can grant antibacterial properties to glasses and can also participate in the physiological functions associated with bone metabolism [30, 31]. $\mathrm{Ga}^{3+}$ interferes with bacterial metabolic and DNA-synthetic pathways by substituting for Iron $\left(\mathrm{Fe}^{3+}\right)$ on transferrin. However, $\mathrm{Ga}^{3+}$ is not reduced under physiological conditions like $\mathrm{Fe}^{3+}$ allowing it to perturb the metabolism of both eukaryotic and prokaryotic cells $[59,60]$. The $\mathrm{Zn}$ ion $\left(\mathrm{Zn}^{2+}\right)$ has demonstrated regulation of osteoblastic activity and bone formation, as well as antimicrobial properties in its ionic form [61, 62]. When incorporated into bioactive glass, it has the ability to kill bacteria through an ion release mechanism similar to that of Ag-doped bioactive glasses [31, 23]. Excess levels of zinc oxide have also been shown to have a detrimental effect on the integrity of cell membranes, thereby eliminating or preventing the proliferation of pathogens [63]. 
The $\mathrm{Ga}^{3+}$ ion also works to combat cancer cells through a variety of mechanisms of physiological interference, mostly involving DNA replication and disruption of its helical structure [64]. $\mathrm{Ga}^{3+}$ is considered a non-functional mimetic of iron (Fe) and can be substituted into transferrin to inhibit ribonucleotide reductase, a key enzyme involved in the replication of DNA [64]. Its effectiveness stems from direct inhibition of the enzyme, as well as blocking the iron available to bind to the enzyme for proper functioning [65]. $\mathrm{Ga}^{3+}$ also competes with the magnesium ion $\left(\mathrm{Mg}^{2+}\right)$ which binds to DNA to stabilize it. The affinity of Ga for DNA has been shown to be 100 times higher than that of $\mathrm{Mg}$ [37]. When higher concentrations of Ga ion are present in vitro with a high Ga: DNA ratio $(\geq 1 / 40)$, it has been reported that destabilizing reactions occur by means of Ga bonding to the nucleic bases [36]. In addition to vying with various ions, $\mathrm{Ga}$ has the ability to induce chromatin condensation in vitro [66]. This is considered an early step in the process of apoptosis, and thus results in cell death through a mechanism of Fe deprivation [66].

With respect to bone metabolism, $\mathrm{Ga}^{3+}$ has been extensively studied due to its marked ability to decrease hypercalcemia associated with cancer $[67,68,69,70]$. Its physiological effects consist of inhibition of osteoclastic activity, an increase in collagen synthesis, as well as an increase of bone tissue formation in vitro $[71,72,73,74,75,76]$. Osteoclast resorption is inhibited through alteration of gene expression of a bone matrix signaling protein [77]. Exposure of mesenchymal or mesenchymally-derived cells to $\mathrm{Ga}$ also causes a change in matrix protein synthesis to favour bone formation through a similar genetic modification mechanism [78]. An additional benefit of inducing tissue fibrosis in the tumor $[79,80]$ and evaluation of vascular permeability have also been observed [81]. Radioactive isotopic compounds have shown promise in their absorption by cancerous deposits in bone [82]. ${ }^{67} \mathrm{Ga}$ scans can also be used to predict the 
effectiveness of this treatment by scanning and observing the degree of visibility of tumors following absorption of the isotope [83].

The abovementioned therapeutic properties of Ga can explain the motives for studies that incorporate it into bioactive glasses [33, 34, 35]. These glasses appear to be beneficial for the treatment of patients with osteoporosis, bone cancer and compromised immune systems that leaves them more vulnerable to postsurgical infections. It has been hypothesized that glass grafts that release $\mathrm{Ga}^{3+}$ can reduce or eliminate the removal of healthy bone tissue that is currently extracted as part of the tumor removal surgery for bone cancer [34, 35]. However, this hypothesis has not been investigated experimentally to date. 


\subsection{Motivation}

Every year, approximately two million patients worldwide require bone graft operations for repairing complex fractures, fusion of spinal bones, enhancing implant attachment to bone, and regeneration of bone lost to diseases such as infection and cancer [84]. Due to the risk of rejection and disease transmission in allografts, and potential morbidity at the donor site, limited quantities, increased blood loss, risk of wound infection and longer anesthetic time in autografts, there is a growing demand for synthetic bone grafts $[85,86,87]$.

Bioactive glasses are one of the most promising categories of materials for bone grafts [2]. Given the therapeutic properties of Ga ions which are particularly desirable for orthopedic applications [32, 88, 89, 90, 91, 92], and the very limited research conducted about the inclusion of this element in such glasses [93, 94, 35, 33], the research conducted here is aimed to exploit the significant potential of $\mathrm{Ga}$ inclusion in bioactive glasses. Five novel zinc borate bioactive glasses with varying Ga content were synthesized; the structural studies determined the impact of $\mathrm{Ga}$ addition on the glass network; biocompatibility and biodegradability of the glasses were evaluated; and finally antibacterial and antineoplastic efficacy of these glasses were assessed in vitro.

These glasses are expected to be beneficial to patients suffering from osteoporosis, bone cancer and compromised immune systems. In this study, for the first time, the effect of $\mathrm{Ga}$ releasing bioactive glasses on bone cancer cells were investigated and compared to their effect on healthy bone cells. 


\subsection{Literature Review}

\subsubsection{Bone}

Bone is a composite material that consists of plate-like crystals of hydroxyapatite (HA) in a collagen matrix [95]. Not only do bones serve as a supportive and protective framework for the human body, but they also store nutrients such as calcium and phosphate ions and produce blood cells $[96,97]$. Bones can be categorized based on their shapes which reflect their functions. With regard to their shape, the four major types of bones are: long bones, short bones, flat bones and irregular bones (Figure 1- 1). Long bones consist of a long shaft with extremities at their ends. They include the bones of the leg, arm, hands and feet, fingers and the clavicles. Short bones are roughly cubic in shape with almost similar width and length and include the tarsals and the carpals in the ankle and wrist, respectively. Flat bones are thin, flattened, and usually curved. Most of the bones of the cranium are flat bones. The ribs and the sternum are also flat bones. Bones that have shapes not matching any of the above three categories are classified as irregular bones. The vertebrae and facial bones are irregular bones [98].

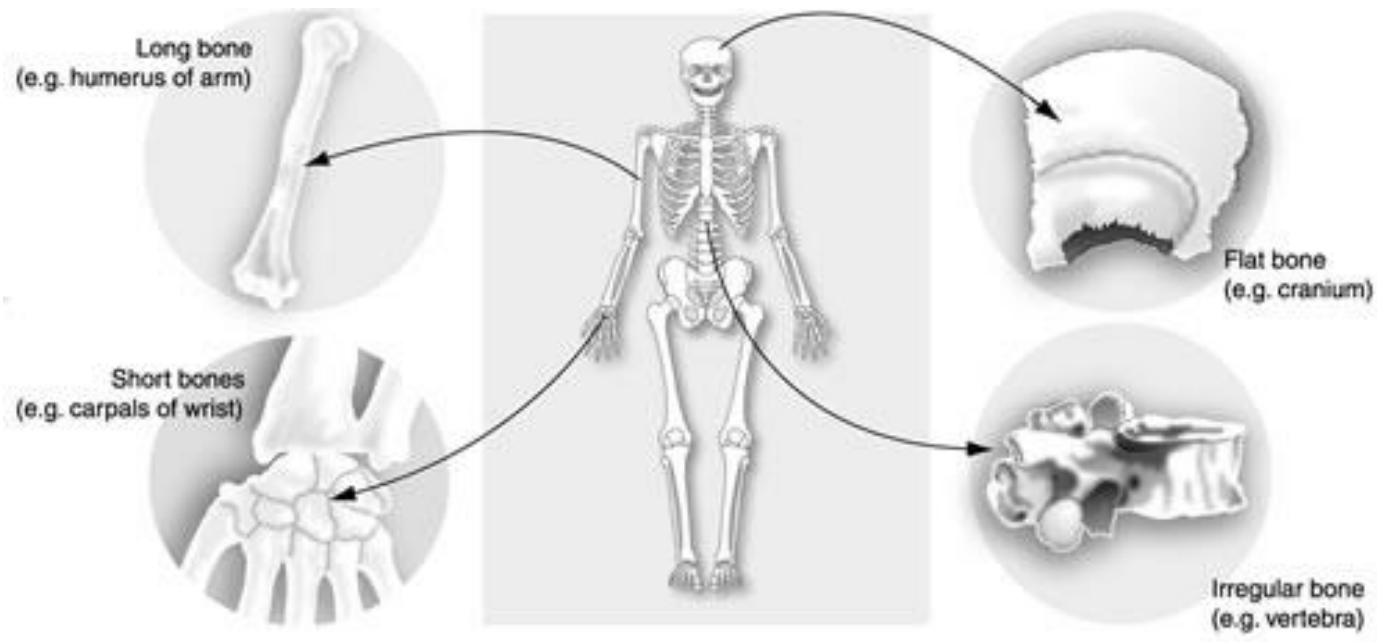

Figure 1- 1: Bone types based on shape [99]. 


\subsubsection{Bone macrostructure}

As shown in Figure 1- 2 a long bone is composed of three main regions: the proximal and distal epiphysis in the two ends and the diaphysis in the middle. The diaphysis or the central tubular shaft is built of a layer of calcified tissue known as cortical bone or compact bone. It surrounds the medullary cavity which houses bone marrow [100]. Epiphyses have a thinner layer of cortical bone than the diaphysis and contain a meshed network of thin calcified trabeculae known as trabecular bone (also called spongy or cancellous bone) [101]. Bone marrow is also found within trabecular bone. The epiphyseal line separates the diaphysis from epiphyses. The internal and external surfaces of bone are covered by membranes. The outer surface of the diaphysis is covered by the periosteum, a dense fibrous membrane serving as an attachment for muscles and tendons, whose inner layer consists of osteogenic cells. Endosteum internally surrounds trabecular surfaces and serves as a lining to the canals that pass through cortical bone [100]. The joint surface and each epiphysis are covered with a thin layer of hyaline cartilage that provides a cushion for opposing ends of a joint during motion [101]. Flat bones have a similar design and have periosteum covered compact bone at the outer surface and endosteum covered trabecular bone internally. These bones do not have a medullary cavity, but contain marrow in their internal trabecular parts. Structures of short and irregular bones are similar to the epiphyses of long bones [100]. 


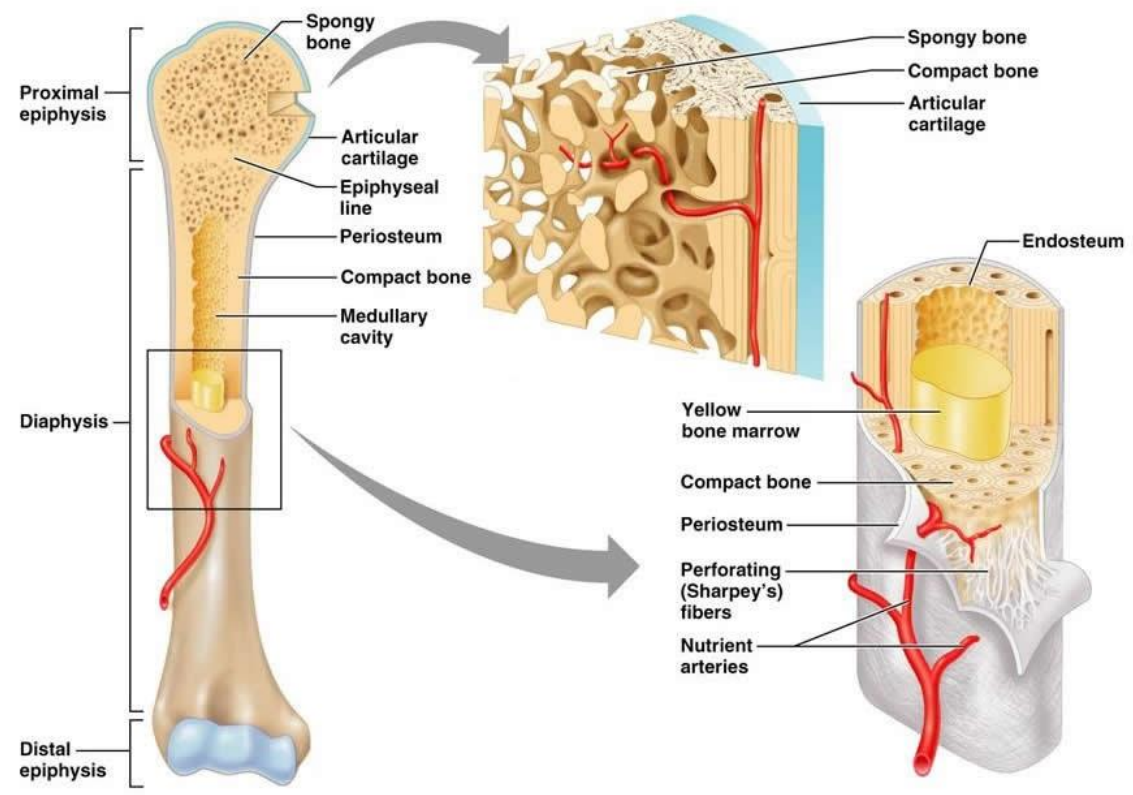

Figure 1- 2: Macrostructure of a long bone [102].

\subsubsection{Bone microstructure}

The osteon also known as the haversian system is the basic functional unit of cortical bone. As illustrated in Figure 1- 3, the osteocytes in an osteon are arranged in concentric layers around a central canal or haversian canal which contains blood vessels. These concentric layers are called lamellae which are produced due to inactivity periods of bone formation. Unlike haversian canals that run parallel to the surface of the bone, Volkmann's canals are positioned perpendicular to the surface of the bone and provide blood to osteons deeper in the bone and tissues of the marrow cavity. The lacunae of bone are pockets typically organized around blood vessels that contain osteocytes and canaliculi are narrow passages between the lacunae and nearby blood vessels. They form a network for the provision of nutrients [103]. 


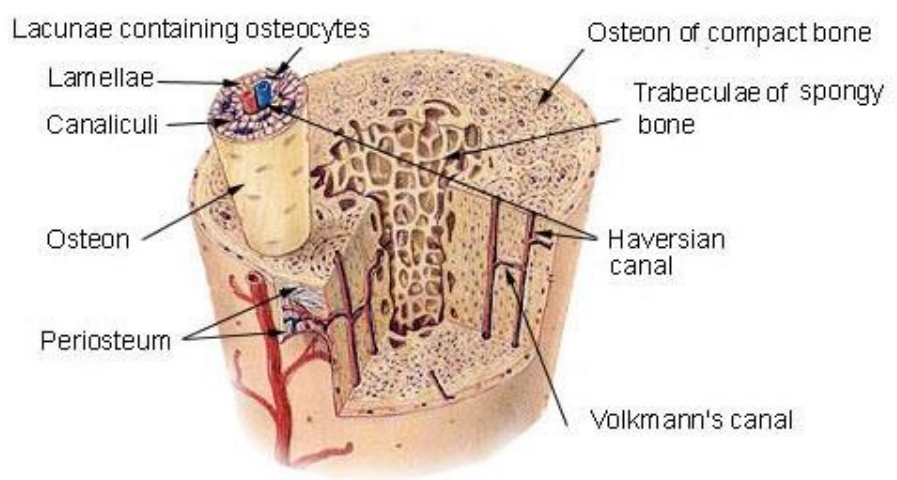

Figure 1- 3: Microstructure of bone [104].

\subsubsection{Bone remodeling}

Frost (1964) confirmed that human bones are continually broken down and reformed by the activities of osteoblasts and osteoclasts through a process known as bone remodeling [105, 106]. In young adults, about $10 \%$ of the skeleton is turned-over each year by this process [107]. Bone remodeling is essential for bone growth, adjustment to stress, changes in bone shape, bone repair and regulation of calcium ion in the body. Bone remodeling is achieved by temporary assemblies of osteoclasts and osteoblasts known as the Basic Multicellular Unit (BMU) with an average life span of about 6 months that remove and replace the old bone matrix. In cortical bone, the osteoclasts break down bone matrix (resorption) leaving tunnels; blood vessels can then grow into the carved tunnels and osteoblasts form new bone in the form of concentric lamellae. In cancellous bone, the osteoclasts resorb the matrix from surface of trabecula leaving cavities for ostesoblasts to form new bone [98]. 


\subsubsection{Bone grafts}

About two million patients worldwide require bone graft operations annually [84]. A bone graft transplantation procedure is commonly used for repairing complex fractures, fusion of vertebral bones, enhancing implants' attachment to bone, and regeneration of bone lost to diseases such as infection and cancer.

\subsubsection{Autograft and allograft}

If the bone graft is taken from a healthy site in the patient's body such as the iliac crest, it is called autograft (autologous bone) and bone graft achieved from a donor is known as allograft which carries the risk of rejection and transmittance of diseases, such as infection and viruses. Although autologous bone graft is still regarded as the gold standard of bone grafts, potential morbidity at the donor site, limited quantities, increased blood loss, risk of wound infection and longer anesthetic time are some of the reasons that has led to the growing market in synthetic bone grafts $[85,86,87]$.

\subsubsection{2. $\quad$ Processed bone matrix and proteins}

Demineralized bone matrix $(\mathrm{DBM})$ is prepared by acid extraction of allografts. It contains collagen and other proteins and growth factors that include bone morphogenetic proteins (BMPs) and is shown to be both osteoconductive and osteoinductive [108, 109]. The performance of DBM can vary from donor to donor and also depends on the preparation process. BMPs 2-7 and BMP 9 are known to be independently osteoinductive [108, 109, 110]. BMP-7 and BMP-2 have been studied in human trials and have shown to induce bone formation in tibial non-unions at the same rate as autologous bone graft [111]. However, the cost of BMP products 
is a major limitation for their extended use; for example 1mg of BMP2 can cost over $\mathrm{C} \$ 4,500$ [112].

\subsubsection{Ceramic bone grafts}

The most commonly used ceramic based bone grafts are hydroxyapatite (HA) and tricalcium phosphate (TCP). They are osteoconductive, have a long shelf life and carry no risk of transmitting disease [86]. HA is a highly crystalline form of calcium phosphate which is considered a very biocompatible ceramic. Its nominal composition is $\mathrm{Ca}_{10}\left(\mathrm{PO}_{4}\right)_{6}(\mathrm{OH})_{2}$. It has an unparalleled chemical similarity to the mineralized phase of bone which leads to its osteoconductive properties and significant biocompatibility [113, 114].

Tricalcium phosphate (TCP) is a bioresorbable and biocompatible ceramic with nominal composition of $\mathrm{Ca}_{3}\left(\mathrm{PO}_{4}\right)_{2}$ and exists in two crystalline forms of $\alpha$ and $\beta$. Its chemical composition and crystallinity are similar to those of the mineral phase of bone. TCP resorbs faster than HA [115].

\subsubsection{Bone cements}

Calcium phosphate cements (CPCs) were introduced more than three decades ago for dental applications. Given their biocompatibility, osteoconductiveness, mouldability, and selfsetting under ambient conditions, CPCs have been attractive candidates as bone grafts and various formulations of them have been developed, especially for percutaneous vertebroplasty and kyphoplasty [116, 117]. Glass polyalkenoate cements (GPCs) have also been developed and used for dental restoration since over three decades ago, and have the advantages similar to those mentioned for CPCs as bone grafts $[118,119,120]$. 


\subsubsection{Bioactive glasses}

Bioactive glasses are a promising category of materials for bone tissue engineering; they are both osteoconductive and osteoinductive; they have the ability to bond to bone due to formation of calcium phosphate on their surface in the body [2]. Formation of a Ca-P layer on bioactive glass surfaces in contact with SBF gives it the ability to chemically bond to collagen fibrils and induces the development of a strong interface between the glass and bone [2]. Moreover, the released ions from the glass can activate genes associated with the differentiation of osteoblasts; therefore, bioactive glasses can be considered osteoinductive [121]. Bioactive glasses also allow for angiogenesis. In vitro studies have shown that increases in angiogenic indicators have been obtained through both direct and indirect contact of relevant cells with 45S5 Bioglass particles or with their dissolution products. An in vivo study has confirmed the ability of bioactive glass, incorporated into scaffolds, to stimulate neovascularization [122]. Over the years, various formulations of bioactive glasses have been developed and biologically active elements, such as $\mathrm{Zn}, \mathrm{Mg}$, copper $(\mathrm{Cu})$, strontium $(\mathrm{Sr})$, potassium $(\mathrm{K})$ and B have been included in the glass formulation in order to add or enhance their therapeutic properties $[123,124,53]$. $\mathrm{Zn}$ is reported to have anti-inflammatory effects and stimulate bone formation by stimulating osteoblasts [123, 53]. $\mathrm{Mg}, \mathrm{B}$ and $\mathrm{Sr}$ are also reported to promote bone formation $[123,53] . \mathrm{Cu}$ is reported to stimulate angiogenesis $[123,53]$. Partial replacement of sodium (Na) and calcium (Ca) with $\mathrm{K}$ and $\mathrm{Mg}$, respectively, tailors the thermal expansion coefficient of the 45S5 Bioglass such that it better matched titanium substrates [124]. 


\subsubsection{Ga and bioactive glasses}

The Ga ion has very desirable therapeutic features for orthopedic applications. It is antibacterial and anti-inflammatory [91, 92], and is used for the treatment of osteoporosis and cancer-related hypercalcemia due to its ability to limit osteoclastic bone resorption and increase the mineral content of the bone $[38,88,89,90] . \mathrm{Ga}^{3+}$ is also known to have antineoplastic properties [32]. In 1971, Hart et al. investigated the toxicity and antineoplastic properties of some of the group III metals (aluminum, gallium, indium and thallium) and for the first time indicated the antitumor potentials of Ga [32]. In vitro studies on calf thymus DNA has shown that trivalent Ga can bind to DNA and destabilize DNA helix. Ga is reported to initiate apoptosis by inducing chromatin condensation. It also inhibits DNA duplication through forming complexes with transferrin and blocking iron, as well as targeting enzymes [36].

The anti-cancerous effects of $\mathrm{Ga}^{3+}$ and related side effects on humans have been investigated. Ga nitrate has been intravenously administered with dosage up to $300 \mathrm{mg} / \mathrm{Kg}$ using protracted venous infusion [36]. This delivery protocol has been shown to be effective against cancer hypercalcemia, bladder carcinoma, carcinoma of the urothelium and lymphoma. However, side effects such as granulocytopenia grade 3 and 4 despite the use of growth factors, renal function alteration grade 3 or 4 , hypocalcemia grade 3 or 4 , thrombocytopenia and temporary blindness have been reported in some of the experimented patients [36]. A successful treatment schedule, especially for bone metastases, is $40 \mathrm{mg}$ administered as a sub-cutaneous injection once daily for 2 weeks [36]. Another gallium nitrite administered dosage as bone resorption inhibitor is $200 \mathrm{mg} / \mathrm{m} 2$ daily for 5 consecutive days [125]. Ga can also be introduced to the body via gallium chloride; its optimal dosage for oral administration is reported to be 400 $\mathrm{mg} / 24 \mathrm{~h}$. Gallium maltolate is another source of Ga that has been orally administered and the 
reported results indicate it has better bioavailability compared to gallium chloride [36, 126, 127]. Moreover, studies show that administration of $\mathrm{Ga}$ in combination with conventional chemotherapy agents leads to synergistic antineoplastic activities [36, 126, 127].

Recently, the therapeutic properties of Ga have motivated some limited studies about the inclusion of Ga in bioactive glasses, and more research needs to be done in order to help patients benefit from the therapeutic potential of Ga containing bioactive glasses [33, 34, 35]. Mourino et al. (2010) trapped gallium nitrite solution in a 45S5 bioglass scaffold using alginate sodium coatings in order to synthesize $45 \mathrm{~S} 5$ scaffolds. The produced scaffolds had antibacterial properties and enhanced mechanical properties without decreasing the bioactivity level provided by the base bioactive glass structure. However, the effect of the release of the Ga ion from these scaffolds on bone cells was not investigated [92]. Shruti et al. (2012) developed Ga containing (up to $3.5 \mathrm{~mol} \% \mathrm{Ga}$ ) silica based bioactive glasses and studied their chemical structure and degradability. The glasses were found to be capable of forming hydroxycarbonate apatite on their surface after immersion in SBF. Although, neither the cytotoxicity nor the potential antibacterial properties of the Ga containing glasses were studied [93, 94].

Wren et al. (2012) produced Ga containing glass ionomer cements (GICs) for treating bone cancer by including $\mathrm{Ga}(0.08 \mathrm{~mol} . \%)$ in the glass component of the GICs. Although the cements were titled "anti-cancerous", ion release and appropriate cell cultures were not reported to back up the authors' hypothesis about the anti-cancerous properties of the synthesized cements [34]. Alhalawani (2013) produced Ga containing GICs as a possible alternative adhesive in sternal fixation by including $\mathrm{Ga}$ (up to $0.16 \mathrm{~mol}$. \%) in silica based glass component of the GICs. The chemical structure of the glass as well as rheological and mechanical properties of the cements were investigated. The resultant cements were reported suitable for use for sternal 
fixation, in conjunction with wires. Although antibacterial and anti-inflammatory properties of $\mathrm{Ga}^{3+}$ were mentioned as motives for its inclusion in the glass formulation, such therapeutic properties and the cytotoxicity of the cements were not evaluated [41].

Zeimaran et al. (2015) synthesized silica based $\mathrm{Ga}\left(0.08 \mathrm{~mol} . \% \mathrm{Ga}_{2} \mathrm{O}_{3}\right)$ containing bioactive glass to produce poly (octanediol citrate) scaffolds impregnated with bioglass microparticles. The mechanical properties of the scaffolds were improved due to the addition of bioactive glass particles. The viability of osteoblast cells on these scaffolds were also investigated and the addition of $10 \mathrm{wt} \%$ glass particles to the scaffolds were reported to improve the attachment and viability of osteoblasts. Although the potential use of these scaffolds for bone grafts involving osteosarcoma patients was mentioned in the article, the impact of these scaffolds on osteosarcoma cells were not studied [35]. Pourshahrestani et al. (2016) synthesized mesoporous silica based bioactive glasses containing various concentrations of $\mathrm{Ga}_{2} \mathrm{O}_{3}$ (up to 3 mol\%) using evaporation-induced self-assembly process and investigated their hemostatic and antibacterial properties [128]. The glasses were found to stimulate blood coagulation, platelet adhesion and thrombus generation and showed antibacterial activity against both Escherichia coli (Gram-negative) and Staphylococcus aureus (Gram-positive). They were also reported to be cytocompatible [128].

Deliormanli (2015) for the first time published on the influence of $\mathrm{Ga}$ on the in vitro bioactivity and dissolution behavior of borate based bioactive glass with up to 5 wt.\% Ga content. Low toxicity associated with bacteriostatic properties of $\mathrm{Ga}^{3+}$ were mentioned as reasons for inclusion of $\mathrm{Ga}$ in the glass formulation. The Ga-containing borate glasses had lower degradation rates compared to the Ga-free borate glass 13-93B3. However, a decline did not occur in their bioactive response when immersed in SBF. Despite the fact that several therapeutic 
properties of $\mathrm{G}^{3+}$ were mentioned in the article, the cell culture experiments were not conducted on the manufactured glasses [33]. Deliormanli et al. (2016) manufactured Ga-containing (up to 5 wt.\%) silicate based 13-93 bioactive glass particles using sol-gel method. The effect of Ga on the in vitro bioactivity and mechanical properties of the prepared powders and scaffolds were studied, and it was reported that the addition of Ga did not negatively affect the in vitro bioactivity and HA forming ability of the glass [129]. Deliormanli (2016) also synthesized Gacontaining (up to 5 wt.\%) silicate based 13-93 bioactive glass fibers using electrospinning approach and studied their in vitro bioactivity, cytotoxicity and antibacterial activity. It was shown that Ga has no negative effect on either bioactivity or the HA forming ability of the dissolution products of the glass in the long term. No cytotoxicity and antibacterial response to the Gram-positive (S. aureus) and Gram-negative (E. coli) bacteria was observed [130]. The observed lack of antibacterial activity is contrary to similar experimental reports in the literature $[92,60,59,128]$. 


\subsection{Research Objectives}

The objectives of this research include:

- Synthesis of a series of novel Ga containing zinc borate bioactive glasses with increasing Ga content for bone graft applications via the melt-quench method.

- Characterization of the synthesized Ga containing zinc borate glasses.

The amorphous state of the synthesized glasses will be verified using X-ray diffraction (XRD) analysis. Differential scanning calorimetry (DSC) will be used to measure the glass transition temperature $\left(\mathrm{T}_{\mathrm{g}}\right)$ and crystallization temperature $\left(\mathrm{T}_{\mathrm{C}}\right)$ for the synthesized glasses. Energy dispersive $\mathrm{X}$-ray spectroscopy (EDS) will be used to study the elemental composition of the synthesized glasses. Raman spectroscopy, Fourier transform infrared (FTIR) spectroscopy, and magic angle spinning- nuclear magnetic resonance (MAS-NMR) spectroscopy will be performed in order to gather information about the chemical bonds and the structure of each glass.

- Biodegradability and antibacterial evaluation of the synthesized bioactive glasses.

Weight loss measurements after immersion in both deionized water and simulated body fluid as well as ion-release measurements after immersion in deionized water will be performed in order to investigate the in vitro time-dependent behavior of the bioactive glasses under bodily conditions. The ability of the glasses to allow for formation of calcium phosphate on their surface will be studied by submerging the glasses in simulated body fluid (SBF) for various periods of time and analyzing the surface of the submerged glasses via scanning electron microscopy (SEM), EDS, XRD, and FTIR. Finally, the antibacterial 
properties of the glasses will be evaluated by studying the ability of the glasses to inhibit both Gram-negative and Gram-positive bacterial growth in vitro.

- Evaluation of biocompatibility and antineoplastic properties of the synthesized glasses. The ability of the glasses to support cell proliferation and function will be evaluated using appropriate in vitro cell culture tests. Antineoplastic properties of the glasses will be evaluated by conducting cell culture studies with bone cancer cell lines.

\subsection{Author's Contribution in the Context of Collaboration}

All glasses under discussion were synthesized by the author. For the structural characterization of the glasses, presented in Chapter 2, network connectivity (NC) calculations, image analysis for particle size distribution, and Fourier Transform Infrared (FTIR) spectrometer analysis were performed by the author; x-ray diffraction (XRD), differential scanning calorimetry, scanning electron microscopy, energy dispersive spectroscopy, Raman spectroscopy, and ${ }^{11} \mathrm{~B}$ and ${ }^{31} \mathrm{P}$ magic-angle spinning/nuclear magnetic resonance (MAS-NMR) were collected by trained personnel and the collected data was analyzed by the author. It should be added that the MASNMR analysis were conducted in the University of Ottawa (Ottawa, Canada). Chapter 2 is based on the following publication: Rahimnejad Yazdi, A. and Towler, M.R., 2016. The effect of the addition of gallium on the structure of zinc borate glass with controlled gallium ion release. Materials and Design, 92, pp.1018-1027.

For the evaluation of degradation, bioactivity and antibacterial potency of the glasses, presented in Chapter 3, the XRD, FTIR and antibacterial data were collected and analyzed by the author; for ion release and weight loss measurements assistance with aspects of data collection 
was received from colleagues and the data was analyzed by the author. Chapter 3 is based on the following publication: Rahimnejad Yazdi, A., Torkan, L., Stone, W. and Towler, M.R., 2017. The impact of gallium content on degradation, bioactivity and antibacterial potency of zinc borate bioactive glass, Journal of Biomedical Materials Research Part B: Applied Biomaterials, published online Feb 2, 2017.

For the cytotoxicity and antineoplastic evaluation of the glasses, presented in Chapter 4, assistance was received from trained personnel with aspects of data collection, and the data was analyzed by the author. Chapter 4 is based on the following manuscript submission: Rahimnejad Yazdi, A., Torkan, L., Waldman, S.D. and Towler, M.R., 2017. Development of a novel bioactive glass suitable for osteosarcoma-related bone grafts, Journal of Biomedical Materials Research Part B: Applied Biomaterials (under review). 
2. The effect of the addition of gallium on the structure of zinc borate glass with controlled gallium ion release 
The work presented in this chapter is based on the following peer-reviewed, published paper [131]:

Rahimnejad Yazdi, A. and Towler, M.R., 2016. The effect of the addition of gallium on the structure of zinc borate glass with controlled gallium ion release. Materials and Design, 92, pp.1018-1027.

\subsection{Introduction}

This chapter discusses the structural characterization of a novel borate-based glass series that contain increasing amounts of gallium oxide $\left(\mathrm{Ga}_{2} \mathrm{O}_{3}\right)$. $\mathrm{Ga}$ has been chosen for its antibacterial and antineoplastic properties as well as its ability to inhibit bone resorption. $2.5,5$, 10 and 15 wt. $\%$ of gallium oxide was added to the glasses' composition at the expense of B oxide. The synthesized glasses were studied using x-ray diffraction (XRD), Scanning electron microscopy-energy dispersive spectroscopy (SEM-EDS), differential scanning calorimetry (DSC), Fourier transform infrared (FTIR) spectroscopy, Raman spectroscopy and magic-angle spinning-nuclear magnetic resonance (MAS-NMR) spectroscopy.

\subsection{Materials and Methods}

\subsubsection{Glass synthesis}

Five compositions of borate glasses were formulated (Table 2-1) in order to study the effect of substitution of $\mathrm{Ga}$ for B. Appropriate amounts of analytical grade reagents (Fisher Scientific, Ottawa, ON, Canada; Sigma-Aldrich, Oakville, ON, Canada) were weighed out (by a

scale with $\mathrm{d}=0.001 \mathrm{~g}$ ) in a plastic tub and mixed into a container for $15 \mathrm{~min}$ to obtain a homogenous mix of all reagents. The mix was dried in oven at $100{ }^{\circ} \mathrm{C}$ for 1 hour, and was then 
transferred to silica crucibles for firing $\left(1200^{\circ} \mathrm{C}, 1 \mathrm{~h}\right)$. The glass melts were shock quenched into water and the resulting frits were dried, ball milled and sieved to retrieve glass powders with particle size of $<20 \mu \mathrm{m}$ and $90-710 \mu \mathrm{m}$.

Table 2- 1: Glass compositions (wt. \%).

\begin{tabular}{cccccc}
\hline & Glass1 $(\mathrm{G} 1)$ & Glass2 (G2) & Glass3 (G3) & Glass4 (G4) & Glass5 (G5) \\
\hline $\mathrm{B}_{2} \mathrm{O}_{3}$ & 52 & 49.5 & 47 & 42 & 37 \\
$\mathrm{ZnO}$ & 16 & 16 & 16 & 16 & 16 \\
$\mathrm{Na} 2 \mathrm{O}$ & 14 & 14 & 14 & 14 & 14 \\
$\mathrm{CaO}$ & 12 & 12 & 12 & 12 & 12 \\
$\mathrm{P}_{2} \mathrm{O}_{5}$ & 6 & 6 & 6 & 6 & 6 \\
$\mathrm{Ga}_{2} \mathrm{O}_{3}$ & 0 & 2.5 & 5 & 10 & 15 \\
\hline
\end{tabular}

\subsubsection{X-ray diffraction $(X R D)$}

The amorphous state of the synthesized glasses was verified using XRD. Diffraction patterns were collected using a PAN analytical X-ray diffractometer with a $\mathrm{Cu}$ source from 10 to $80^{\circ}$, at a scan step size $0.05^{\circ}$. A generator voltage of $45 \mathrm{kV}$ and a tube current of $40 \mathrm{~mA}$ were employed. Glass powders with a maximum particle size of $20 \mu \mathrm{m}$ were used as samples. Any crystalline phases present in the obtained XRD patterns were identified using the ICDD (International Centre for Diffraction Data) standard diffraction patterns.

\subsubsection{Scanning Electron Microscopy-Energy Dispersive Spectroscopy (SEM-EDS)}

A JEOL 6380LV scanning electron microscope (SEM) equipped with Oxford energy dispersive X-ray spectroscopy (EDS) was used to study the composition and the particle size 
distribution of the glass powders (Table 2-2) with the size range of 90-710 $\mu \mathrm{m}$. All EDS spectra were collected at $20 \mathrm{kV}$.

Table 2- 2: D10, D50 and D90 values in micrometers for the glass powders.

\begin{tabular}{ccc|ccc|ccc|ccc|ccc}
\hline & G1 & \multicolumn{4}{c}{ G2 } & \multicolumn{4}{c}{ G3 } & \multicolumn{3}{c}{ G4 } & \multicolumn{3}{c}{ G5 } \\
\hline D10 & D50 & D90 & D10 & D50 & D90 & D10 & D50 & D90 & D10 & D50 & D90 & D10 & D50 & D90 \\
\hline 95 & 141 & 271 & 101 & 152 & 277 & 97 & 143 & 282 & 96 & 147 & 279 & 98 & 149 & 276 \\
\hline
\end{tabular}

\subsubsection{Differential scanning calorimetry (DSC)}

A combined differential thermal analyser-thermal gravimetric analyser (SDT 2960 Simultaneous DSC-TGA, TA Instruments, DW, USA) was used to measure the glass transition temperature $\left(\mathrm{T}_{\mathrm{g}}\right)$ and crystallization temperature $\left(\mathrm{T}_{\mathrm{C}}\right)$ for the synthesized glasses. A heating rate of $20{ }^{\circ} \mathrm{C} / \mathrm{min}$ was employed using an air atmosphere with alumina in a matched platinum crucible as a reference. Glass powders with a maximum particle size of $20 \mu \mathrm{m}$ were used as samples. Sample measurements were carried out every six seconds between $30{ }^{\circ} \mathrm{C}$ and $1300{ }^{\circ} \mathrm{C}$. The glass transmission temperature and the crystallization temperature were determined using the TA Instrument Universal Analysis 2000 (version 4.5A) software.

\subsubsection{Network connectivity (NC)}

The network connectivity of the glasses was calculated by solving Equation 2-1 using the molar compositions of the glasses. Network connectivity calculations were performed assuming both network modifier and network former roles for $\mathrm{Zn}$, and network modifier role for Ga.

$\mathrm{NC}=\frac{(\text { No.BOs }- \text { No.NBOs })}{(\text { Total No. bridging species })}$ 
where NC stands for Network Connectivity, and BOs and NBOs refer to Bridging Oxygens and Non-Bridging Oxygens, respectively. The assumed network roles of the elements in the glass composition are provided in Table 2- 3.

Table 2- 3: The assumed role of the elements in the glass network.

\begin{tabular}{ccccccc}
\hline Element & $\mathrm{B}$ & $\mathrm{Ca}$ & $\mathrm{P}$ & $\mathrm{Na}$ & $\mathrm{Zn}$ & $\mathrm{Ga}$ \\
\hline $\begin{array}{c}\text { Assumed role in } \\
\text { glass network }\end{array}$ & former & modifier & former & modifier & former/modifier & former/modifier \\
\hline
\end{tabular}

\subsubsection{Fourier transform infrared spectroscopy (FTIR)}

The Perkin Elmer Spectrum 1 spectrophotometer with a scanning range from 4000 to 450 $\mathrm{cm}^{-1}$ controlled with Spectrum 6 software was used to obtain the FTIR spectra of the samples. The spectral resolution was $4 \mathrm{~cm}^{-1}$. Glass powders with a maximum particle size of $20 \mu \mathrm{m}$ were used as samples. Measurements were performed by Attenuated Total Reflectance (ATR) technique with a ZnSe crystal. The spectrum for each sample was obtained by averaging 25 scans.

\subsubsection{Raman spectroscopy}

The Raman spectra of the glass powders were studied using a Snowy Range Instruments (Sierra Model) Reader with the laser wavelength of $785 \mathrm{~nm}$, the power of $72 \mathrm{~mW}$, and the spectral resolution of $4 \mathrm{~cm}^{-1}$. Snowy Range Instruments built-in Software was used to scan and generate SPC files, and Grams Software was utilized to generate ASCII files from SPC ones. Glass powders with a maximum particle size of $20 \mu \mathrm{m}$ were used as samples. For each sample, five scans were performed and their average was considered as the sample's Raman spectra. Then, the obtained spectra were normalized. 


\subsubsection{Magic-angle spinning- Nuclear magnetic resonance spectroscopy (MAS-NMR)}

300 grams of powdered samples of the synthesized glasses with particle size of $<20 \mu \mathrm{m}$ were analyzed using Solid State ${ }^{31} \mathrm{P}$ and ${ }^{11} \mathrm{~B}$ MAS-NMR. The ${ }^{31} \mathrm{P}$ MAS NMR spectra were acquired with high power continuous wave (CW) 1H decoupling on a Bruker AVANCE III 200 MHz NMR spectrometer equipped with a 7 mm CPMAS probe. The MAS rate was $5 \mathrm{kHz}$, and the ${ }^{31} \mathrm{P} 90^{\circ}$ pulse, acquisition time, and the recycle delay were $3.25 \mu \mathrm{sec}, 10 \mathrm{msec}$, and $60 \mathrm{sec}$ respectively. All spectra represent at least 40 minutes of data collection. The chemical shifts were referenced externally to ammonium dihydrogen phosphate which was assigned a chemical shift of $0.81 \mathrm{ppm}$ with respect to $85 \%$ phosphoric acid at $0 \mathrm{ppm}$. Data were processed with 50 $\mathrm{Hz}$ of exponential line broadening.

The ${ }^{11} \mathrm{~B}$ NMR spectra were acquired on a Bruker AVANCE $500 \mathrm{MHz}$ NMR spectrometer equipped with a $2.5 \mathrm{~mm}$ CPMAS probe. The MAS rate was $20 \mathrm{kHz}$, and the spectra were acquired with a Hahn echo sequence synchronized to the rotor cycle. The data were collected immediately after the $180^{\circ}$ pulse, and the data points collected before the echo were omitted prior to Fourier transformation. The ${ }^{11} \mathrm{~B} 90^{\circ}$ pulse (corrected for the central transition of $\left.{ }^{11} \mathrm{~B}\right)$, echo delay, acquisition time, and the recycle delay were $1.65 \mu \mathrm{sec}, 50 \mu \mathrm{sec}, 20 \mathrm{msec}$, and $30 \mathrm{sec}$ respectively. The chemical shifts were referenced externally to sodium borohydride which was assigned a chemical shift of $-42.06 \mathrm{ppm}$ with respect to BF3OEt2 at 0 ppm. Data were processed with $100 \mathrm{~Hz}$ of exponential line broadening. All spectra represent at least 32 scans. 


\subsection{Results and discussion}

As it can be seen in Figure 2-1, the diffraction patterns of all five glasses indicated fully amorphous compositions. The EDS spectra of the five synthesized glasses (Figure 2-2) are also in agreement with their nominal compositions shown in Table 2- 1 .

Differential scanning calorimetry (DSC) was employed to measure the glass transition temperature $\left(\mathrm{T}_{\mathrm{g}}\right)$ and the first crystallization temperatures $\left(\mathrm{T}_{\mathrm{C} 1}\right)$ of the synthesized glasses. $\mathrm{T}_{\mathrm{g}}$ is the temperature at which the glass commences to transform from a solid material to a supercooled viscous liquid [132].

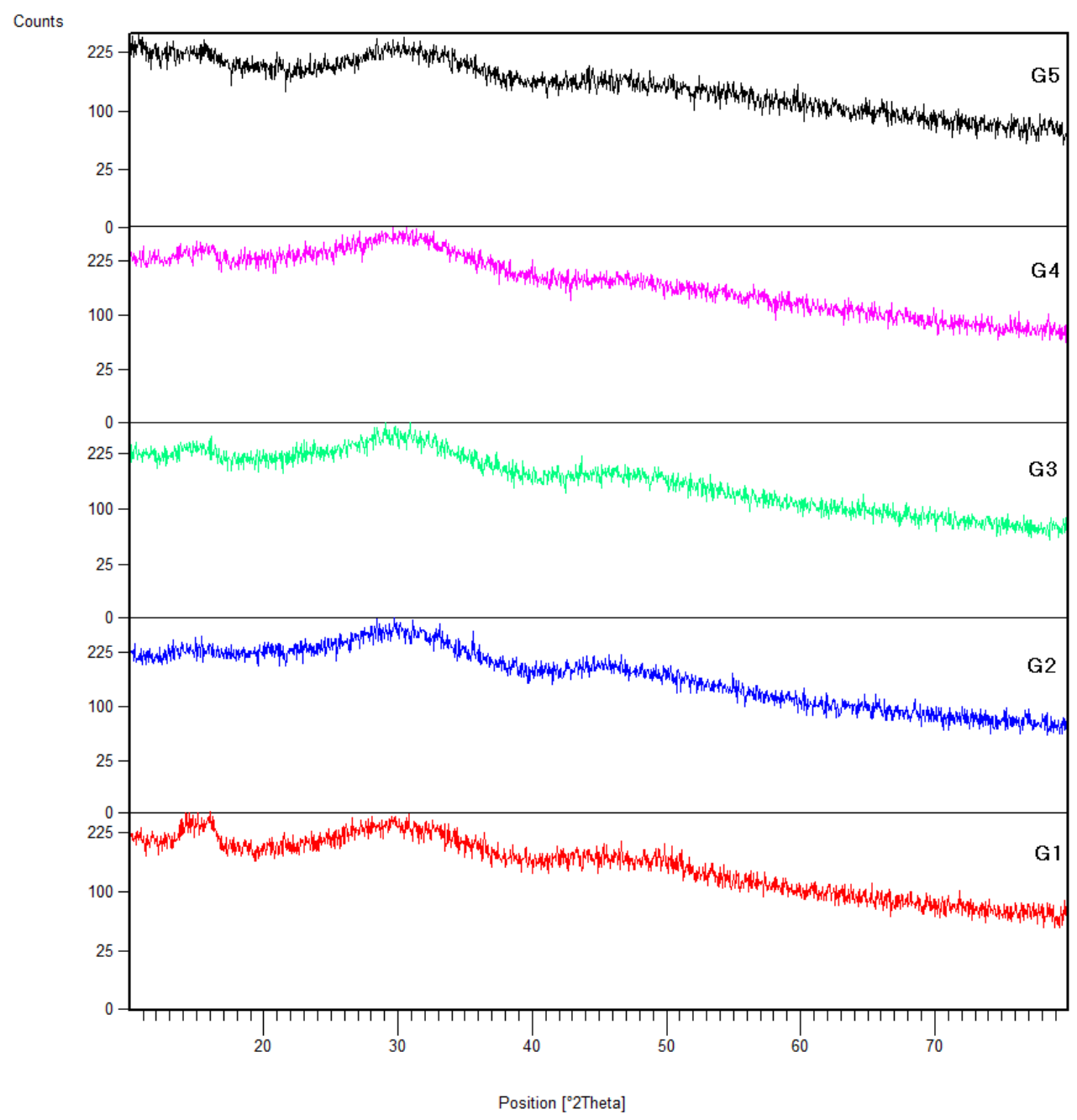

Figure 2- 1: Diffraction patterns of the synthesized glasses. 
The DSC curves of the synthesized glasses are similar (Figure 2- 3); however, as it can be seen in Table 2-4, by addition of Ga to the glass composition at the expense of $\mathrm{B}$, both $\mathrm{T}_{\mathrm{g}}$ and $\mathrm{T}_{\mathrm{C} 1}$ decrease steadily.

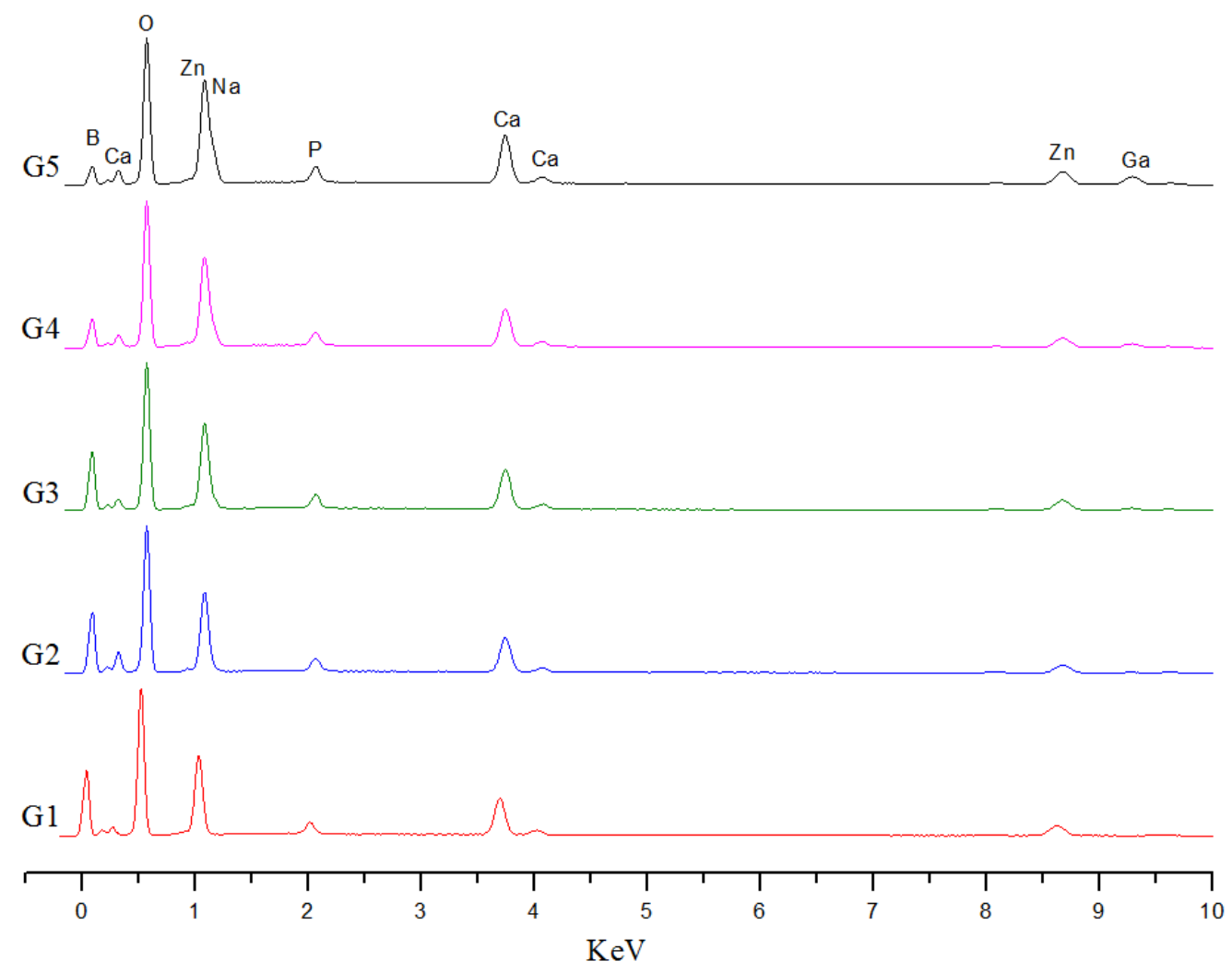

Figure 2- 2: The EDS spectra of the synthesized glasses with normalized counts.

Moreover, as can been seen in Figure 2- 3, the synthesized glasses have multiple crystallization peaks; however, only the values for the first crystallization peaks are tabulated in Table 2- 4 due to their importance; any subsequent heat treatment of the glass should be performed at temperatures lower than the first crystallization temperature in order to maintain the amorphous state of the glass. 

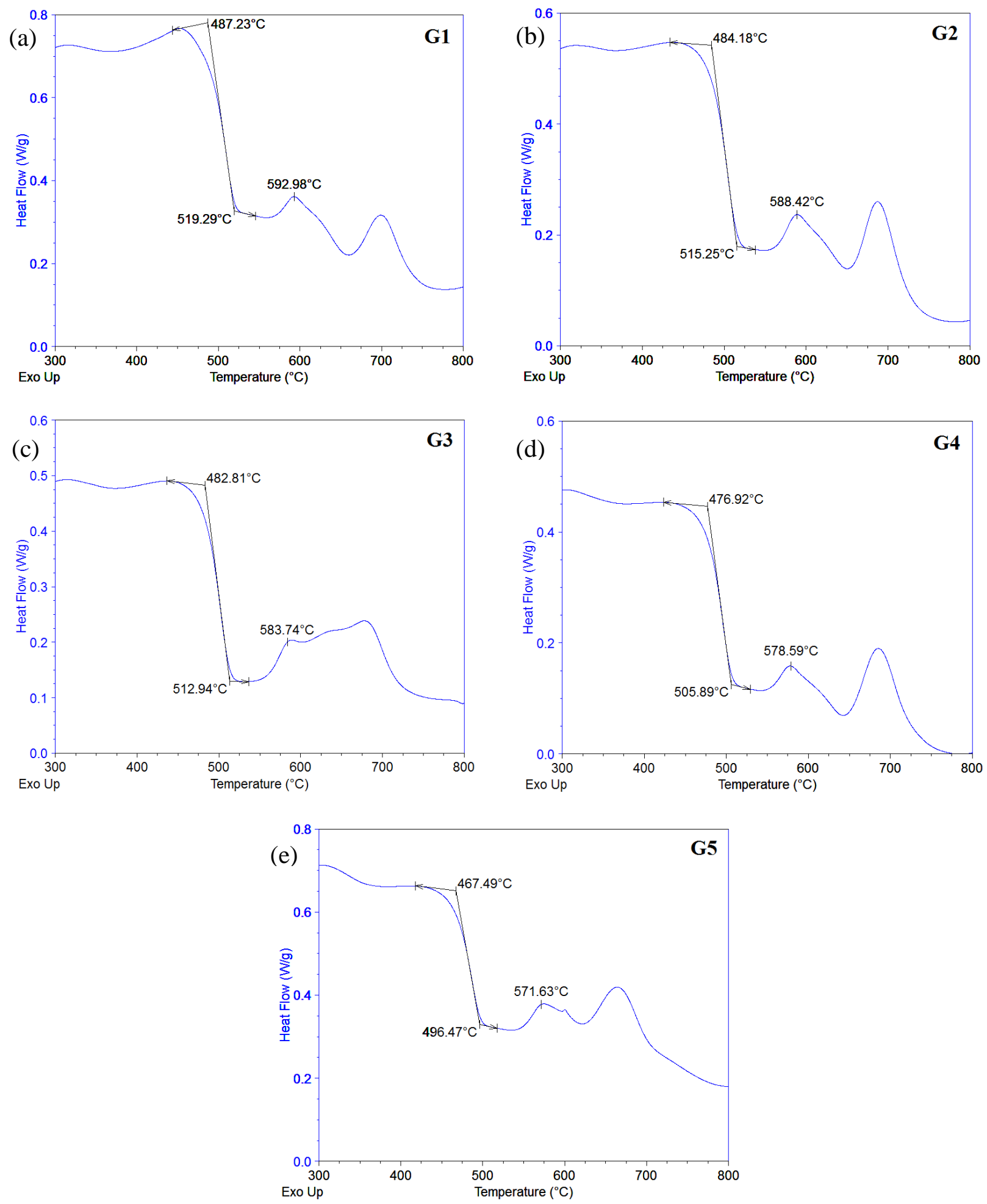

Figure 2- 3: DSC curves of the synthesized glasses; (a) G1, (b) G2, (c) G3, (d) G4, (e) G5. 
Table 2- 4: Glass transition temperature $\left(\mathrm{T}_{\mathrm{g}}\right)$ and first crystallization temperature $\left(\mathrm{T}_{\mathrm{C} 1}\right)$ of the synthesized glasses.

\begin{tabular}{cccccc}
\hline & $\mathrm{G} 1$ & $\mathrm{G} 2$ & $\mathrm{G} 3$ & $\mathrm{G} 4$ & $\mathrm{G} 5$ \\
\hline $\mathrm{T}_{\mathrm{g}}$-onset $\left({ }^{\circ} \mathrm{C}\right)$ & 487 & 484 & 483 & 477 & 467 \\
$\mathrm{~T}_{\mathrm{C} 1}\left({ }^{\circ} \mathrm{C}\right)$ & 593 & 588 & 584 & 579 & 572 \\
\hline
\end{tabular}

The network connectivity (NC) of the synthesized glasses was calculated using Equation

2-1. The assumed network roles of the elements in the glass composition are provided in Table 2- 3. Table 2- 5 lists the calculated values of network connectivity for each glass. $\mathrm{Zn}$ and $\mathrm{Ga}$ are both intermediate elements; therefore, the network connectivity of the glasses is calculated for both of the possible roles of $\mathrm{Zn}$ and $\mathrm{Ga}$ in the glass network. As it can be seen in Table 2- 5, the network connectivity values are close to two which indicates their susceptibility to degradation [19].

Table 2- 5: The calculated values of network connectivity of the synthesized glass compositions.

\begin{tabular}{cccccc}
\hline & G1 & G2 & G3 & G4 & G5 \\
\hline NC (Zn: modifier, Ga: modifier) & 2.3 & 2.24 & 2.16 & 2.02 & 1.84 \\
NC (Zn: former, Ga: modifier) & 2.49 & 2.44 & 2.39 & 2.28 & 2.16 \\
NC (Zn: modifier, Ga: former) & 2.3 & 2.23 & 2.16 & 2.01 & 1.87 \\
NC (Zn: former, Ga: former) & 2.49 & 2.43 & 2.37 & 2.25 & 2.13 \\
\hline
\end{tabular}

Table 2- 6: FTIR peak assignments of the synthesized glasses.

\begin{tabular}{cr}
\hline $\begin{array}{c}\text { Wave numbers } \\
\left(\mathrm{cm}^{-1}\right)\end{array}$ & Assignments (FTIR) \\
$\sim 700$ & bending vibrations of B-O-B linkage pentaborate groups \\
$\sim 930$ & stretching vibrations of $\mathrm{B}-\mathrm{O}$ bonds in $\mathrm{BO}_{4}$ tetrahedra from diborate groups \\
$\sim 1060$ & stretching vibrations of $\mathrm{B}^{3}-\mathrm{O}-\mathrm{B}^{4}$ bridges \\
$\sim 1235$ & asymmetric stretching vibration of $\mathrm{B}-\mathrm{O}$ bonds from orthoborate groups \\
$\sim 1345$ & stretching vibrations of borate triangles $\left(\mathrm{B} \emptyset_{3}\right.$ and $\left.\mathrm{B}_{2} \mathrm{O}^{-}\right)$ \\
\hline
\end{tabular}




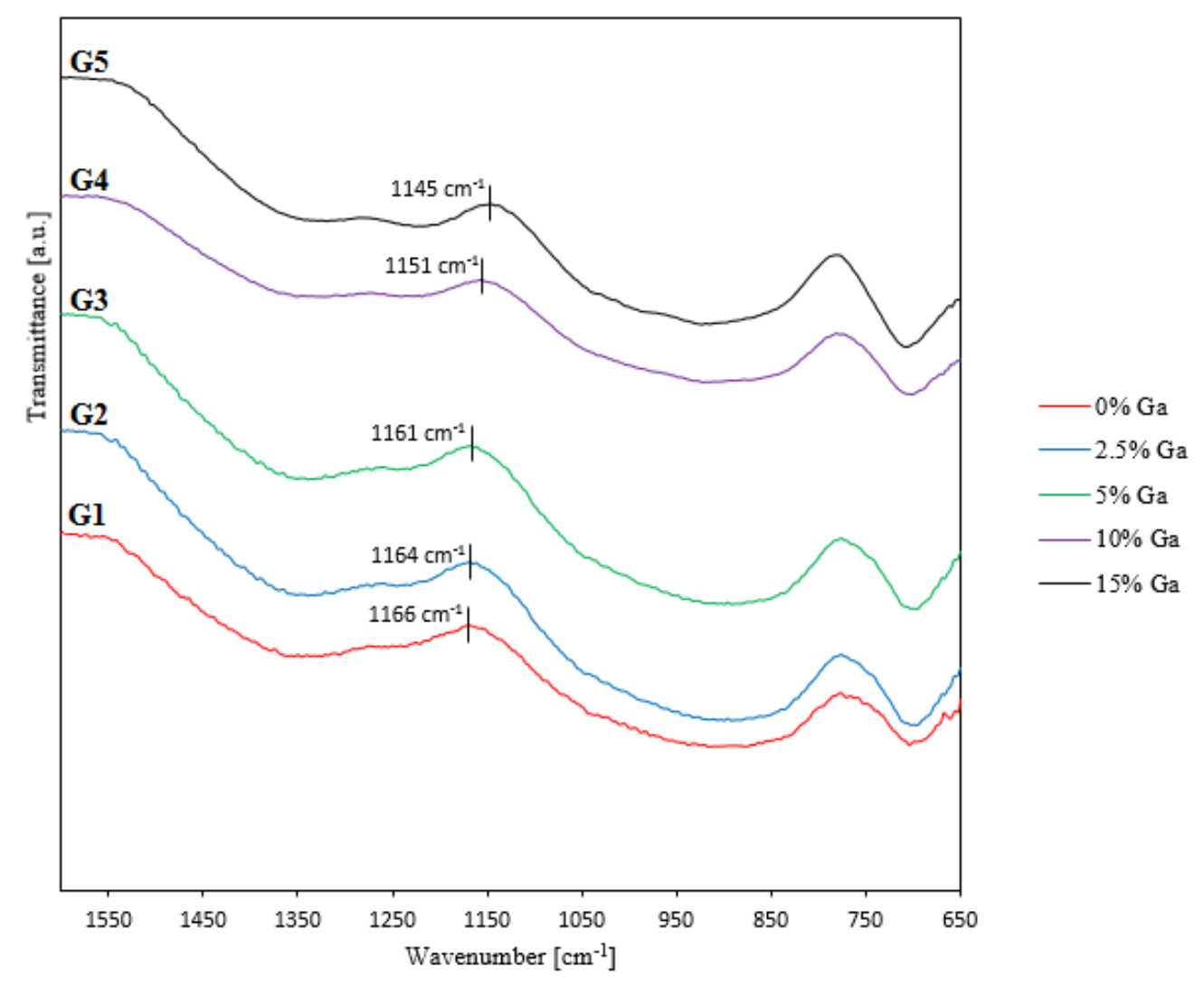

Figure 2- 4: FTIR spectra of the synthesized glasses.

The FTIR spectra of the synthesized glasses are illustrated in Figure 2- 4.

Table 2- 6 shows the assignments of the observed FTIR peaks. The focus of the FTIR analysis is on the wave numbers between $650-1600 \mathrm{~cm}^{-1}$ due to the following reasons: the occurrence of B-O arrangement vibrations mainly in the range of $400-1600 \mathrm{~cm}^{-1}$ known as the mid-infrared region [133]; lack of significant vibration observed after $1600 \mathrm{~cm}^{-1}$; and the spectral lower limit of the $\mathrm{ZnSe}$ crystal used for the measurements which is $650 \mathrm{~cm}^{-1}$. Three different regions could be identified in the G1 glass with $0 \% \mathrm{Ga}\left(650-780 \mathrm{~cm}^{-1}, 780-1166 \mathrm{~cm}^{-1}\right.$, and $1166-$ $1550 \mathrm{~cm}^{-1}$ ) which are very similar to those observed in the other four Ga containing glasses. The $650-780 \mathrm{~cm}^{-1}$ region can be attributed to the bending vibrations of B-O-B linkage in pentaborate 
groups [133]; the 780-1166 $\mathrm{cm}^{-1}$ region matches the superposition of the bands caused by the stretching vibrations of $\mathrm{B}-\mathrm{O}$ bonds in $\mathrm{BO}_{4}$ tetrahedra from diborate groups and the stretching vibrations of $\mathrm{B}^{3}-\mathrm{O}-\mathrm{B}^{4}$ bridges, which center at $\sim 930 \mathrm{~cm}^{-1}$ and $\sim 1060 \mathrm{~cm}^{-1}$, respectively [133, 134]; and the $1166-1550 \mathrm{~cm}^{-1}$ region corresponds to the superposition of bands caused by asymmetric stretching vibrations of B-O bonds in orthoborate groups at $\sim 1235 \mathrm{~cm}^{-1}$ and borate triangles $\left(\mathrm{B}_{3}\right.$ and $\left.\mathrm{B}_{2} \mathrm{O}^{-}\right)$at $\sim 1345 \mathrm{~cm}^{-1}$ [133]. $\varnothing$ and $\mathrm{O}^{-}$represent bridging oxygens and nonbridging oxygens, respectively. As it can be seen in Figure 2- 4, by addition of Ga the absorption onset of the stretching vibrations of borate triangles shifts to the lower wave numbers and changes from $1166 \mathrm{~cm}^{-1}$ for $\mathrm{G} 1$ to $1145 \mathrm{~cm}^{-1}$ for $\mathrm{G} 5$; such small shifts that take place by increasing the $\mathrm{Ga}$ in the glass can be seen as an indicator of short-range order rearrangements in the structure of the glass network [133].

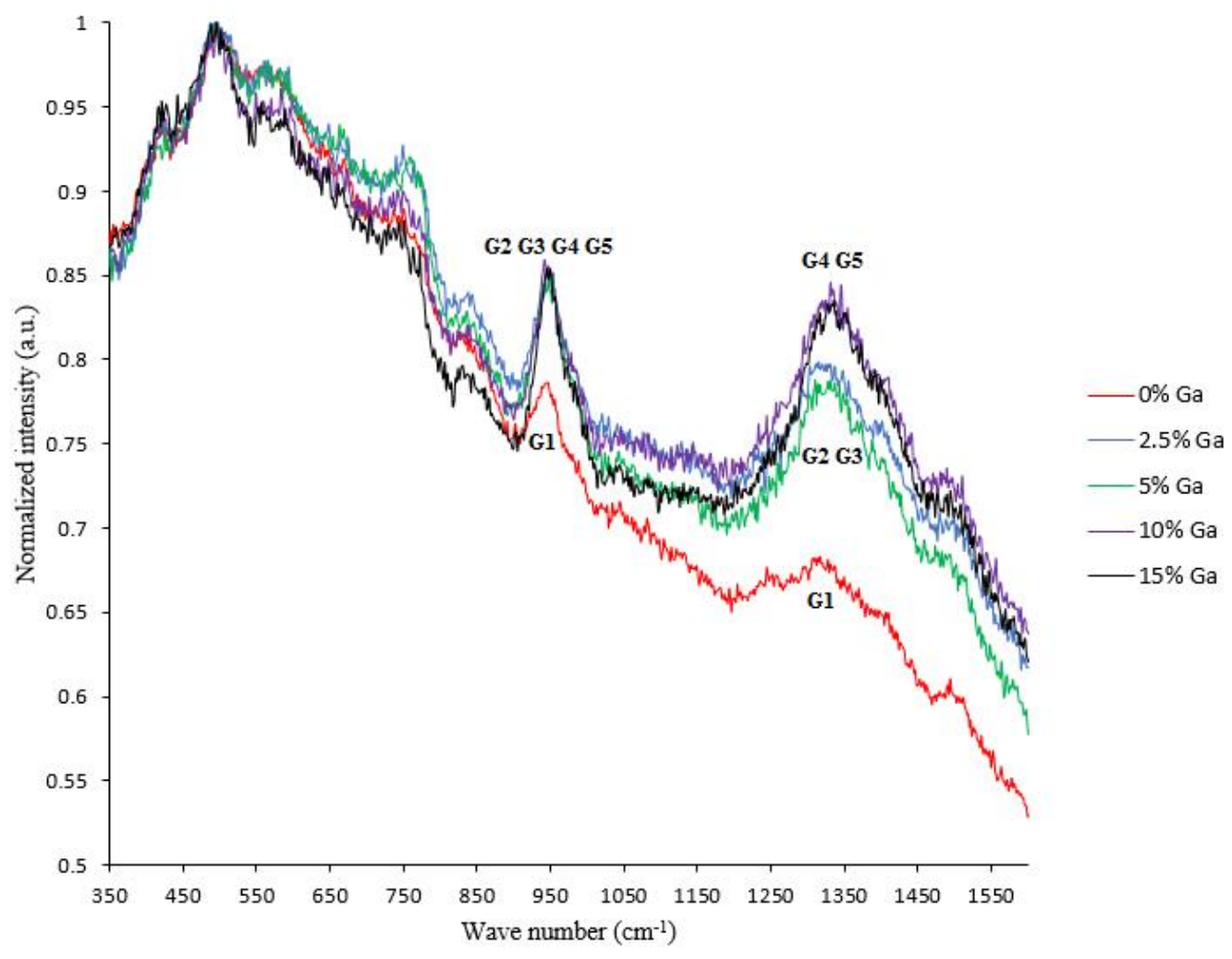

Figure 2- 5: Raman spectra of the synthesized glasses. 
Figure 2- 5 shows the Raman spectra of the synthesized glasses. The assignments of the Raman peaks are provided in Table 2- 7. The peaks centered at $\sim 420 \mathrm{~cm}^{-1}$ and $\sim 850 \mathrm{~cm}^{-1}$ are assigned to the asymmetric vibration of loose $\mathrm{BO}^{4-}$ tetrahedra [135]. The peak at $\sim 485 \mathrm{~cm}^{-1}$ is assigned to the ring angle (B-O-B) bending $[135,136]$. The peak around $670 \mathrm{~cm}^{-1}$ is assigned to Metaborate units $[135,136]$. The $\sim 755 \mathrm{~cm}^{-1}$ peak is considered to be caused by the symmetric breathing vibration of six-membered rings with two $\mathrm{BO}_{4}$ tetrahedra which can occur in diborates, tetraborates, or pentaborates [135]. The band around $930 \mathrm{~cm}^{-1}$ is assigned to pentaborate groups [135], and that around $1275 \mathrm{~cm}^{-1}$ is considered the result of asymmetric stretching vibration of BO bonds from orthoborate groups [133]. The band around $1320 \mathrm{~cm}^{-1}$ is considered as an evidence of the presence of loose $\mathrm{BO}_{3}$ units [137], and the peak centered at $\sim 1480 \mathrm{~cm}^{-1}$ is assigned to $\mathrm{B}_{2} \mathrm{O}^{-}$triangles linked to other borate triangular units [133]. As it can be seen in Figure 2- 5, by the addition of Ga to the glass composition, the Raman peaks centered at $\sim 930 \mathrm{~cm}^{-1}$ and $\sim 1320$ $\mathrm{cm}^{-1}$ show a considerable growth in intensity which is an indicator of an increase in the fraction of the structural units they represent in the glass structure.

Table 2- 7: Raman peak assignments of the synthesized glasses.

\begin{tabular}{|c|c|}
\hline Wave numbers $\left(\mathrm{cm}^{-1}\right)$ & Assignments (Raman) \\
\hline$\sim 420$ & asymmetric vibration of loose $\mathrm{BO}_{4}^{-}$tetrahedral \\
\hline$\sim 485$ & ring angle $(\mathrm{B}-\mathrm{O}-\mathrm{B})$ bending \\
\hline$\sim 670$ & metaborate units \\
\hline$\sim 755$ & $\begin{array}{c}\text { symmetric breathing vibration of six-membered rings with two } \mathrm{BO}_{4} \\
\text { tetrahedra (diborate, tetraborate, or pentaborate) }\end{array}$ \\
\hline$\sim 850$ & asymmetric vivbration of loose $\mathrm{BO}_{4}^{-}$tetrahedral \\
\hline$\sim 930$ & pentaborate groups \\
\hline$\sim 1275$ & $\begin{array}{l}\text { asymmetric stretching vibration of B-O bonds from orthoborate } \\
\text { groups }\end{array}$ \\
\hline$\sim 1320$ & loose $\mathrm{BO}_{3}$ \\
\hline$\sim 1480$ & $\mathrm{~B} \emptyset_{2} \mathrm{O}^{-}$triangles linked to other borate triangular units \\
\hline
\end{tabular}




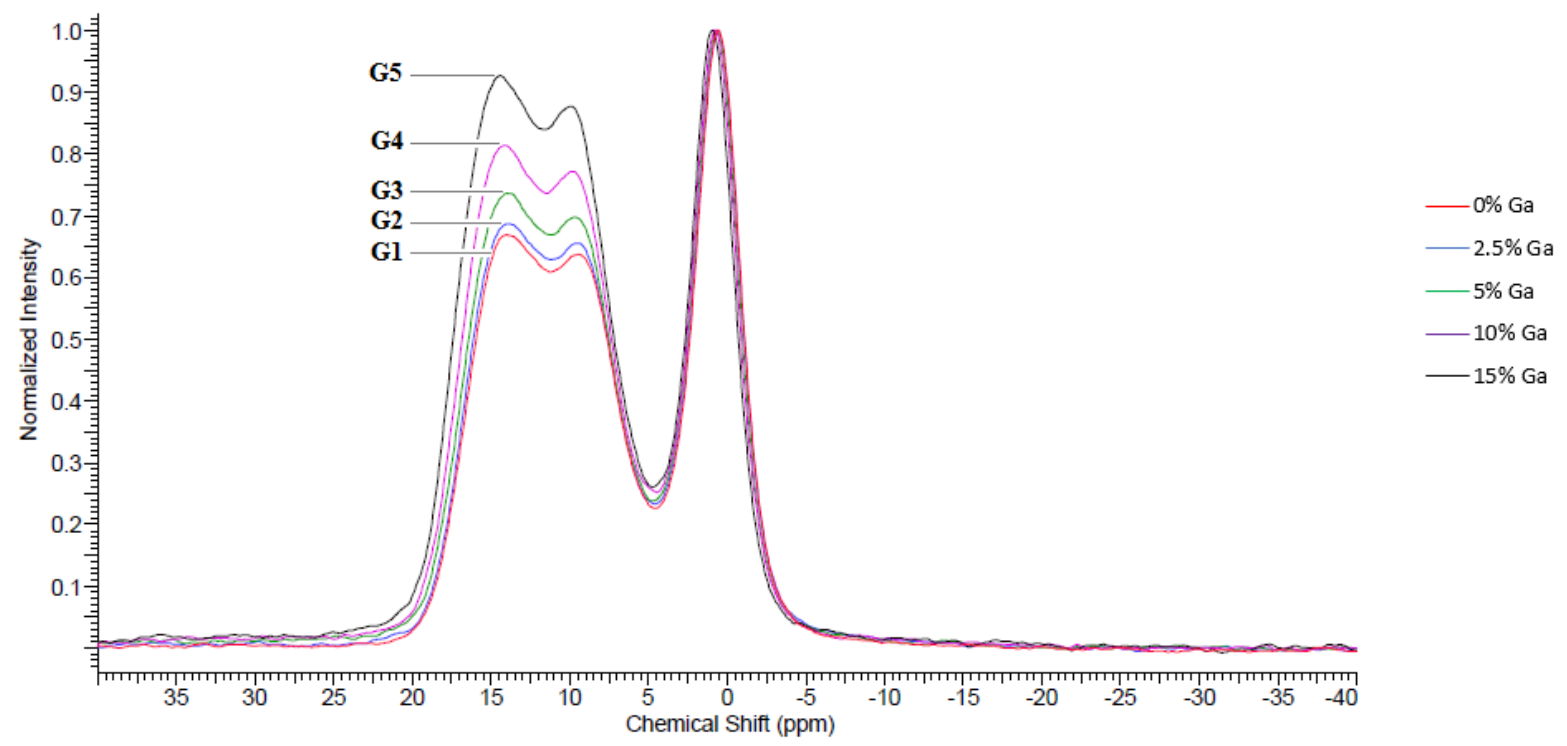

Figure 2- 6: The ${ }^{11} \mathrm{~B}$ NMR MAS spectra for the synthesized glasses.

Table 2- 8: The peak centers and peak area percentages from the fitted ${ }^{11} \mathrm{~B}$ NMR MAS lineshape for G1, G2, G3, G4, and G5.

\begin{tabular}{|c|c|c|c|c|c|c|c|c|c|c|c|c|c|c|c|}
\hline & \multicolumn{3}{|c|}{ G1 } & \multicolumn{3}{|c|}{$\mathrm{G} 2$} & \multicolumn{3}{|c|}{ G3 } & \multicolumn{3}{|c|}{ G4 } & \multicolumn{3}{|c|}{ G5 } \\
\hline \multirow[b]{2}{*}{$\begin{array}{c}\text { Area } \\
(\%)\end{array}$} & $\mathrm{BO}_{4}$ & $\mathrm{BO}_{3 \mathrm{~A}}$ & $\mathrm{BO}_{3 \mathrm{~S}}$ & $\mathrm{BO}_{4}$ & $\mathrm{BO}_{3 \mathrm{~A}}$ & $\mathrm{BO}_{3 \mathrm{~S}}$ & $\mathrm{BO}_{4}$ & $\mathrm{BO}_{3 \mathrm{~A}}$ & $\mathrm{BO}_{3 \mathrm{~S}}$ & $\mathrm{BO}_{4}$ & $\mathrm{BO}_{3 \mathrm{~A}}$ & $\mathrm{BO}_{3 \mathrm{~S}}$ & $\mathrm{BO}_{4}$ & $\mathrm{BO}_{3 \mathrm{~A}}$ & $\mathrm{BO}_{3 \mathrm{~S}}$ \\
\hline & 34.04 & 44.38 & 21.58 & 33.46 & 45.06 & 21.48 & 31.92 & 44.32 & 23.76 & 29.63 & 45.83 & 24.54 & 26.54 & 46.88 & 26.58 \\
\hline $\begin{array}{c}\text { Peak } \\
\text { center } \\
(\mathrm{ppm})\end{array}$ & 0.57 & 9.65 & 14.92 & 0.60 & 9.73 & 15.00 & 0.69 & 9.76 & 15.08 & 0.78 & 9.92 & 15.25 & 0.92 & 10.08 & 15.47 \\
\hline
\end{tabular}



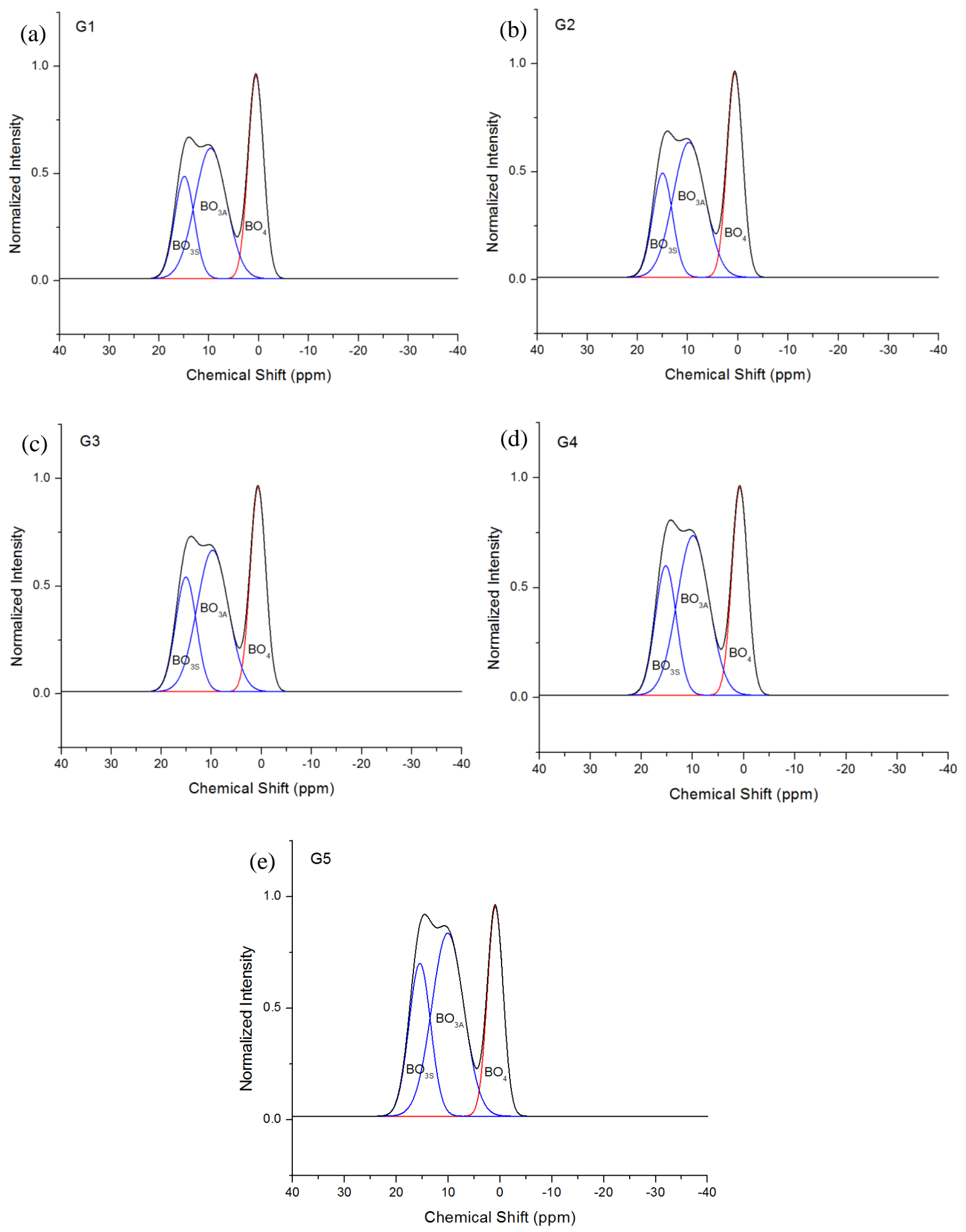

Figure 2- 7: The fit of ${ }^{11}$ B NMR MAS lineshape for (a) G1, (b) G2, (c) G3, (d) G4, and (e) G5. 
The ${ }^{11} \mathrm{~B}$ MAS spectra for the synthesized glasses are shown in Figure 2- 6. The peaks centered between 0.5 and $1 \mathrm{ppm}$ are assigned to $\mathrm{BO}_{4}$ units, and the wide superposition between 5 and 20 ppm is assigned to $\mathrm{BO}_{3}$ units: $\mathrm{BO}_{3 \mathrm{~A}}$ (centered at 9.4-10 ppm) and $\mathrm{BO}_{3 \mathrm{~S}}$ (centered at 13.9$14.5 \mathrm{ppm}$ ) which represent asymmetric $\mathrm{BO}_{3}$ units with one or two non-bridging oxygens and symmetric $\mathrm{BO}_{3}$ units with zero or three non-bridging oxygens, respectively [138, 139]. It has been reported that the addition of network modifiers at modifier contents above 35 mol\% decreases the $\mathrm{BO}_{4}$ concentration and leads to formation of $\mathrm{BO}_{3}$ units with non-bridging oxygens $[139,140]$. As it can be seen in Figure 2- 6 , the $\mathrm{BO}_{4} / \mathrm{BO}_{3}$ ratio decreases by addition of Ga to the glass structure at the expense of B. The peak area analysis that were conducted after curve fitting show that the introduction of $15 \mathrm{wt} \%$ Ga to the glass structure causes $7.5 \%$ drop in the fraction of $\mathrm{BO}_{4}$ units, and $2.5 \%$ and $5 \%$ rise in the fraction of $\mathrm{BO}_{3 \mathrm{~A}}$ and $\mathrm{BO}_{3 \mathrm{~S}}$ units, respectively (Figure 2- 7 and Table 2-8).

Phosphorus (P) in mixed glass former borophosphate glasses is known to participate in the glass network as a former by bonding to the neighboring $\mathrm{P}$ or $\mathrm{B}$ via bridging oxygens. Depending on the composition, P may be connected to between zero and four bridging oxygens. However, when the P/B ratio drops, so does the number of bridging oxygens connected to each P. Moreover, the drop in the $\mathrm{P} / \mathrm{B}$ ratio is accompanied by a significant change in the chemical shift in the positive direction [138, 141]. For example, Christensen et al. [141] reported a $21 \mathrm{ppm}$ shift to the positive direction in the ${ }^{31} \mathrm{P}$ NMR peak for the $\mathrm{P}^{2}$ structural units as the $\mathrm{B} / \mathrm{P}$ molar ratio was raised from zero to nine in a series of sodium borophosphate glasses. The P/B molar ratio in the synthesized glasses falls in the range of $0.05-0.08$ where a considerable presence of phosphorus ions with three and four bridging oxygens is not expected. 


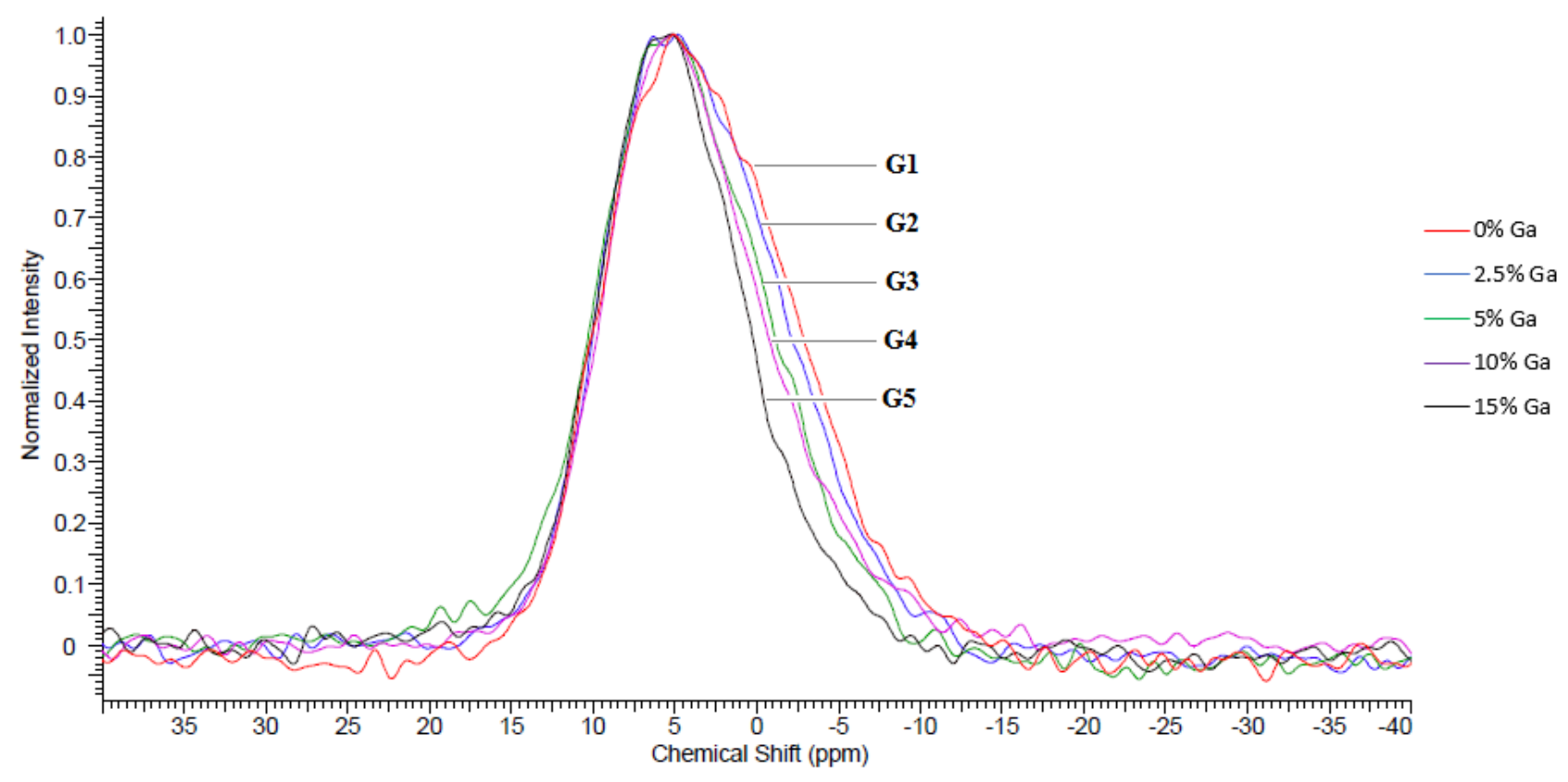

Figure 2- 8: The ${ }^{31} \mathrm{P}$ NMR MAS spectra for the synthesized glasses

Table 2- 9: The peak centers and peak area percentages from the fitted ${ }^{31} \mathrm{P}$ NMR MAS lineshape for G1, G2, G3, G4, and G5.

\begin{tabular}{|c|c|c|c|c|c|c|c|c|c|c|}
\hline & \multicolumn{2}{|c|}{ G1 } & \multicolumn{2}{|c|}{ G2 } & \multicolumn{2}{|c|}{ G3 } & \multicolumn{2}{|c|}{ G4 } & \multicolumn{2}{|c|}{ G5 } \\
\hline & $\mathrm{P}^{1}$ & $\mathrm{P}^{2}$ & $\mathrm{P}^{1}$ & $\mathrm{P}^{2}$ & $\mathrm{P}^{1}$ & $\mathrm{P}^{2}$ & $\mathrm{P}^{1}$ & $\mathrm{P}^{2}$ & $\mathrm{P}^{1}$ & $\mathrm{P}^{2}$ \\
\hline $\begin{array}{c}\text { Area } \\
(\%)\end{array}$ & 33.64 & 66.36 & 24.58 & 75.42 & 47.79 & 52.21 & 82.51 & 17.49 & 82.97 & 17.03 \\
\hline $\begin{array}{l}\text { Peak } \\
\text { center } \\
(\mathrm{ppm})\end{array}$ & 6.91 & 1.18 & 7.07 & 2.33 & 6.02 & 1.65 & 5.63 & -1.76 & 5.91 & -0.59 \\
\hline
\end{tabular}



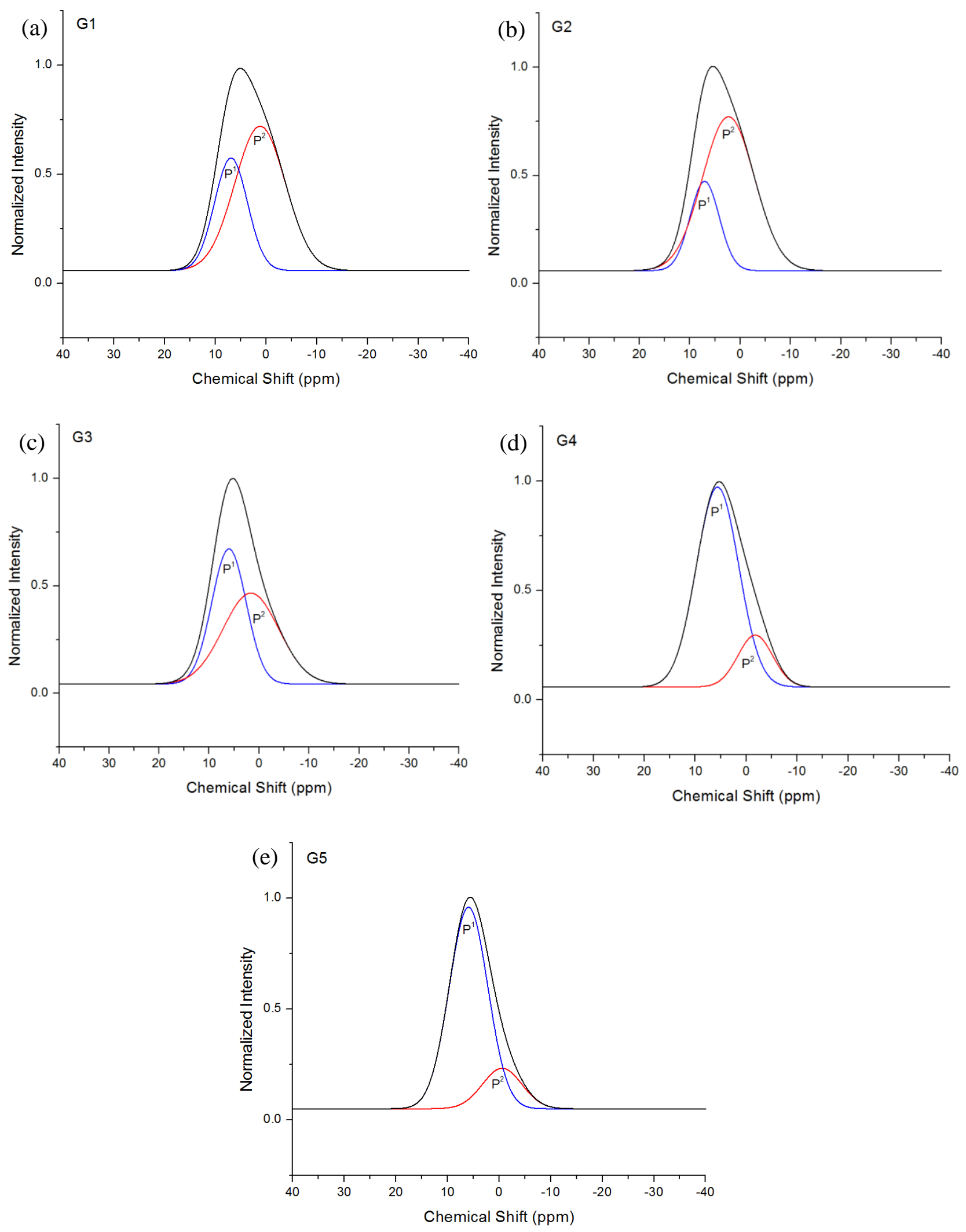

Figure 2- 9: The fit of ${ }^{31}$ P NMR MAS lineshape for (a) G1, (b) G2, (c) G3, (d) G4, and (e) G5. 
The ${ }^{31} \mathrm{P}$ MAS spectra for the synthesized glasses are shown in Figure 2- 8. All glasses have a broad superposition centered in the range of 4.8-5.3 ppm that gets smaller on the righthand side by the addition of Ga. This superposition is attributed to the overlap of peaks of orthophosphate units with one bridging oxygen $\left(\mathrm{P}^{1}\right)$ and orthophosphate units with two bridging oxygens $\left(\mathrm{P}^{2}\right)$ [138]. The curve fittings and the area analysis (Figure 2- 9 and Table 2- 9) show that- despite a slight increase for G2- the fraction of $\mathrm{P}^{2}$ units generally drops by the addition of $\mathrm{Ga}$ at the expense of $\mathrm{B}$. Furthermore, as Ga increases at the expense of $\mathrm{B}$, the $\mathrm{P} / \mathrm{B}$ molar ratio increases from 0.05 in G1 to 0.08 in G5 which can cause the fluctuation observed in the fraction of $\mathrm{P}^{2}$ units and is accompanied by alterations in the position of $\mathrm{P}^{2}$ peaks that indicate changes in the intermediate range order of the glass network [138]. Such changes in the structure of the glass network were also identified in the Raman spectroscopy analysis of these glasses as discussed earlier in the current chapter.

\subsection{Chapter Summary}

The structural analyses on the synthesized glasses shows that the addition of Ga leads to alterations in the glass network. The XRD patterns of all five synthesized glasses confirmed that the glasses were amorphous. The DSC results showed a steady drop in the glass transition and crystallization temperatures by addition of $\mathrm{Ga}$. The calculated network connectivity values were close to two which is known as sign of susceptibility to biodegradation [19]. The FTIR analysis identified pentaborate, diborate, and orthoborate groups, as well as borate triangles $\left(\mathrm{B} \emptyset_{3}\right.$ and $\left.\mathrm{B}_{2} \mathrm{O}^{-}\right)$. Small shifts in the position of FTIR peaks of borate triangles to the higher wave numbers were observed in glasses with more Ga content; such shifts indicate that introduction of Ga causes short-range order rearrangements in the glass structure. The Raman spectroscopy data 
showed the presence of loose $\mathrm{BO}^{4-}$ tetrahedra, metaborate, diborate, pentaborate, orthoborate, loose $\mathrm{BO}_{3}, \mathrm{~B}_{2} \mathrm{O}^{-}$triangles, and possibly tetraborate groups. It also revealed that the addition of Ga leads to an increase in the fraction of pentaborate and loose $\mathrm{BO}_{3}$ groups. The ${ }^{11} \mathrm{~B}$ MAS NMR results showed that the $\mathrm{BO}_{4} / \mathrm{BO}_{3}$ ratio decreases by the addition of $\mathrm{Ga}$, and the introduction of 15 wt. $\% \mathrm{Ga}$ to the glass structure caused $7.5 \%$ drop in the fraction of $\mathrm{BO}_{4}$ units, and $2.5 \%$ and $5 \%$ rise in the fraction of $\mathrm{BO}_{3 \mathrm{~A}}$ and $\mathrm{BO}_{3 \mathrm{~S}}$ units, respectively. The ${ }^{31} \mathrm{P}$ MAS NMR analysis detected orthophosphate units with one $\left(\mathrm{P}^{1}\right)$ and two $\left(\mathrm{P}^{2}\right)$ bridging oxygens, and identified a decreasing trend in the fraction of $\mathrm{P}_{2}$ units by the addition of Ga. 
3. The impact of gallium content on degradation, bioactivity and antibacterial potency of zinc borate bioactive glass 
The work presented in this chapter is based on the following peer-reviewed, published paper [142]:

Rahimnejad Yazdi, A., Torkan, L., Stone, W. and Towler, M.R., 2017. The impact of gallium content on degradation, bioactivity and antibacterial potency of zinc borate bioactive glass, Journal of Biomedical Materials Research Part B: Applied Biomaterials, published online Feb 2, 2017.

\subsection{Introduction}

In the previous chapter the structural characterization of a novel borate-based glass series that contained increasing amounts $(2.5,5,10$, and 15 wt. \%) of gallium oxide were discussed, and the results showed that Ga was successfully incorporated in the structure of the synthesized glasses without forming additional crystalline phases that can impede the bioactivity of the glass.

This chapter discusses the degradation, bioactivity in SBF and antibacterial properties of the series. The weight loss profiles of the glasses were obtained after incubation for 1, 7 and 28 days in both deionized (DI) water and simulated body fluid (SBF). The released ions in the degradation extracts were quantified using ICP-AES. The surface of the samples incubated in SBF were studied using FTIR, SEM and XRD. Moreover, the agar disc-diffusion method and $P$. aeruginosa (Gram-negative) and S. epidermidis (Gram-positive) were utilized in order to investigate the antibacterial behavior of the glasses. 


\subsection{Materials and methods}

\subsubsection{Glass synthesis and preparation}

Glass synthesis and preparation for this work was performed as described in Section 2.2.1.

\subsubsection{Weight loss and ion release}

Glass powders were soaked in deionized water (with the ratio of $0.5 \mathrm{~g}$ powders to 50.0 $\mathrm{mL}$ solution [143]) for 1,7 , and 28 days at $37^{\circ} \mathrm{C}$. Glass particles within the size range of 90-710 $\mu \mathrm{m}$ and D10, D50, and D90 values shown in Table 2- 2 were used as samples. The samples were filtered after 1, 7 and 28 days soaking in deionized water.

The filtered solutions were tested by ICP-AES (Perkin Elmer Optima 7300, Waltham, MA, USA) in order to measure the concentration of released $\mathrm{B}, \mathrm{Ca}, \mathrm{Ga}, \mathrm{P}, \mathrm{Na}$, and $\mathrm{Zn}$ ions. Five calibration standards were prepared for each element and deionized water was used as control. Measurements were repeated three times for each sample. After incubation, the glass powders were dried in an oven at $37{ }^{\circ} \mathrm{C}$ for 48 hours and weighed in order to measure the weight loss.

\subsubsection{Simulated body fluid (SBF) trial}

\subsubsection{SBF preparation and incubation}

The SBF composition shown in Table 3- 1 was prepared in accordance with the procedure described by Kokubo \& Takadama [3]. The reagents were added, in the order shown in Table 3- 1 , to $700 \mathrm{ml}$ of deionized water and mixed by a magnetic stirrer at $36.5^{\circ} \mathrm{C}$. The $\mathrm{pH}$ of the solution was adjusted to 7.4 by gradual addition of $1.0 \mathrm{M}-\mathrm{HCl}$, and deionized water was added to the solution to increase its volume to 11 . Glass powders were soaked in SBF (with the ratio of $0.50 \mathrm{~g}$ powders to $50.0 \mathrm{~mL}$ solution [143]) for 1,7 , and 28 days at $37{ }^{\circ} \mathrm{C}$. Glass particles 
within the size range of $90-710 \mu \mathrm{m}$ and D10, D50, and D90 values shown in Table 2- 2 were used as samples. The samples were filtered after 1, 7 and 28 days soaking in SBF. The glass powders were rinsed gently with deionized water, dried in an oven at $37{ }^{\circ} \mathrm{C}$ for 48 hours, and their weight was measured in order to calculate their weight loss in SBF.

Table 3- 1: Order and amounts of reagents for preparing $1000 \mathrm{ml}$ of SBF.

\begin{tabular}{lll}
\hline Order & Reagent & Amount \\
\hline 1 & $\mathrm{NaCl}$ & $8.035 \mathrm{~g}$ \\
2 & $\mathrm{NaHCO} 3$ & $0.355 \mathrm{~g}$ \\
3 & $\mathrm{KCl}$ & $0.225 \mathrm{~g}$ \\
4 & $\mathrm{~K}_{2} \mathrm{HPO}_{4} \cdot 3 \mathrm{H}_{2} \mathrm{O}$ & $0.231 \mathrm{~g}$ \\
5 & $\mathrm{MgCl}_{2} \cdot 6 \mathrm{H}_{2} \mathrm{O}$ & $0.311 \mathrm{~g}$ \\
6 & $1.0 \mathrm{M}-\mathrm{HCl}$ & $39 \mathrm{ml}$ \\
7 & $\mathrm{CaCl}_{2}$ & $0.292 \mathrm{~g}$ \\
8 & $\mathrm{Na}_{2} \mathrm{SO}_{4}$ & $0.072 \mathrm{~g}$ \\
9 & $\mathrm{Tris}$ & $6.118 \mathrm{~g}$ \\
\hline
\end{tabular}

\subsubsection{2. $\quad$ Scanning electron microscopy-energy dispersive spectroscopy}

A JEOL 6380LV scanning electron microscope (JEOL USA, Inc.) equipped with Oxford energy dispersive X-ray spectroscopy (EDS) was used to study the composition and observe the surface of the glass powders after incubation in SBF. The glass powders were coated with gold, and EDS spectra were collected at $20 \mathrm{kV}$.

\subsubsection{Fourier transform infrared spectroscopy (FTIR)}

The Agilent Cary 630 FTIR spectrometer (Agilent Technologies, Santa Clara, CA, USA) with a scanning range from 4000 to $650 \mathrm{~cm}^{-1}$, controlled with Microlab software, was used to obtain the FTIR spectra of the incubated glass powders. The spectral resolution was $4 \mathrm{~cm}^{-1}$. 
Measurements were performed by Attenuated Total Reflectance (ATR) technique with a diamond crystal. The spectrum for each sample was obtained by averaging 4 scans.

\subsubsection{X-ray diffraction $(X R D)$}

XRD analysis was used to study the crystallinity of the precipitations on the glass surface after immersion in SBF and determine the potential crystalline phases. Diffraction patterns were collected using a Philips PW3710 X-ray diffractometer with a $\mathrm{Cu}$ source from 20 to $55^{\circ}$, at a scan step size of $0.02^{\circ}$. A generator voltage of $40 \mathrm{kV}$ and a tube current of $40 \mathrm{~mA}$ were employed. Any crystalline phases present in the obtained XRD patterns were identified using the ICDD (International Centre for Diffraction Data) standard diffraction patterns.

\subsubsection{Antibacterial evaluation}

The antimicrobial properties of the glass powders were evaluated using the Agar Disk Diffusion method [144], against both P. aeruginosa (Gram-negative) and S. epidermidis (Grampositive) species. Glass powders were sterilized by exposing them to ultra violet (UV) light in a biological safety cabinet overnight. The diameter of the glass powder site was $10 \mathrm{~mm}$, and 0.1 gram of glass powder was used for each site. The antibacterial properties of the glass powders were quantitatively assessed on bacterial lawns, spread on Tryptic Soy Agar (3 g/L Tryptic Soy Broth, $15 \mathrm{~g} / \mathrm{L}$ agar). All chemicals were purchased from Fisher Scientific (Ottawa, ON, Canada). Bacterial cultures were grown to exponential phase (12-16 h), diluted in Physiological Saline Solution $(9 \mathrm{~g} / \mathrm{L} \mathrm{NaCl})$ to 106 cells/mL, and spread onto Tryptic Soy Agar (TSA). Antimicrobial properties were quantified by measuring and comparing the zones of growth inhibition. Each plate had a single microbial species, and each species was repeated in triplicate for statistical 
comparisons. The diameters of the bacterial inhibition zones were measured $(\mathrm{mm})$ and the means of triplicate samples were calculated.

\subsubsection{Statistical analysis}

Non-parametric Kruskal-Wallis H Test was used to analyze the data and report the statistically significant differences when p-value $\leq 0.05$. Statistical analysis was performed on groups where $\mathrm{n} \geq 3$ using SPSS software (IBM SPSS statistics 21, IBM Corp., Armonk, NY, USA).

\subsection{Results and discussion}

The degradation of the glasses in both deionized water and SBF was accompanied by weight loss. Figure 3- 1 shows the percentage weight loss of the synthesized glasses after 1, 7 and 28 days of immersion in both deionized water and SBF. Weight losses were higher for all three immersion periods in deionized water compared to those immersed in SBF. For samples immersed in deionized water, G1 had the highest percentage weight loss for all three immersion periods, and percentage weight loss of the glasses decreased slightly by the addition of Ga. Moreover, for all five compositions, weight loss increased at a higher rate in the first week of incubation, compared to the following 3 weeks. Samples immersed in SBF also showed a rapid increase in weight loss during the first week of incubation. However, there was a slight weight gain observed for G1, G2, G3 and G4 compositions after 28 days of incubation compared to those incubated for 7 days, and for the same period, G5 composition did not experience any weight change. The observed weight gains or lack of weight loss in SBF can be attributed to the formation of $\mathrm{Ca}-\mathrm{P}$ and precipitation of the released ions on the surface of the glass powders. 
According to Kruskal-Wallis $\mathrm{H}$ Test analysis, the degradability values of different glass compositions, in both deionized water and SBF, in 1,7 and 28 days groups were significantly different $(\mathrm{P} \leq 0.05)$, with the exception of the 7 days data for deionized water (Table $3-2)$.

Table 3- 2: The p-values for degradability measurements of the glasses according to the KruskalWallis H Test.

\begin{tabular}{cccc}
\hline & 1 day & 7days & 28 days \\
\hline Deionized water & 0.027 & 0.121 & 0.036 \\
SBF & 0.019 & 0.015 & 0.014 \\
\hline
\end{tabular}

The low solubility products of the released ions can cause them to precipitate on the glass surface either as a separate phase or as a solid solution in $\mathrm{Ca}-\mathrm{P}$ or $\mathrm{HA}$ which will lower the weight loss of the glass [145]; incomplete dissolution of the elements of the glass is also another factor that can cause partial conversion of the glass to Ca-P or HA. Borate based bioactive glasses, unlike silicates, do not have a $\mathrm{SiO}_{2}$ rich layer separating the unconverted glass from the precipitated Ca-P, HA or HA-like material layer, and diffusion of the ions to the interface is considered as the rate controlling factor [145].

ICP measurements were conducted in order to determine the quantity of the various released ions from the glass after 1, 7 and 28 days incubation. It can be seen in Figure 3- 2 that, except for $\mathrm{Ga}$, the release of ions from the glass follows a descending trend going through the series. ICP measurements showed that boron ions had the highest concentration in the solutions for G1, G2, and G3 glasses. However, as more B is replaced by Ga in G4 and G5, the concentration of sodium ions surpasses boron ion concentration. Moreover, the concentrations of 
$\mathrm{B}, \mathrm{Na}, \mathrm{Ca}$ and $\mathrm{Ga}$ ions (only in $\mathrm{Ga}$ containing glasses) released into the solution were considerably higher than those of $\mathrm{P}$ and $\mathrm{Zn}$ ions.

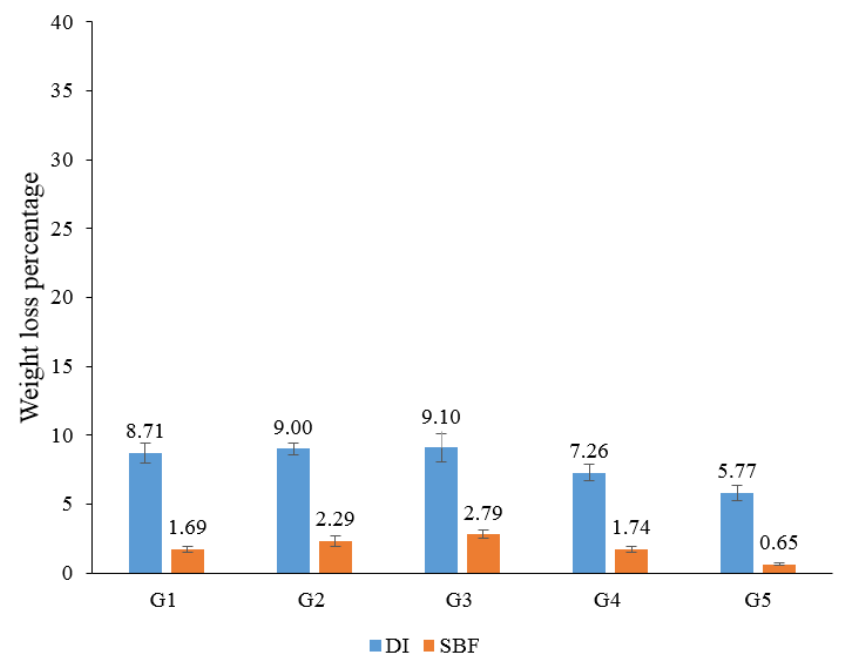

(a)

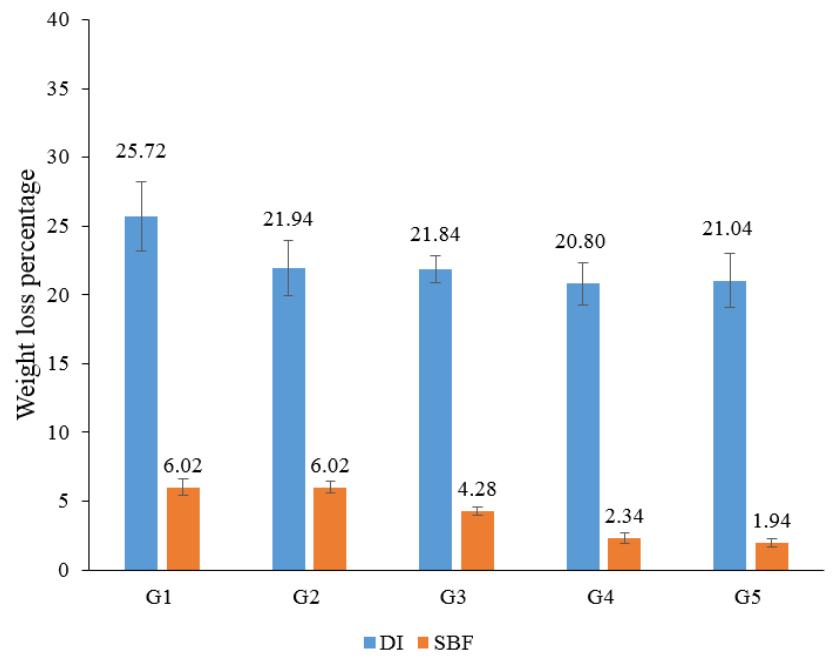

(b)

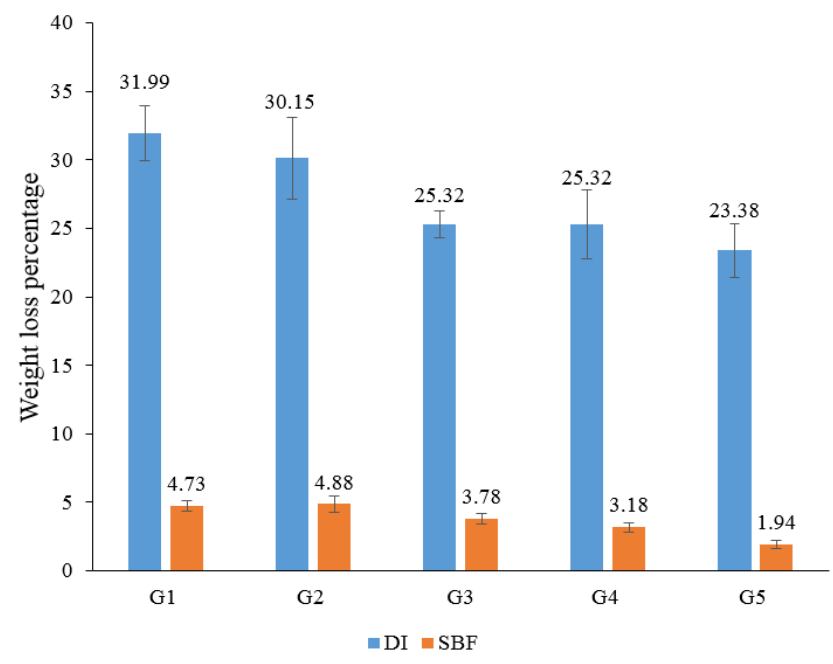

(c)

Figure 3- 1: The weight loss percentages of the synthesized glasses in deionized water and SBF after (a) 1, (b) 7 and (c) 28 days of incubation at $37^{\circ} \mathrm{C}$; error bars represent standard deviation. 
The ICP measurements are in agreement with the results from the weight loss trials which also show higher weight loss percentages for glass compositions with less Ga content. The concentrations of ions in solutions show considerable growth over the first 7 days, but their release rate declines sharply during the following three weeks; similar trends were observed in the weight loss trials. Kruskal-Wallis $H$ Test statistical analysis showed that the measured concentrations for different glass compositions after 1, 7 and 28 days were significantly different $(\mathrm{P} \leq 0.05)$, with the exception of 1 and 7 days data for phosphorus ions and 7 days data for zinc ions (Table 3- 3).

The decline in the degradation of the glasses by the addition of $\mathrm{Ga}$, observed by both ion release and weight loss results, is due to the changes in the glass network structure as $\mathrm{Ga}$ is added to the glass composition at the expense of B. Similar trends have been previously reported suggesting that the addition of Ga contributes to lower degradability of the glass [33, 34, 35]. 

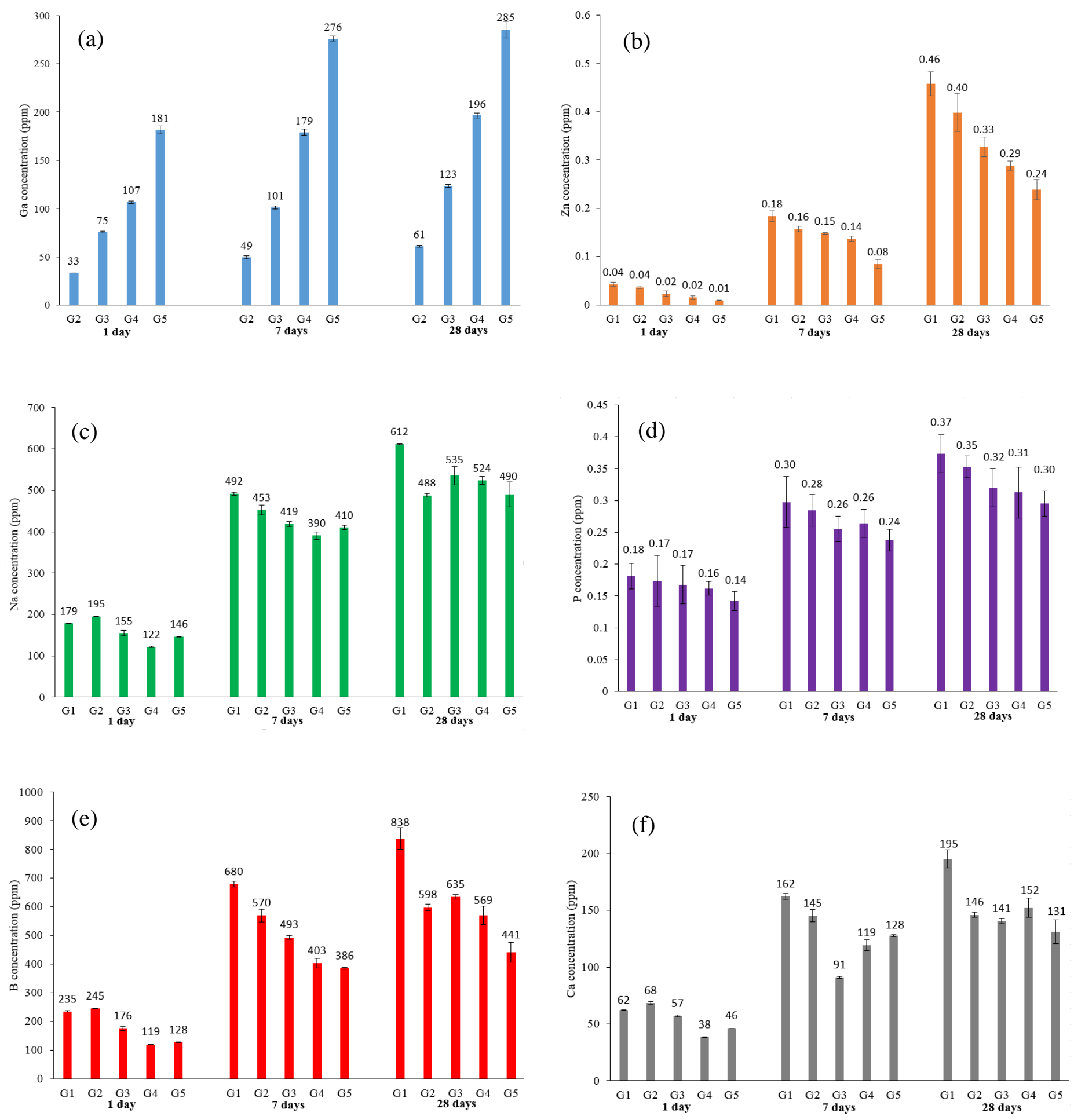

Figure 3- 2: The concentration of the ions released from G1, G2, G3, G4, and G5 after soaking in DI water for 1, 7, and 28 days at $37^{\circ} \mathrm{C}$; (a) $\mathrm{Ga}$, (b) Zn, (c) Na, (d) P, (e) B, (f) Ca; error bars represent standard deviation. 
Table 3- 3: The p-values for ion release measurements of the glasses according to Kruskal-Wallis H Test.

\begin{tabular}{cccc}
\hline Element & 1 day & 7days & 28 days \\
\hline $\mathrm{B}$ & 0.009 & 0.011 & 0.011 \\
$\mathrm{Ca}$ & 0.009 & 0.009 & 0.014 \\
$\mathrm{Ga}$ & 0.009 & 0.009 & 0.009 \\
$\mathrm{Na}$ & 0.009 & 0.009 & 0.014 \\
$\mathrm{P}$ & 0.106 & 0.848 & 0.031 \\
$\mathrm{Zn}$ & 0.01 & 0.112 & 0.01 \\
\hline
\end{tabular}

The structural analysis of the glasses showed a rise in the ratio of $\mathrm{BO}_{3}$ to $\mathrm{BO}_{4}$ units as $\mathrm{Ga}$ percentage in the glasses increased [131]. These new $\mathrm{BO}_{3}$ units could either be symmetric (with three bridging oxygens or three non-bridging oxygens) or asymmetric (with one or two bridging oxygens). Given the weight loss and ion release results and the contribution of non-bridging oxygens to the higher degradability of the glasses, more symmetric $\mathrm{BO}_{3}$ units with three bridging oxygens and asymmetric $\mathrm{BO}_{3}$ units with two bridging oxygens appear to be formed in the glass network by increasing the Ga content in the synthesized glasses. However, the growth of bridging oxygens when the ratio of $\mathrm{BO}_{3}$ to $\mathrm{BO}_{4}$ increases in glasses with modifier content of higher than roughly $35 \mathrm{~mol} \%$ is contrary to the findings of pervious reports on borate based glasses with different formulations [139, 140].

SEM images of the powders after 24 hours immersion in SBF showed precipitations on the surface for all five compositions (Figure 3- 3). The morphology of the observed precipitations is comparable to $\mathrm{Ca}-\mathrm{P}$ and $\mathrm{HA}$ precipitations on bioactive glasses reported in the literature [33, 94, 146, 147]. The normalized EDS spectra of the synthesized glasses after incubation in SBF revealed that the $\mathrm{Ca}$ and $\mathrm{P}$ on the surface of the incubated glass powders 
increase with immersion time (Figure 3-4). Similar trends have been reported for incubated bioactive glasses [33, 94, 146, 147]. The observed increase in the intensity of the $\mathrm{Ca}, \mathrm{P}$, and $\mathrm{Zn}$ peaks in the EDS spectra can be seen as an indication of formation of $\mathrm{Ca}-\mathrm{P}$ layer where $\mathrm{Ca}$ appears to be partially replaced by $\mathrm{Zn}$; this partial replacement of $\mathrm{Ca}$ with $\mathrm{Zn}$ has been previously reported for other bioactive glasses with $\mathrm{Zn}$ in their composition $[148,149,150,151$, 152]. Further analyses such as FTIR and XRD can provide more information about the chemical composition and crystallinity of the observed precipitations.

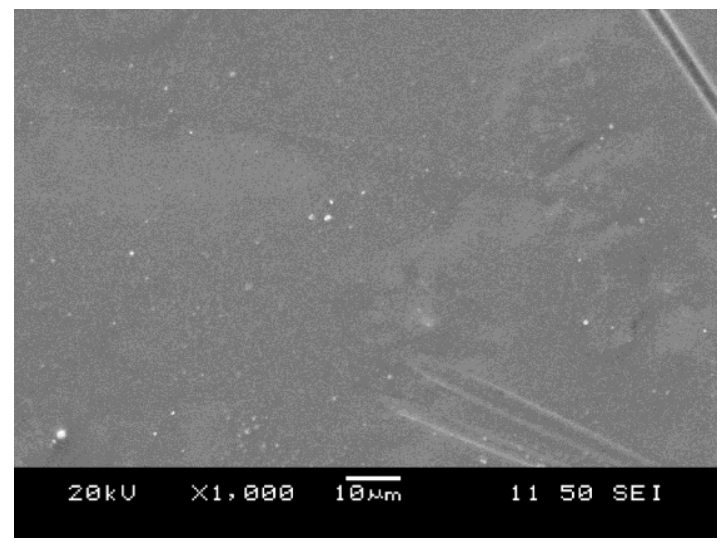

(a)

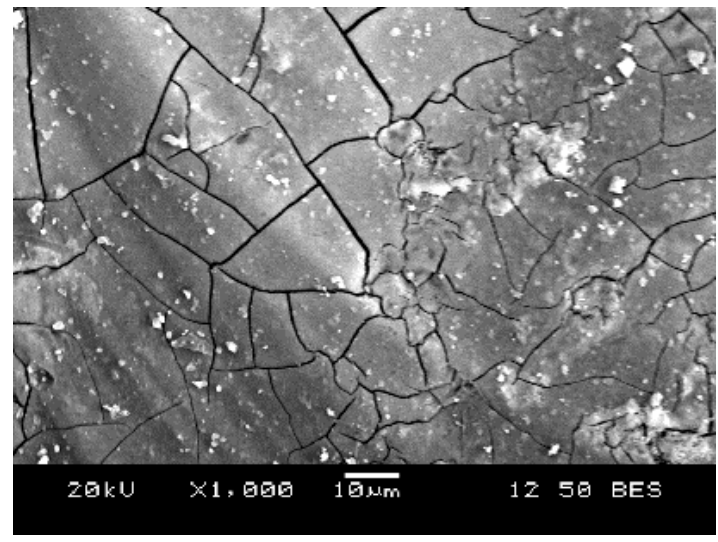

(c)

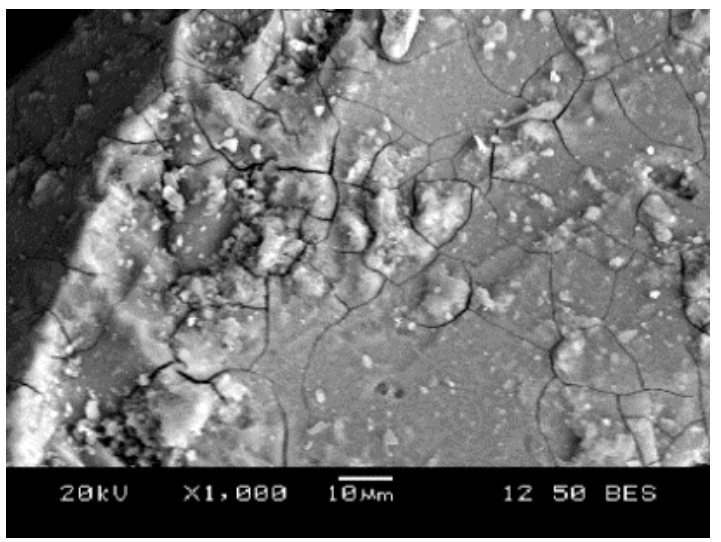

(b)

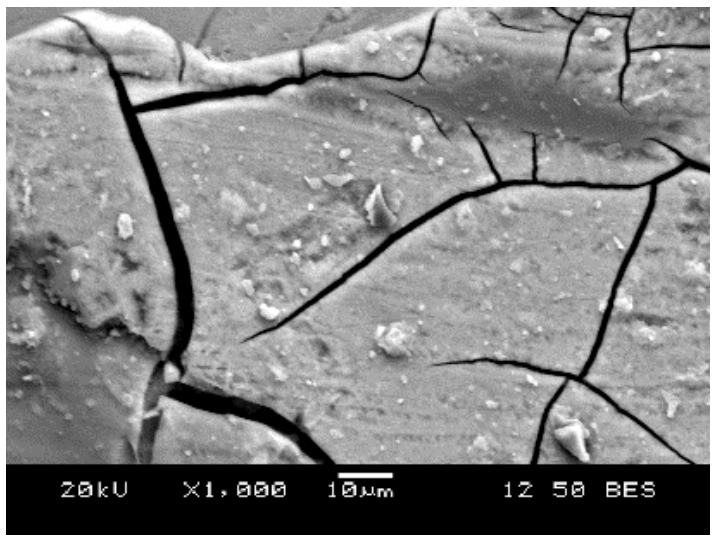

(d)

Figure 3- 3: SEM image of the precipitations on the surface of a G1 glass particle; (a) before immersion in SBF, and after immersion in SBF for: (b) 1 day, (c) 7 days, and (d) 28 days. 


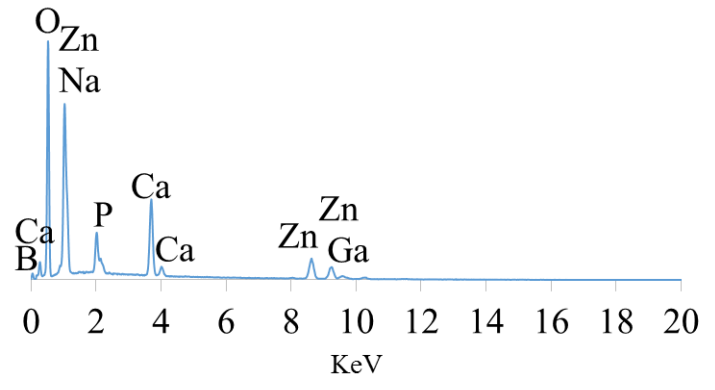

(a)

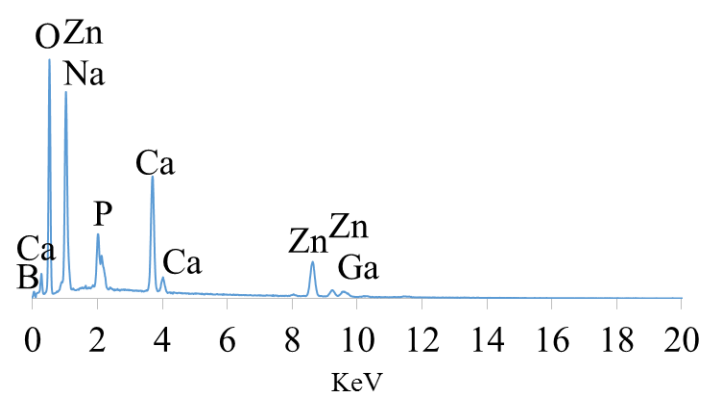

(b)

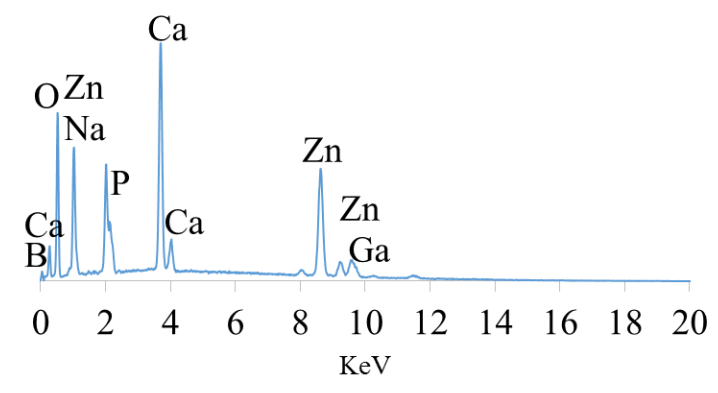

(c)

Figure 3- 4: The normalized EDS spectra of G3 glass particles after incubation in SBF for (a) 1, (b) 7 , and (c) 28 days.

XRD analysis did not detect any crystalline phase on the glass powders after incubation in SBF (as shown in Figure 3- 5). The amorphous state of the precipitations is in agreement with the previous investigations that have suggested $\mathrm{Zn}$ can inhibit the crystallization of the precipitations from the released ions and those in SBF by slowing down the growth and crystallization kinetics $[148,149,150,151,152]$. 


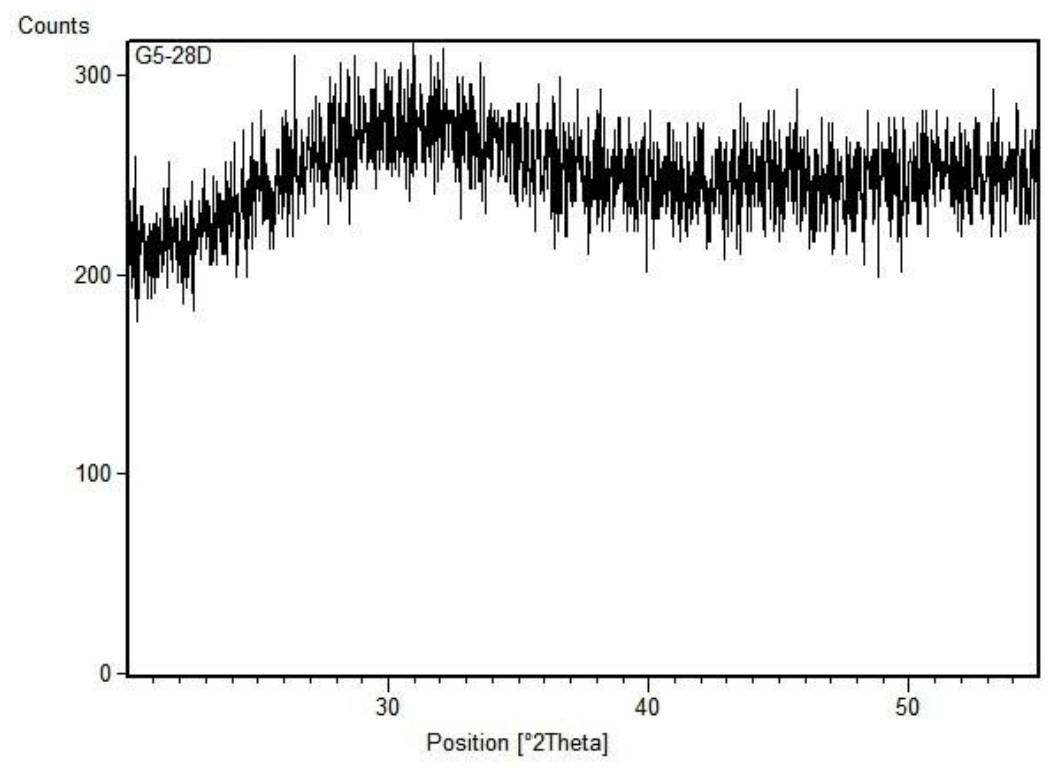

Figure 3- 5: X-ray Diffraction pattern of G5 particles after immersion in SBF for 28 days.

The FTIR spectra of the synthesized glasses before and after immersion in SBF for 1, 7 and 28 days are illustrated in Figure 6. In the raw glasses (before immersion in SBF), only the characteristic peaks of various B-O bonds were observed. The peaks of the raw glasses include $\sim 700 \mathrm{~cm}^{-1}$ : bending vibrations of B-O-B linkage in pentaborate groups; $\sim 930 \mathrm{~cm}^{-1}$ : stretching vibrations of $\mathrm{B}-\mathrm{O}$ bonds in $\mathrm{BO}_{4}$ tetrahedra in diborate group; $1060 \mathrm{~cm}^{-1}$ : stretching vibrations of $\mathrm{B}_{3}-\mathrm{O}-\mathrm{B}_{4}$ bridges; $1235 \mathrm{~cm}^{-1}$ : asymmetric stretching vibration of $\mathrm{B}-\mathrm{O}$ bonds in orthoborate groups; and $\sim 1345 \mathrm{~cm}^{-1}$ : stretching vibrations of borate triangles $\left(\mathrm{B} \varnothing_{3}\right.$ and $\left.\mathrm{B}_{2} \mathrm{O}^{-}\right)$[131].

However, the immersion of glasses in SBF causes an ion exchange between the solution and the glass powder, and this ion exchange causes the precipitation of $\mathrm{Ca}^{2+}$ cations and $\mathrm{PO}_{4}{ }^{3-}$ anions on the surface of the glass powders. The resultant layer on the glass is amorphous Ca-P that can crystallize to HA $[33,94]$. But, due to the fact that incubation of the glasses in SBF has been carried out in the presence of air, the atmospheric $\mathrm{CO}_{2}$ could dissolve into the solution 
which can lead to partial substitution of $\mathrm{CO}_{3}{ }^{2-}$ for $\mathrm{OH}^{-}$in the precipitated layer and eventually formation of carbonated hydroxyapatite (HCA) instead of HA.

(a) ---G1-raw - G1-1day ------ G1-7days ……..... G1-28 days

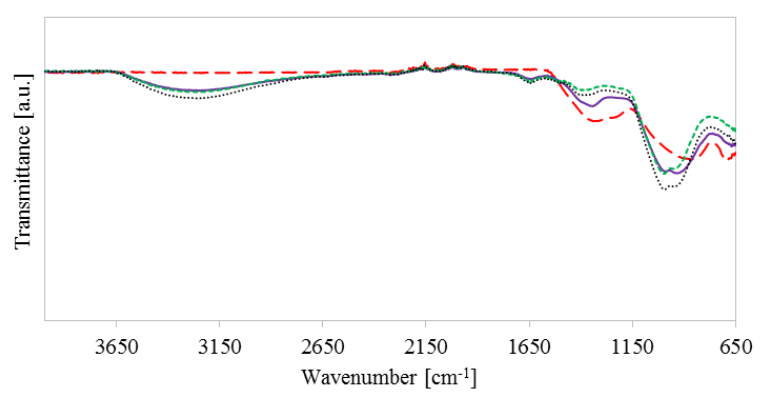

(c)

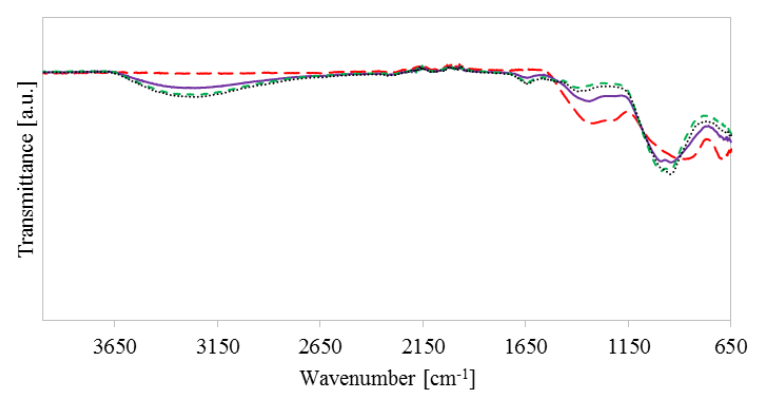

(b) - --G2-raw — G2-1day -..-G2-7days ……... G2-28days

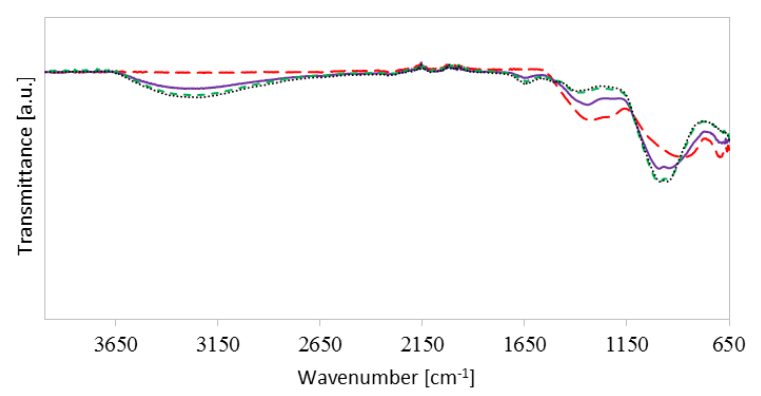

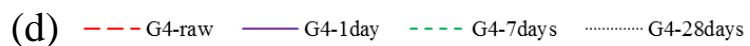

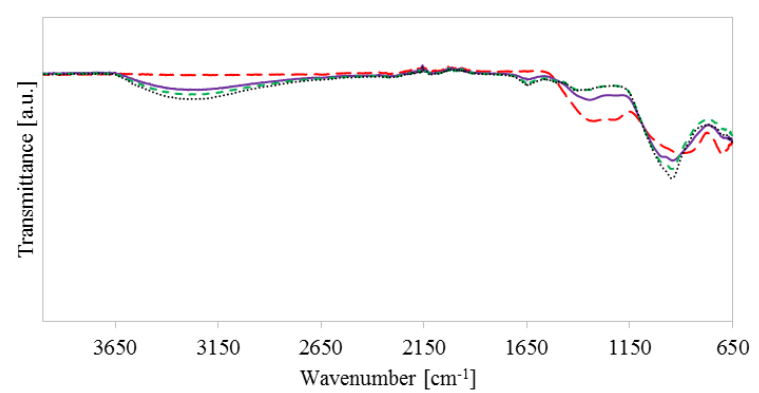

(e) ---G5-raw — G5-1day ----G5-7days …….... G5-28days

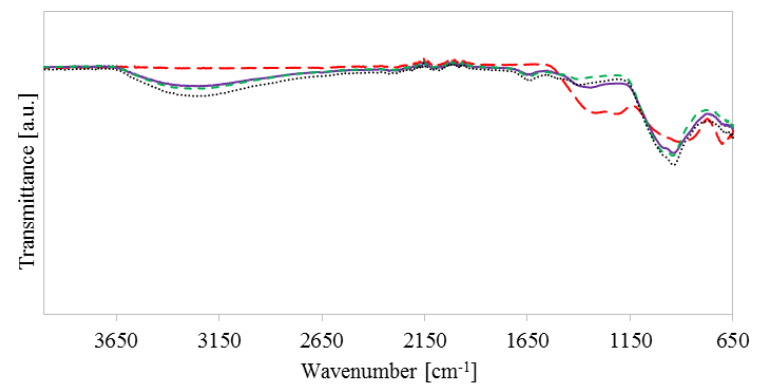

Figure 3- 6: The FTIR spectra of the synthesized glasses before and after immersion in SBF for 1, 7 and 28 days; (a) G1, (b) G2, (c) G3, (d) G4, (e) G5. 
The FTIR results show that the characteristic peaks of B-O bonds were replaced for samples that were immersed in SBF. The peaks between $\sim 1000 \mathrm{~cm}^{-1}$ and $\sim 1100 \mathrm{~cm}^{-1}$ are attributed to calcium phosphate $[33,153,154,155]$; the peaks at $\sim 1390 \mathrm{~cm}^{-1}$ and $\sim 1640 \mathrm{~cm}^{-1}$ correspond to $\mathrm{C}-\mathrm{O}$ resonance in $\mathrm{CO}_{3}{ }^{2-}[33,155,156,157]$; and the broad peak between $\sim 3000$ $\mathrm{cm}^{-1}$ and $\sim 3700 \mathrm{~cm}^{-1}$ can be attributed to the resonance of the $\mathrm{O}-\mathrm{H}$ bond [158]. As can be seen in Figure 6, the intensity of calcium phosphate and O-H peaks shows a steady rise by increasing the immersion time for all the glass compositions which is an indicator of a rise in the quantity of the deposited Ca-P layer.

Antimicrobial evaluation revealed contrasting inhibition trends between the two strains of bacteria with distinct Gram-stain characteristics. Glasses with higher $\mathrm{Zn}$ ion release had a stronger inhibitory effect on the Gram-positive bacterium (Figure 3- 2 and Figure 3- 7). Glasses with higher Ga ion release inhibited the growth of Gram-negative bacterium more effectively (Figure 3- 2 and Figure 3-8). The changes in the sizes of the inhibition zones were consistent with the ion release profiles of $\mathrm{Zn}$ and $\mathrm{Ga}$, indicative of their antibacterial efficacy. It was shown that the $\mathrm{Zn}$ ions from all of the glass samples had antibacterial effect on the Gram-positive species, S. epidermidis. However, this was not the case with the Gram-negative species, $P$. aeruginosa, which had no visible inhibition when incubated with the glass sample containing $0 \%$ Ga concentration (G1). In contrast, the varying quantities of Ga in the glass samples G2 to G5 showed considerably higher levels of inhibition, consistent with the increase in Ga content. Kruskal-Wallis H Test statistical analysis showed that the measured inhibition zones, for both species, for different glass compositions in 1, 7 and 28 days groups were significantly different ( $\mathrm{P} \leq 0.05)$, with the exception of the 28 days data for S. epidermidis (Table 3- 4). 
Table 3- 4: The p-values for inhibition zone measurements of the glasses according to KruskalWallis H Test.

\begin{tabular}{lccc}
\hline & 1 day & 7 days & 28 days \\
\hline S. epidermidis & 0.016 & 0.03 & 0.06 \\
P. aeruginosa & 0.012 & 0.009 & 0.009 \\
\hline
\end{tabular}

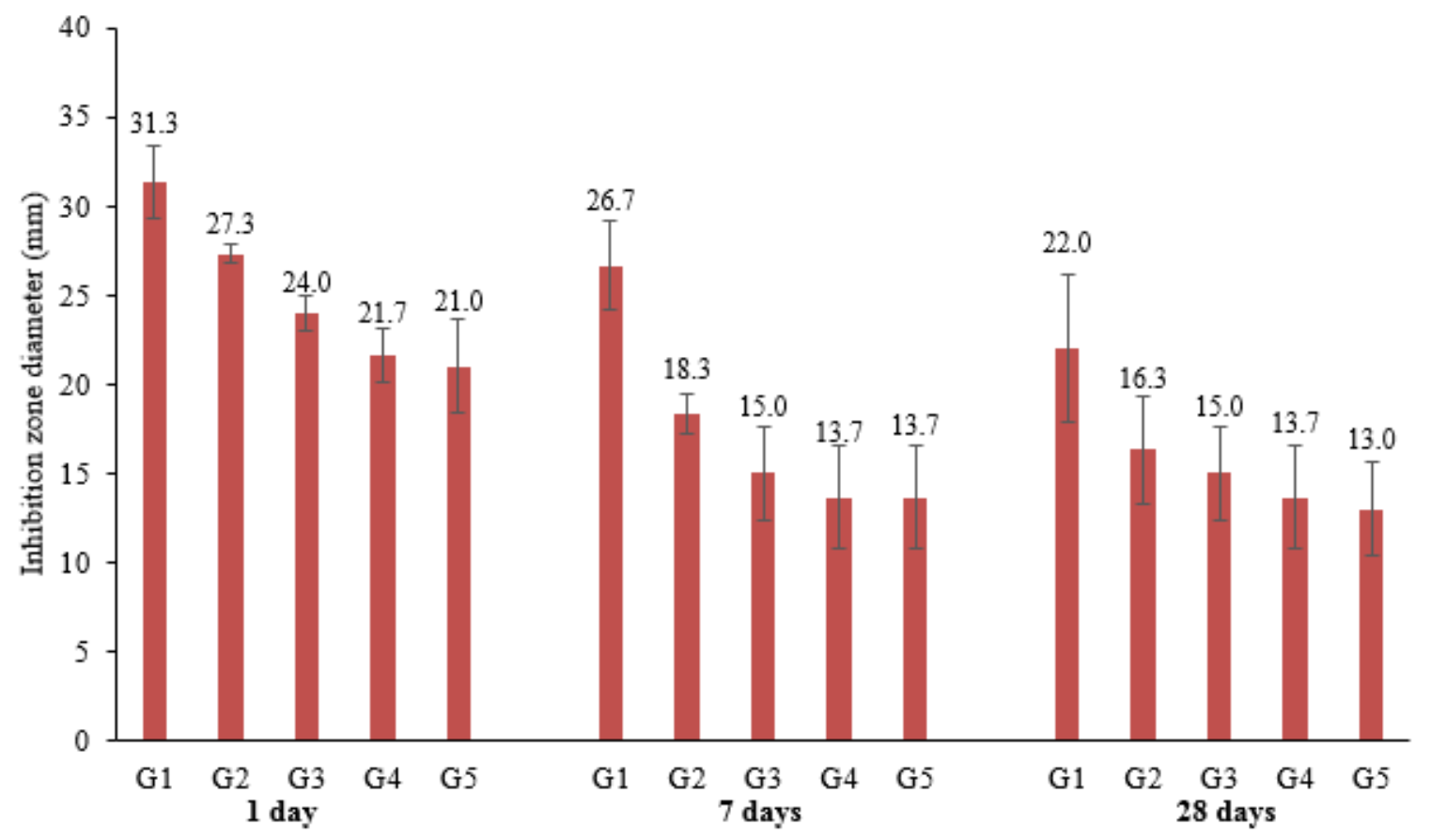

Figure 3- 7: Inhibition zone diameters of the synthesized glasses against S. epidermidis after 1, 7, and 28 days of incubation (irregular growth of bacteria in the inhibition zone was observed in 7 and 28 day samples); error bars represent standard deviation. 


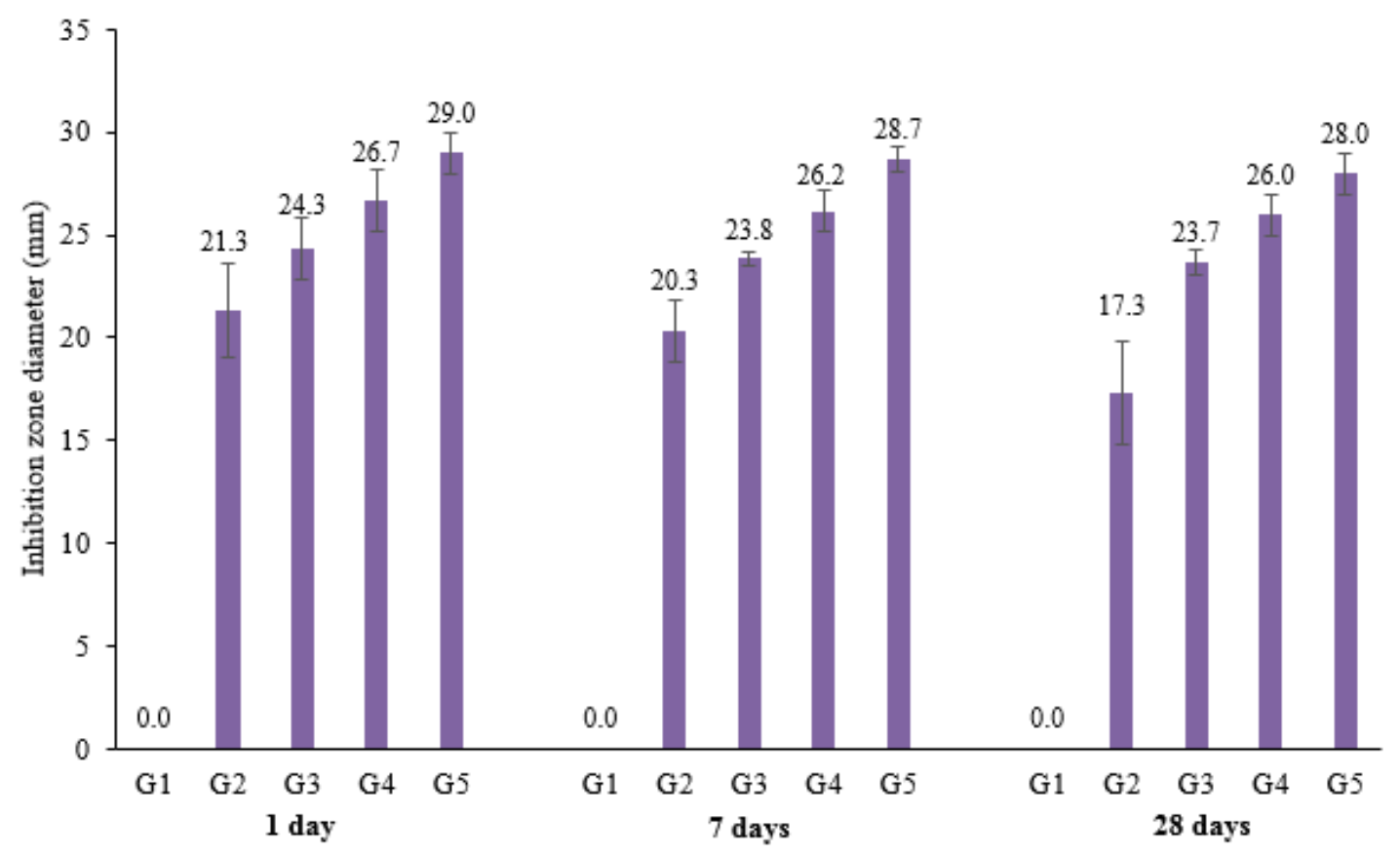

Figure 3- 8: Inhibition zone diameters of the synthesized glasses against $P$. aeruginosa after 1, 7, and 28 days of incubation (irregular growth of bacteria in the inhibition zone was observed in 28 day samples); error bars represent standard deviation.

The mechanism of action for the Zn ion involves its attachment to the microorganism's membrane, or cell wall [159]. In a previous study, it was found that Gram-positive bacteria were more susceptible to $\mathrm{Zn}$ ions than those that were Gram-negative. In some cases, they were not inhibited even at significantly higher concentrations [160]. This difference in affinity has been attributed to the disparity of the peptidoglycan layers and the higher content of associated protein constituents in the Gram-positive bacterium cell wall [161]. The results have also been corroborated by another study conducted by Atmaca et al. [162], where the antimicrobial effects of the $\mathrm{Zn}$ ion against S. epidermidis were statistically significant.

The Ga ion can exhibit antibacterial activity through the interference of various enzymes involved in vital metabolic functions, such as DNA synthesis and electron transport [163]. These 
processes and their associated enzymes require iron $(\mathrm{Fe})$ for proper functioning, proving to be a major vulnerability for invading bacteria since free Fe levels in vivo are low due to consumption by the host [163]. Ga has a nearly identical ionic radius to iron and has been shown to disrupt these Fe-dependent properties by remaining in its trivalent state, rather than being reduced under physiological conditions [164]. Previous studies have demonstrated the Ga ion's ability to inhibit the growth of $P$. aeruginosa in a dose-dependent manner by targeting Fe metabolism [165]. Following inhibition, a high molar ratio (5:1) of Fe to Ga was needed to restore bacterial growth and reverse the antibacterial effect, thus revealing Ga's involvement in the mediation of ironrequiring processes [165].

\subsection{Chapter Summary}

The degradation, ability to form Ca-P/HA on their surface in SBF, and antibacterial activity of the synthesized zinc borate glasses were investigated. The degradation experiments showed that the weight loss percentages were considerably higher for samples immersed in deionized water than those immersed in SBF, and the weight loss percentage of the glasses decreased slightly by the addition of Ga. Samples immersed in SBF did not experience weight loss after 28 days in comparison to 7 day samples which can be caused by the formation of Ca-P and precipitation of the released ions on the surface of the glass powders. ICP measurements showed that, except for $\mathrm{Ga}$, the release of ions from the glass followed a descending trend with the addition of Ga to the glasses' formulations at the expense of B. Both ion release and weight loss results showed a decline in the degradability of the glasses by the addition of Ga. The previously reported structural analyses of these glasses have shown a rise in the ratio of $\mathrm{BO}_{3}$ to $\mathrm{BO}_{4}$ units as the Ga percentage in the glasses increases [131], and considering the contribution of 
non-bridging oxygens to the higher degradability of the glasses, more symmetric $\mathrm{BO}_{3}$ units with three bridging oxygens and asymmetric $\mathrm{BO}_{3}$ units with two bridging oxygens appear to be formed in the glass network by increasing the $\mathrm{Ga}$ content in the synthesized glasses. Precipitations could be observed in the SEM images for all samples after immersion in SBF, and EDS analysis showed an increase in the concentration of $\mathrm{Ca}, \mathrm{P}$, and $\mathrm{Zn}$ on the surface of those samples after longer immersion periods. XRD analysis revealed the amorphous state of the observed precipitations; this can be explained by the presence of $\mathrm{Zn}$ in glasses and solutions which inhibits crystallization of the precipitations by slowing down the growth and crystallization kinetics. FTIR analysis showed that the intensity of calcium phosphate and O-H peaks rise steadily by increasing the immersion time for all the glass compositions which is an indicator of larger quantities of the deposited Ca-P layer. Finally, the antibacterial evaluation of the glasses revealed that glasses with higher $\mathrm{Zn}$ ion release had a more significant inhibitory effect on the Gram-positive bacterium (S. epidermidis), and glasses with higher Ga ion release could inhibit the growth of Gram-negative ( $P$. aeruginosa) bacterium more effectively. 
4. Development of a novel bioactive glass suitable for osteosarcomarelated bone grafting applications 
The work presented in this chapter has been accepted for publication as follows [166]:

Rahimnejad Yazdi, A., Torkan, L., Waldman, S.D. and Towler, M.R., 2017. Development of a novel bioactive glass suitable for osteosarcoma-related bone grafts, Journal of Biomedical Materials Research Part B: Applied Biomaterials (accepted).

\subsection{Introduction}

In the previous chapters the structural characterization, bioactivity and antibacterial properties of a novel borate-based glass series that contain increasing amounts $(2.5,5,10$, and 15 wt. \%) of Ga were discussed. The results showed that Ga was successfully incorporated in the structure of the synthesized glasses without forming additional crystalline phases that could impede the bioactivity of the glass. The bioactivity studies confirmed the presence of an amorphous Ca-P layer on glass samples immersed in SBF, and the antibacterial evaluation of the glasses confirmed their effectiveness against both Gram-positive and Gram-negative bacterial species.

This chapter discusses the suitability of these glasses for osteosarcoma-related bone grafting applications. The effect of these glasses on viability and proliferation of preosteoblasts and osteosarcoma cancer cells were studied in vitro. Methyl Thiazolyl Tetrazolium (MTT) cell viability assays were used to investigate the behavior of preosteoblasts and osteosarcoma cells after exposure to various glass degradation extracts in order to choose the most suitable compositions for osteosarcoma-related bone grafts. The selected compositions were further studied (in powder form) using both preosteoblasts and osteosarcoma cells. Finally, Live/Dead assays were performed in order to determine the mechanism behind the observed drop in the cell viability values of osteosarcoma cells exposed to the selected glass composition. 


\subsection{Materials and methods}

\subsubsection{Glass synthesis and preparation}

Glass synthesis and preparation for this work was performed as per Section 2.2.1.

\subsubsection{Glass degradation extracts}

Glass degradation extracts preparations and ICP measurements of the released ions for this work were performed as per Section 3.2.2.

\subsubsection{MTT cell viability tests}

\subsubsection{Cytotoxicity of the glasses' degradation extracts}

Cell viability assays using the Methyl Thiazolyl Tetrazolium (MTT) kits were conducted to determine in vitro cytotoxicity of the glasses. Preosteoblastic MC3T3-E1 (ATCC CRL-2593) and SaOS2 Osteosarcoma (ATCC HTB-85 ${ }^{\mathrm{TM}}$ ) cells were used for this study. Cells were seeded into 24 well plates at a density of 10,000 cells per well in Minimum Essential Medium Alpha $(\mathrm{MEM} \alpha)$ supplemented with $10 \%$ fetal bovine serum and $1 \%(2 \mathrm{mM})$ L-glutamine (Cambrex, MD, USA) and maintained in a cell culture incubator at $37^{\circ} \mathrm{C} / 5 \% \mathrm{CO} 2.24$ hours after seeding, $100 \mu \mathrm{l}$ of liquid extract (from the degradation samples at 1, 7 and 30 days for all glasses) was added into the wells containing the cells in culture medium $(1 \mathrm{ml})$ and further cultured for $24 \mathrm{~h}$. The MTT was added in an amount equal to $10 \%$ of the culture medium volume/well. The cultures were then re-incubated for a further $2 \mathrm{hr}\left(37^{\circ} \mathrm{C} / 5 \% \mathrm{CO}_{2}\right)$ after which they were removed from the incubator and the resultant formazan crystals were dissolved by adding an amount of MTT Solubilization Solution (10\% Triton x-100 in Acidic Isopropanol (0.1 n HCI)) equal to the original culture medium volume. Once the crystals were fully dissolved, the absorbance was 
measured at a wavelength of $570 \mathrm{~nm}$. Control media and cells cultured in absence of liquid extracts were used as a reference. This cytotoxicity experiment was repeated in triplicate for degradation extracts of each glass composition and degradation period.

\subsubsection{Cytotoxicity of the glass powders}

After conducting cytotoxicity tests with the glass extracts, G3 glass formulation was selected for further analysis as it was nontoxic to preosteoblasts (healthy bone cells) and did not enhance the viability of osteosarcoma cancer cells. 1, 2, and $5 \mathrm{mg}$ of G3 glass powders were weighed (Mettler- Toledo XP26, Max $22 \mathrm{~g}, \mathrm{~d}=0.001 \mathrm{mg}$ ) and sprinkled on the bottom of the wells. Then, preosteoblastic MC3T3-E1 (ATCC CRL-2593) and SaOS2 Osteosarcoma (ATCC HTB-85 ${ }^{\mathrm{TM}}$ ) cells were seeded into the well plates at a density of 10,000 cells per well in Minimum Essential Medium Alpha (MEM $\alpha$ ) supplemented with 10\% fetal bovine serum and 1\% (2 mM) L-glutamine (Cambrex, MD, USA) and cultured for 48 hours. The MTT was added in an amount equal to $10 \%$ of the culture medium volume/well. The cultures were then re-incubated for a further $2 \mathrm{hr}\left(37^{\circ} \mathrm{C} / 5 \% \mathrm{CO} 2\right)$ after which the cultures were removed from the incubator and the resultant formazan crystals were dissolved by adding an amount of MTT Solubilization Solution (10\% Triton $\mathrm{x}-100$ in Acidic Isopropanol (0.1 n HCI)) equal to the original culture medium volume. Once the crystals were fully dissolved, the absorbance was measured at a wavelength of $570 \mathrm{~nm}$. Control media and healthy growing cell population were used as a reference. This cytotoxicity experiment was repeated in triplicate for G3 glass powder. 


\subsubsection{Live/Dead cell viability}

Fluorescence-based Live-Dead assay (Molecular Probes Inc. OR, USA) with calcein AM (for labeling live cells) and EthD-1 (for labeling dead cells) were used to evaluate the viability of the preosteoblastic MC3T3-E1 (ATCC CRL-2593) and SaOS2 Osteosarcoma (ATCC® HTB$85^{\mathrm{TM}}$ ) cells after exposure to G3 glass powders. First, adherent cells were cultured with 1, 2, and $5 \mathrm{mg}$ of glass powders in 24 well plates as confluent monolayers. Cells were then washed with PBS to remove serum esterase activity in growth media. Next, $100 \mu \mathrm{L}$ of the combined Live/Dead assay reagents with standard concentrations $(2 \mu \mathrm{M}$ calcein $\mathrm{AM}$ and $4 \mu \mathrm{M}$ EthD-1) were added directly to the wells to cover all cells. Then the cells were incubated for 45 minutes at room temperature. After incubation, wells were rinsed with PBS and labeled cells were viewed under microscope (Zeiss Axio Observer A1).

\subsubsection{Statistical analysis}

The non-parametric Kruskal-Wallis $\mathrm{H}$ test and Mann-Whitney $\mathrm{U}$ test were used to analyze the data, compare the relative means, and report any statistically significant differences when $\mathrm{P} \leq 0.05$. Statistical analysis was performed on all groups where $3 \leq \mathrm{n} \leq 9$. Statistical analysis was performed using SPSS software (IBM SPSS statistics 21, IBM Corp., Armonk, NY, USA).

\subsection{Results and discussion}

Preosteoblast (PO) cells were initially tested with degradation extracts obtained by immersion of the glass particles containing varying Ga concentrations (G1-G5) in deionized water for assorted lengths of time. The results from the cell viability test, determined by MTT 
assays, are presented in Figure 4- 1. The goal of this test was to determine the glass compositions with biologically feasible Ga concentrations to allow for viability of preosteoblasts. As seen in Figure 4- 1, the average number of viable cells generally declined as Ga content increased. For 1 day extracts, all glass compositions facilitated increased cell viability compared to the control; for 7 day extracts, G1-G3 compositions facilitated better cell viability compared to the control; and for 28 day extracts, G1-G4 were found to increase cell viability with respect to the control. It is possible that the G5 extracts (7 days and 28 days) contained levels of Ga that surpassed the toxic level for preosteoblasts. This would explain the reduced cell viability in the G5 extract relative to the control media. According to the Kruskal-Wallis $\mathrm{H}$ test, the measurements for preosteoblast cell viability in different extracts for each incubation time were significantly different $(\mathrm{P} \leq 0.05): \mathrm{P}_{1 \text { day }}=0.007, \mathrm{P}_{7 \text { days }}=0.009$, and $\mathrm{P}_{28 \text { days }}=0.012$. The statistical significance between the means for each incubation time were compared using the Mann-Whitney $U$ test (Table 4- 1). The Mann-Whitney $U$ test results confirm that the observed reductions in the preosteoblast cell viability for all G5 extracts (1day, 7 days, and 28 days) with respect to control samples were statistically significant. It should be noted that the statistical significance of the results (viability of PO in the presence of glass extracts) were already confirmed using KruskalWallis $\mathrm{H}$ test and all the reported p-values were calculated using SPSS software as mentioned in Section 4.2.5.

At non-toxic levels, Ga-releasing substances have been studied and proven to have a number of benefits with respect to bone metabolism. Gallium nitrate has been used in both in vivo and in vitro models for the purpose of inhibiting bone resorption without cytotoxic effects on bone cells $[72,74,75,76,167]$. Studies conducted by means of Ga-treated rat calvaria suggest that Ga ions may act directly on osteoblasts at the level of gene expression. It was found 
that treatment with gallium nitrate can suppress stimulation of osteocalcin (OC), an abundant protein synthesized by osteoblasts; reduction of synthesis of OC in vivo is associated with enhanced mineralization $[78,168]$. Osteocalcin has been hypothesized to serve as a signal molecule synthesized by osteoblasts in order for resorption to commence [77, 169, 170, 171]. Suppression of resorption would indicate to the cell that collagen and bone formation is favored, thus promoting preosteoblast proliferation. Since it has been shown that Ga affects protein synthesis related to the fully differentiated osteoblast phenotype, it is possible that optimal levels of Ga could contribute to the enhancement of preosteoblast proliferation and differentiation.
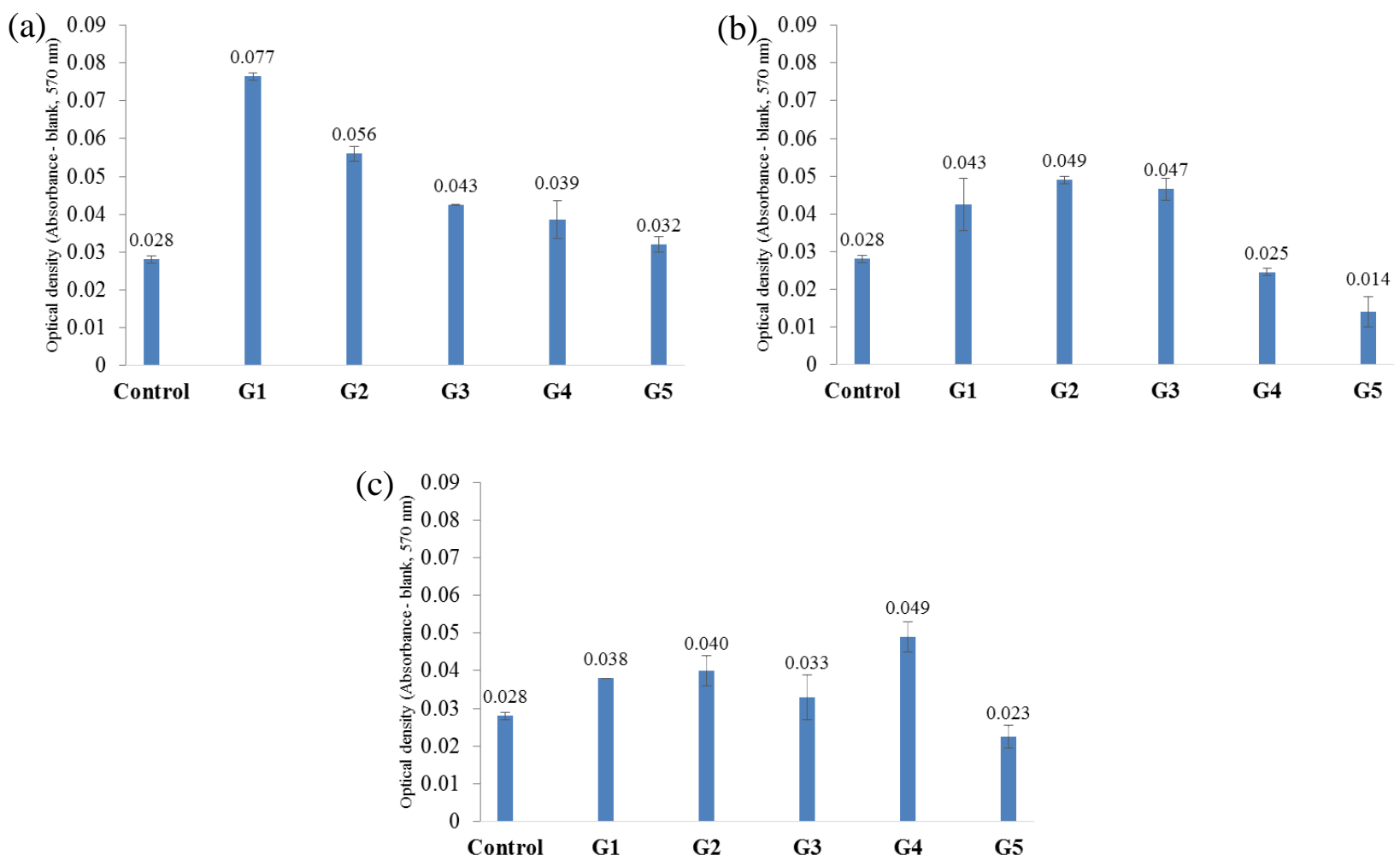

Figure 4- 1: The viability of the preosteoblast cells in the presence of (a) 1 day, (b) 7 day, and (c) 28 day glass extracts; error bars represent standard deviation. 
Table 4- 1: The p-values for the PO cell viability measurements of the glass extracts and control (C) according to Mann-Whitney $U$ test: Those with $\mathrm{P}>0.05$ are underlined.

\begin{tabular}{|c|c|c|c|c|c|c|c|c|c|c|c|c|c|c|c|}
\hline & $\begin{array}{l}\mathrm{C}, \\
\mathrm{G} 1\end{array}$ & $\begin{array}{c}\mathrm{C}, \\
\mathrm{G} 2\end{array}$ & $\begin{array}{l}\mathrm{C}, \\
\text { G3 }\end{array}$ & $\begin{array}{l}\mathrm{C}, \\
\mathrm{G} 4\end{array}$ & $\begin{array}{l}\text { C, } \\
\text { G5 }\end{array}$ & $\begin{array}{l}\text { G1, } \\
\text { G2 }\end{array}$ & $\begin{array}{l}\text { G1, } \\
\text { G3 }\end{array}$ & $\begin{array}{l}\text { G1, } \\
\text { G4 }\end{array}$ & $\begin{array}{l}\text { G1, } \\
\text { G5 }\end{array}$ & $\begin{array}{l}\text { G2, } \\
\text { G3 }\end{array}$ & $\begin{array}{l}\text { G2, } \\
\text { G4 }\end{array}$ & $\begin{array}{l}\text { G2, } \\
\text { G5 }\end{array}$ & $\begin{array}{l}\text { G3, } \\
\text { G4 }\end{array}$ & $\begin{array}{l}\text { G3, } \\
\text { G5 }\end{array}$ & $\begin{array}{l}\text { G4, } \\
\text { G5 }\end{array}$ \\
\hline $\mathrm{P}_{1 \text { day }}$ & 0.05 & 0.05 & 0.05 & 0.05 & 0.05 & 0.05 & 0.05 & 0.05 & 0.05 & 0.05 & 0.05 & 0.05 & $\underline{0.376}$ & 0.05 & 0.127 \\
\hline $\mathrm{P}_{7 \text { days }}$ & 0.05 & 0.05 & 0.05 & 0.05 & 0.05 & $\underline{0.275}$ & $\underline{0.376}$ & 0.05 & 0.05 & $\underline{0.275}$ & 0.05 & 0.05 & 0.05 & 0.05 & 0.05 \\
\hline $\mathrm{P}_{28 \text { days }}$ & 0.037 & 0.05 & $\underline{0.376}$ & 0.05 & 0.05 & $\underline{0.487}$ & $\underline{0.487}$ & 0.037 & 0.037 & $\underline{0.127}$ & 0.05 & 0.05 & 0.05 & 0.05 & 0.05 \\
\hline
\end{tabular}

The viability of the preosteoblast cells could be affected by the other ions released from the glasses. A key ion in the extracts that is involved in bone metabolism is $\mathrm{Zn}$. It plays an active role in stimulating bone formation and has been shown to be concentrated in osteoid prior to its calcification to bone $[172,173,174,175]$. Studies conducted on in vivo models confirm that dietary $\mathrm{Zn}$ enhances osteoblast differentiation while inhibiting osteoclastic differentiation and subsequent resorption $[176,177,178,179]$. $\mathrm{Zn}$ also enhances ATPase activity, and regulates transcription of genes, such as osteocalcin, osteopontin, ALP, and collagen I, that are responsible for differentiation of osteoblastic cells $[28,180,123]$. Calcium ions also are reported to intensify osteoblast proliferation; they can activate $\mathrm{Ca}$-sensing receptors in osteoblasts and enhance the expression of growth factors such as IGF-I and IGF-II [123, 181, 182, 183]. The ICP measurements of the above-mentioned ions in the degradation extracts are shown in Table 4- 2.

Table 4- 2: The concentration ( $\mathrm{ppm}$ ) of the released ions from glass powder after soaking in DI water for 1,7 , and 28 days at $37^{\circ} \mathrm{C}$.

\begin{tabular}{ccccccccccc}
\hline & \multicolumn{3}{c}{1 day } & \multicolumn{3}{c}{7 days } & \multicolumn{3}{c}{28 days } \\
& $\mathrm{Ga}$ & $\mathrm{Zn}$ & $\mathrm{Ca}$ & $\mathrm{Ga}$ & $\mathrm{Zn}$ & $\mathrm{Ca}$ & $\mathrm{Ga}$ & $\mathrm{Zn}$ & $\mathrm{Ca}$ \\
\hline G1 & 0 & 0.04 & 62 & 0 & 0.18 & 162 & 0 & 0.46 & 195 \\
$\mathrm{G} 2$ & 33 & 0.04 & 68 & 49 & 0.16 & 145 & 61 & 0.40 & 146 \\
G3 & 75 & 0.02 & 57 & 101 & 0.15 & 91 & 123 & 0.33 & 141 \\
G4 & 107 & 0.02 & 38 & 179 & 0.14 & 119 & 196 & 0.29 & 152 \\
G5 & 181 & 0.01 & 46 & 276 & 0.08 & 128 & 285 & 0.24 & 131 \\
\hline
\end{tabular}


The viability of osteosarcoma (OS) cells in the presence of the degradation extracts of the glasses was also investigated using MTT assays. As seen in Figure 4- 2, all 1 day degradation extracts facilitated enhanced viability of the osteosarcoma cells compared to the control media. For 7 day extracts, only those from G3 glass could suppress the proliferation of the osteosarcoma cells. For 28 day extracts, G2-G5 could suppress the proliferation of the osteosarcoma cells. According to the Kruskal-Wallis $\mathrm{H}$ test, the measurements for osteosarcoma cell viability in the presence of different extracts for each incubation time were not significantly different $(\mathrm{P} \geq 0.05)$ : $\mathrm{P}_{1 \text { day }}=0.087, \mathrm{P}_{7 \text { days }}=0.051$, and $\mathrm{P}_{28 \text { days }}=0.997$. The statistical significance between the means for each incubation time were compared using Mann-Whitney $U$ test (Table 4- 3). The MannWhitney $U$ test results show that the observed increase in the osteosarcoma cell viability (compared to the control media) for 1 day G2, G4, and G5 extracts, and 7 day extracts of G1 and G2 were statistically significant.

Table 4- 3: The p-values for the OS cell viability measurements of the glass extracts and control (C) according to Mann-Whitney $\mathrm{U}$ test: Those with $\mathrm{P} \leq 0.05$ are underlined.

\begin{tabular}{cccccccccccccccc}
\hline & $\mathrm{C}$, & $\mathrm{C}$, & $\mathrm{C}$, & $\mathrm{C}$, & $\mathrm{C}$, & $\mathrm{G} 1$, & $\mathrm{G} 1$, & $\mathrm{G} 1$, & $\mathrm{G} 1$, & $\mathrm{G} 2$, & $\mathrm{G} 2$, & $\mathrm{G} 2$, & $\mathrm{G} 3$, & $\mathrm{G} 3$, & $\mathrm{G} 4$, \\
& $\mathrm{G} 1$ & $\mathrm{G} 2$ & $\mathrm{G} 3$ & $\mathrm{G} 4$ & $\mathrm{G} 5$ & $\mathrm{G} 2$ & $\mathrm{G} 3$ & $\mathrm{G} 4$ & $\mathrm{G} 5$ & $\mathrm{G} 3$ & $\mathrm{G} 4$ & $\mathrm{G} 5$ & $\mathrm{G} 4$ & $\mathrm{G} 5$ & $\mathrm{G} 5$ \\
\hline $\mathrm{P}_{1 \text { day }}$ & 0.268 & $\underline{0.046}$ & 0.121 & $\underline{0.046}$ & $\underline{0.046}$ & 0.127 & 0.827 & 0.513 & 0.513 & 0.127 & 0.127 & 0.127 & 0.275 & 0.275 & 0.376 \\
$\mathrm{P}_{7 \text { days }}$ & $\underline{0.046}$ & $\underline{0.046}$ & 0.825 & 0.268 & 0.5 & 0.275 & $\underline{0.05}$ & 0.275 & $\underline{0.046}$ & $\underline{0.05}$ & 0.184 & $\underline{0.046}$ & 0.275 & 0.268 & 0.825 \\
$\mathrm{P}_{\text {28days }}$ & 0.825 & 0.5 & 0.825 & 0.5 & 0.825 & 0.817 & 0.827 & 0.825 & 0.827 & 1 & 0.361 & 0.825 & 1 & 0.827 & 0.825 \\
& & & & & & & & & & & & & & & \\
\hline
\end{tabular}


(a)

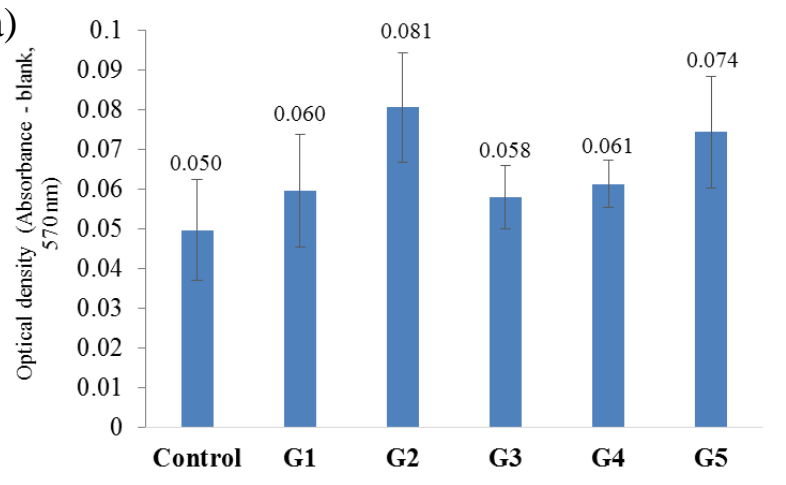

(b)

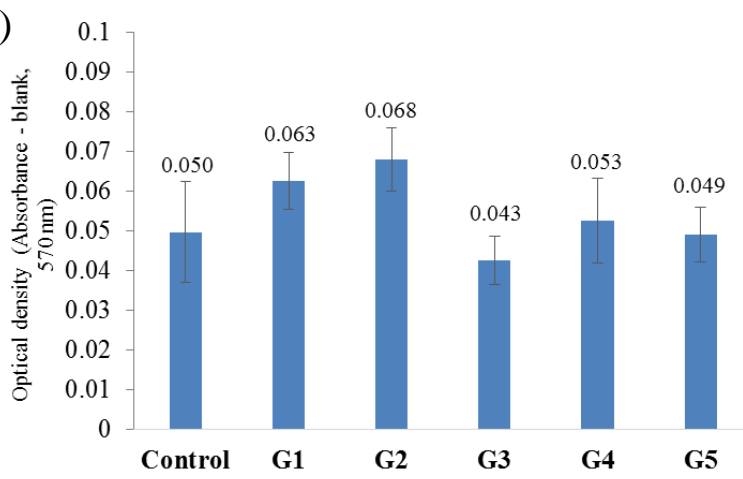

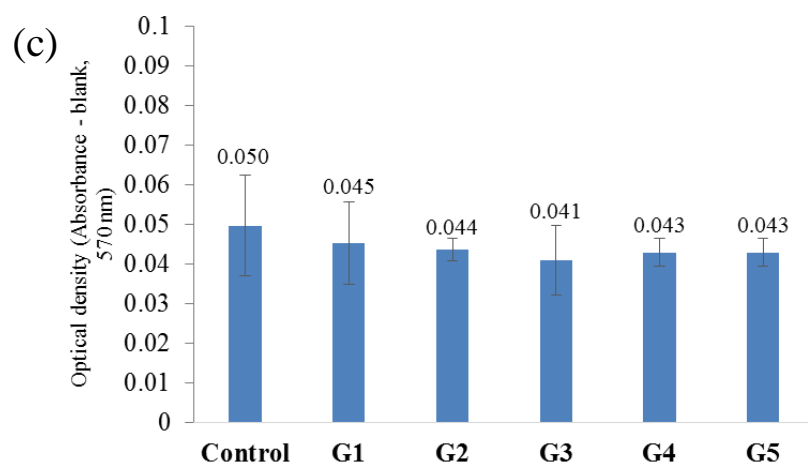

Figure 4- 2: The viability of the osteosarcoma cells in the presence of (a) 1 day, (b) 7 day, and (c) 28 day glass extracts; error bars represent standard deviation.

Considering the results of the conducted MTT assay with glass extracts on both preosteoblast and osteosarcoma cells, the G3 extract was the only one that did not produce a statistically significant rise in the viability of osteosarcoma cells. At the same time, 1 day and 7 day extracts of G3 composition significantly enhanced the viability of preosteoblast cells, while its 28 day extract did not suppress the proliferation of preosteoblasts. Therefore, G3 was chosen for further studies using the glass powders.

MTT assays were used to study the viability of preosteoblast and osteosarcoma cells in the presence of G3 glass powders. 1, 2, and $5 \mathrm{mg}$ of each glass composition were assayed with both preosteoblast and osteosarcoma cells (Figure 4- 3). It was found that the most effective 
quantity of the G3 sample, considering the criteria of promoting the viability of osteoblasts and suppressing that of osteosarcoma cells, was between 2 and 5 milligrams. According to the Kruskal-Wallis $\mathrm{H}$ test, the measurements for the viability of preosteoblast cells exposed to different glass powder weights for the G3 composition were significantly different $(\mathrm{P} \leq 0.05)$ : $\mathrm{P}_{\mathrm{G} 3, \mathrm{PO}}=0.034$. However, the measurements for the cell viability of osteosarcoma cells for various glass powder weights were not statistically significant $(\mathrm{P} \geq 0.05): \mathrm{P}_{\mathrm{G} 3}$, os $=0.114$.

Table 4- 4: The p-values for the PO \& OS cell viability measurements of the glass powders and control (C) according to Mann-Whitney $\mathrm{U}$ test: Those with $\mathrm{P} \leq 0.05$ are underlined.

\begin{tabular}{lllllll}
\hline & $\mathrm{C}, 1 \mathrm{mg}$ & $\mathrm{C}, 2 \mathrm{mg}$ & $\mathrm{C}, 5 \mathrm{mg}$ & $\begin{array}{c}1 \mathrm{mg}, \\
2 \mathrm{mg}\end{array}$ & $\begin{array}{c}1 \mathrm{mg}, \\
3 \mathrm{mg}\end{array}$ & $\begin{array}{c}2 \mathrm{mg}, \\
3 \mathrm{mg}\end{array}$ \\
\hline $\mathrm{P}_{\mathrm{G} 3, \mathrm{PO}}$ & 0.275 & $\underline{0.05}$ & $\underline{0.05}$ & $\underline{0.05}$ & $\underline{0.05}$ & 0.827 \\
$\mathrm{P}_{\mathrm{G} 3, \text { OS }}$ & 0.827 & $\underline{0.05}$ & 0.184 & $\underline{0.05}$ & 0.275 & 0.513 \\
\hline
\end{tabular}

The statistical significance between the means for various powder masses were compared using Mann-Whitney $U$ test (Table 4- 4). The comparison of the means showed that increasing the powder mass in contact with the osteosarcoma cells could lead to statistically significant reduction in their viability.

In order to gain a better understanding of the mechanism causing the observed reduction in the viability of osteosarcoma cells by G3 powders (suppression of proliferation versus induction of apoptosis), fluorescence-based Live-Dead assay, with calcein AM for labeling live cells and EthD-1 for labeling dead cells, were conducted. As shown in Figure 4- 4, the number of dead osteosarcoma cells stays at the same level for samples exposed to various amounts of G3 glass powders and control media. However, the number of live osteosarcoma cells drops by increasing the amount of G3 glass powders, suggesting that suppression of cell proliferation 
appears to be the mechanism behind the observed reduction in the cell viability values of osteosarcoma cells exposed to G3 glass powders.

(a)

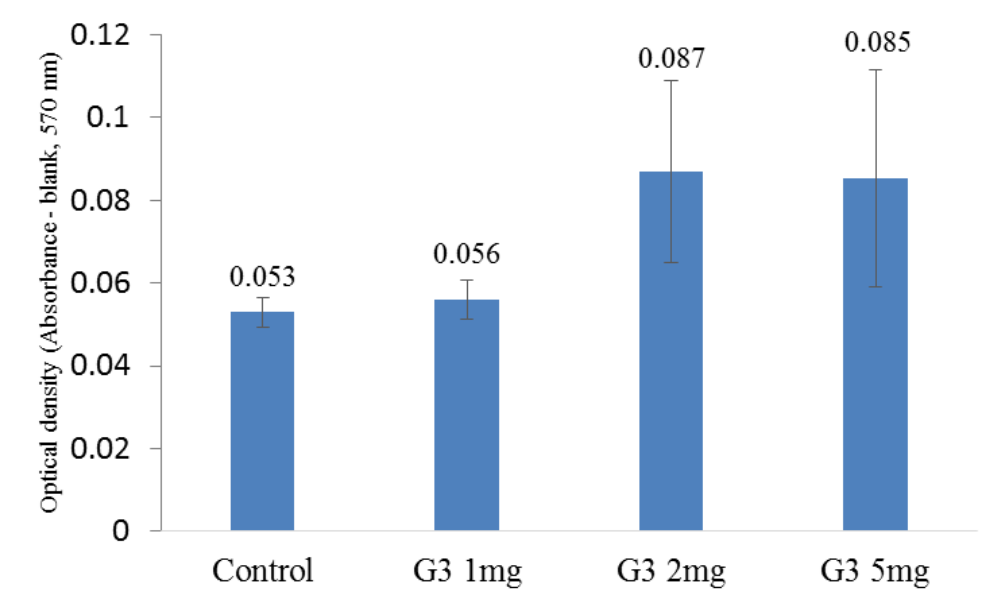

(b)

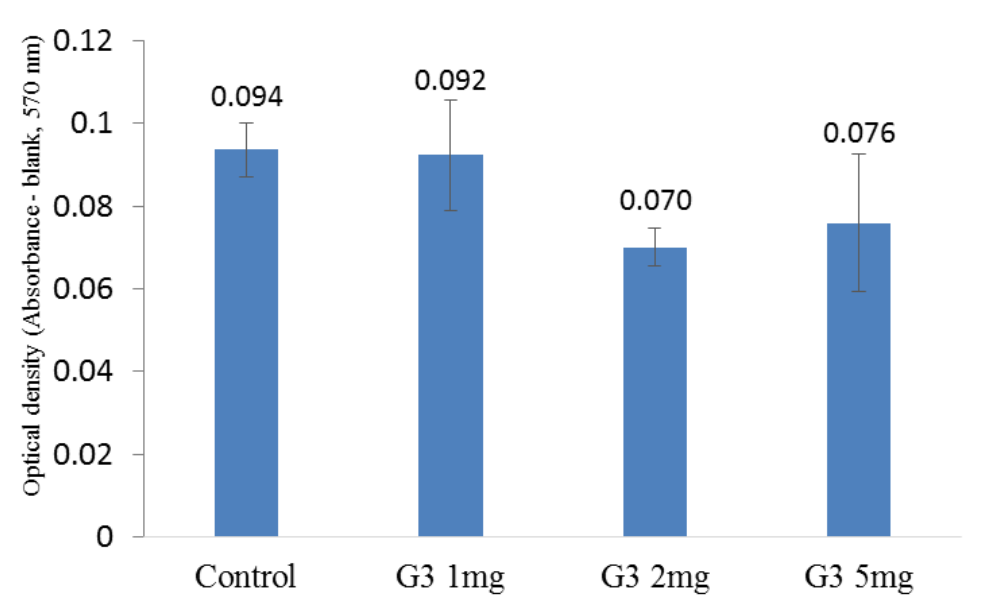

Figure 4- 3: Cell viability of (a) PO and (b) OS cells in the presence of 1, 2 and $5 \mathrm{mg}$ of G3 glass powders; error bars represent standard deviation. 


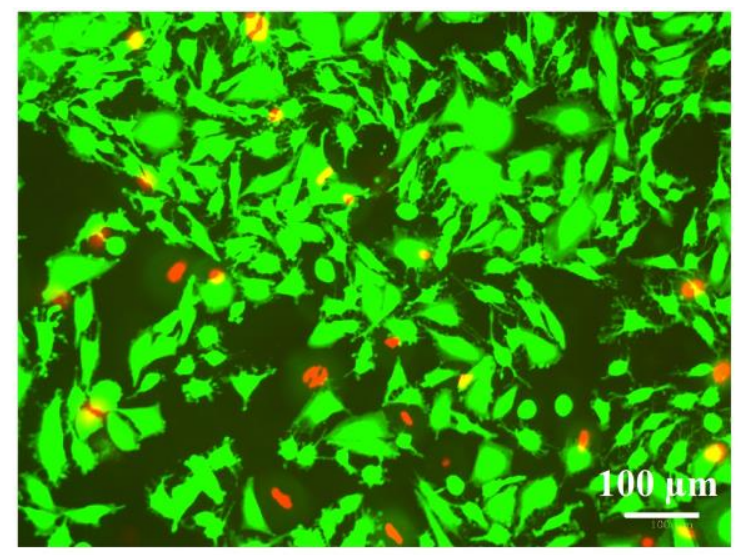

Control

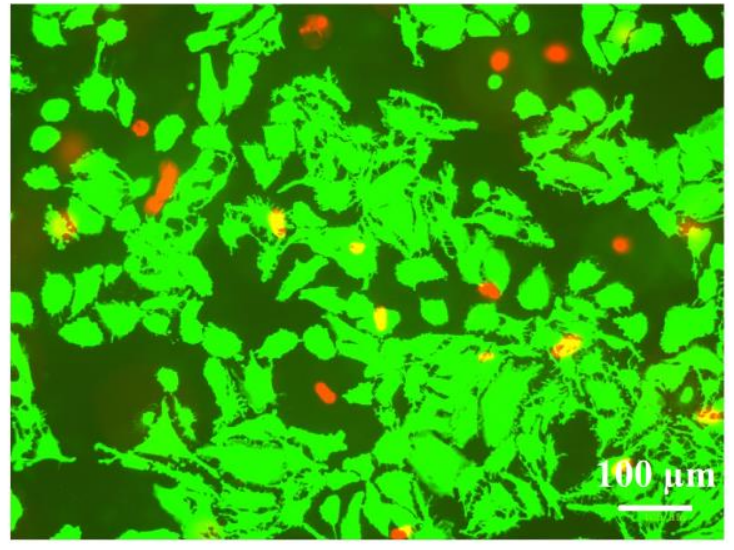

$1 \mathrm{mg}$

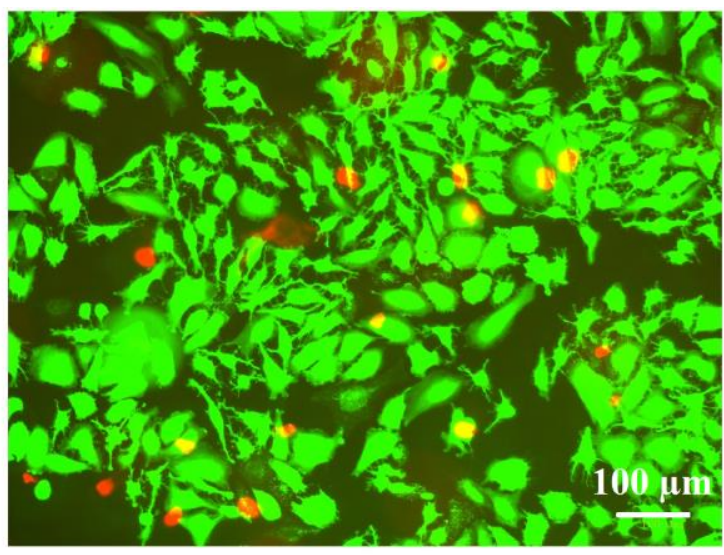

$2 \mathrm{mg}$

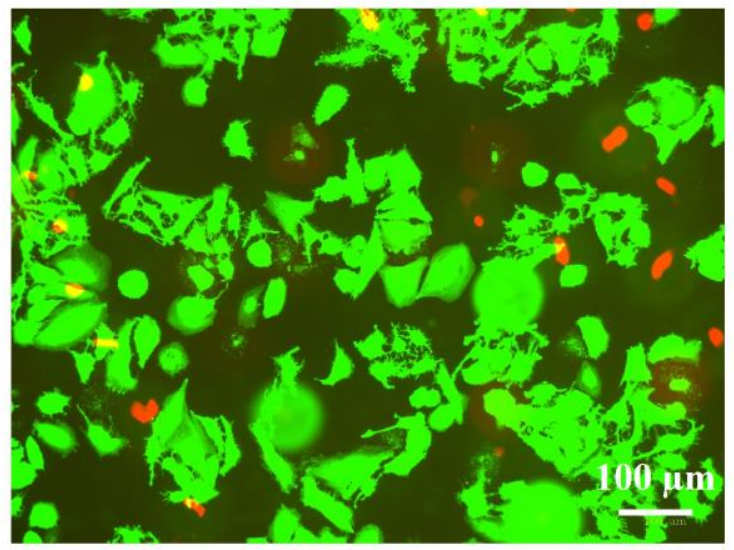

$5 \mathrm{mg}$

Figure 4- 4: Labeled live (green) and dead (red) OS cells after exposure to 1, 2, and 5 mg G3 glass powders.

\subsection{Chapter Summary}

The suitability of a novel series of Ga-releasing zinc borate bioactive glasses for osteosarcoma related bone graft operations was investigated using MTT and Live/Dead assays. First, the MTT assays were conducted with preosteoblasts and osteosarcoma cells in the presence of glass degradation extracts. The G3 extract was the only one that did not cause a statistically significant increase in the viability of osteosarcoma cells. At the same time, 1 day and 7 day extracts of G3 significantly improved the viability of preosteoblast cells, while its 28 day extract 
did not suppress the viability of preosteoblast cells. Therefore, the composition of G3 was selected for further analyses. Next, MTT assays were conducted to study the effect of the G3 glass powders on the viability of both preosteoblast and osteosarcoma cells. The results indicated that G3 powders could also enhance the viability of preosteoblasts while reducing that of osteosarcoma cells. Finally, the performed fluorescence-based Live-Dead assay on osteosarcoma cells that were exposed to G3 powders indicated that suppression of proliferation, not induction of apoptosis, was responsible for the observed reduction in the viability of osteosarcoma cells. 
5. Conclusions and Future Work 


\subsection{Conclusions}

A zinc borate glass series containing increasing amounts of $\mathrm{Ga}(0,2.5,5,10$ and 15 wt.\%) at the expense of B was synthesized and evaluated for their potential as bone graft materials. The impact of the addition of $\mathrm{Ga}$ on the chemical structure, bioactivity and biocompatibility, antibacterial potency, and effectiveness against osteosarcoma cancer cells were investigated. It was observed that:

- The incorporation of up to $15 \mathrm{wt} . \%$ Ga into the glasses did not lead to the formation of crystalline phases upon melt quenching and XRD analysis confirmed the amorphous state of all synthesized glasses in the series.

- Both glass transition and crystallization temperatures declined as Ga was introduced to the series.

- The addition of $\mathrm{Ga}$ led to an increase in the ratio of $\mathrm{BO}_{3}$ units (both symmetric and asymmetric) to $\mathrm{BO}_{4}$ units.

- The degradability of the glasses in the series (in both DI water and SBF) was inversely dependent on Ga content; the lower the GA content, the more degradable the glass.

- Incubation of all glasses in SBF resulted in the formation of an amorphous Ca-P layer on the surface of the glass particles. The amorphous nature of the deposited Ca-P was due to the presence of zinc in the glasses and the solutions which hinders the crystallization of Ca-P.

- Glasses that exhibited higher Zn ion release had a larger inhibitory effect on the Gram-positive bacterium (S. epidermidis), and glasses with higher $\mathrm{Ga}$ ion release 
could inhibit the growth of Gram-negative (P. aeruginosa) bacterium more effectively.

- According to MTT cell viability assays with glass extracts, G5 was the only composition in the series that led to the reduced viability of preosteoblasts.

- The G3 degradation extract was the only glass extract in the series that could improve the viability of preosteoblasts without having a similar effect on osteosarcoma cancer cells.

- G3 glass powders exhibited improved the viability of preosteoblasts while suppressing the viability of osteosarcoma cancer cells, compared to the control medium.

- According to Live/Dead assays, suppression of proliferation appeared to be the mechanism behind the lower viability values of osteosarcoma cells exposed to G3 glass powders.

Based on these findings, up to $10 \mathrm{wt} \% \mathrm{Ga}$ could be successfully incorporated into the zinc borate glass series without the glasses becoming cytotoxic in vitro. All the Ga containing glasses in the series exhibited antibacterial properties against both Gram-negative and Grampositive bacterial species. Finally, the G3 composition with 5 wt.\% Ga was the only one in the series, in the preliminary in vitro tests, that exhibited suitably for osteosarcoma-related bone grafting applications. 


\subsection{Novel Contributions}

Novel zinc borate glasses incorporating increasing amounts of $\mathrm{Ga}(0,2.5,5,10$ and 15 wt.\%) were successfully synthesized. A borate base was chosen because of its higher degradability compared to the silica based glasses. For the first time, Ga ion release capacities as high as 285pm (G5 glass, after 28 days of incubation in water) could be achieved which facilitate the therapeutic properties of the Ga ion to be exhibited, in this study, in-vitro.

The cytotoxicity experiments revealed significantly improved viability of preosteoblast cells by G1, G2, G3, and G4 compositions compared to the control samples. Therefore, it is expected that the synthesized glasses with Ga content of up to $10 \mathrm{wt}$ \% could allow patients to experience faster recovery of their damaged bone tissue. These compositions could also benefit patients suffering from osteoporosis with an age-related decline in the preosteoblast activity compared to their osteoclast cells.

Finally, for the very first time, the suitability of a Ga releasing bioactive glass as an osteosarcoma cancer graft material was investigated in-vitro. G3 was found to be the only composition from the series suitable for such operations. It may improve the viability of the healthy bone cells (preosteoblasts), while suppressing that of osteosarcoma cancer cells. 


\subsection{Future Work}

Despite the in vitro experiments on the synthesized glasses and evaluation of their applicability as bone graft materials, additional tests are required before the proposed bioactive glasses can be implemented and tested in human beings. These tests include, but are not limited to:

1. Further in vitro evaluation: $\mathrm{Ga}$ and $\mathrm{Zn}$ ions released from these glasses are known to suppress osteoclastic cell activity and have anti-inflammatory properties. Therefore, it is anticipated that these glasses have anti-inflammatory properties and reduce the activity of osteoclasts. However, these needs to be confirmed by in vitro studies.

2. Dynamic degradation tests: All degradation tests were conducted under static conditions. The lack of agitation could lead to the early saturation of the released ions in the media immediately around the glass particles. In order to better predict the release capacities that can occur in-vivo, those experiments using the select compositions should be repeated under dynamic conditions.

3. Animal trials: All experiments performed to date have occurred in vitro. In order to better simulate the conditions within the human body, glass particles should be implanted in animals to determine their performance. In vivo studies offer the advantage of a complex biological environment that allows investigation of how the glass may inhibit bacterial growth, promotes bone formation, and possibly suppresses the proliferation of cancer cells in a living organism. Small animal models such as rabbits would be applicable here. Rabbits could undergo surgery in which a cavitary defect would be created in both proximal femurs. One side could be filled with the synthesized bioactive glass granules and the other with autologous bone grafted from 
the contralateral side. Fourteen days post surgery, the animals would be euthanized so that the bone neoformation and osteoblast cell-counts in the two sites with bioactive glass and autograft can be evaluated [184]. In order to study the effect of the glasses on osteosarcoma cells in vivo, osteosarcoma can be induced in the femur of the rabbits followed by graft operations using the glasses, euthanization, and appropriate histological examinations [185]. 


\section{References}


[1] L. Hench, O. Peitl and E. Zanotto, "Highly bioactive P2O5-Na2O-CaO-SiO2 glass cramics," J Non Cryst Sol, vol. 292, pp. 115-126, 2001.

[2] L. Hench, "The story of bioglass," J Mater Sci Mater Med, vol. 17, pp. 967-978, 2006.

[3] T. Kokubo and H. Takadama, "How useful is SBF in predicting in vivo bone bioactivity," Biomaterials, vol. 27, pp. 2907-2915, 2006.

[4] T. Kokubo, H. Kim and M. Kawashita, "Novel bioactive materials with different mechanical properties," Biomaterials, vol. 24, pp. 2161-2175, 2003.

[5] J. Heikkila, A. Aho, I. Kangasniemi and A. Yli-Urpo, "Polymethacrylate composites: disturbed bone formation at the surface of bioactive glass and hydroxyapatite," Biomaterials , vol. 17, no. 18, pp. 1755-1760, 1996.

[6] S. Daglilar, M. Erkan, O. Gunduz, L. Ozyegin, S. Salman, S. Agathopoulos and F. Oktar, "Water resistance of bone-cements reinforced with bioceramics," Mater Lett, vol. 61, no. 11-12, pp. 2295-2298, 2007.

[7] W. Lacefleld and L. Hench, "The bonding of Bioglass to a cobaltchromium surgical implant alloy," Biomaterials , vol. 7, no. 2, pp. 104-108, 1986.

[8] K. Rezwan, Q. Chen, J. Blaker and A. Boccaccini, "Biodegradable and bioactive porous polymer/inorganic composite scaffolds for bone tissue engineering," Biomaterials, vol. 27, no. 18 , pp. 3413-3431, 2006.

[9] Q. Fu, M. Rahaman, B. Bal, L. Bonewald, K. Kuroki and R. Brown, "Bioactive glass scaffolds with controllable degradation rates for bone tissue engineering applications. II. In vitro and in vivo biological evaluation," J Biomed Mater Res, vol. 95A, pp. 172-179, 2010.

[10] H. Oonishi, S. Kushitani, E. Yasukawa, H. Iwaki, L. Hench, J. Wilson, E. Tsuji and T. Sugihara, "Particulate bioglass compared with hydroxyapatite as a bone graft substitute," 
Clin Orthop Relat Res, vol. 334, pp. 316-325, 1997.

[11] R. Silveira, R. Machado, C. Silveira and R. Oliveira, "Bone repair process in calvarial defects using bioactive glass and calcium sulfate barrier," Acta Cir Bras , vol. 23, no. 4, pp. 322-328, 2008.

[12] Q. Fu, E. Saiz, M. Rahaman and A. Tomsia, "Bioactive glass scaffolds for bone tissue engineering: state of the art and future perspectives," Mater Sci Eng C Mater Biol Appl, vol. 31, no. 7, pp. 1245-1256, 2011.

[13] J. Jones, S. Lin, S. Yue, P. Lee, J. Hanna, M. Smith and R. Newport, "Bioactive glass scaffolds for bone regeneration and their hierarchical characterisation," Proc Inst Mech Eng H, vol. 224, no. 12, pp. 1373-1387, 2010.

[14] L. Gerhardt and A. Boccaccini, "Bioactive glass and glass-ceramic scaffolds for bone tissue engineering," Materials, vol. 3, no. 7, pp. 3867-3910, 2010.

[15] R. D. Goodridge, D. J. Wood, C. Ohtsuki and K. W. Dalgarno, "Biological evaluation of an apatite-mullite glass-ceramic produced via selective laser sintering," Acta Biomaterialia , vol. 3, pp. 221-231, 2007.

[16] L. Hench and I. Thompson, "Twenty-first century challenges for biomaterials," J R Soc Interface, vol. 7, pp. 379-391, 2010.

[17] M. Diba, F. Tapia and A. Boccaccini, "Magnesium-containing bioactive glasses for biomedical applications," Int J Appl Glass Sci, vol. 3, pp. 221-253, 2012.

[18] J. Jones, L. Ehrenfried, P. Saravanapavan and L. Hench, "Controlling ion release from bioactive glass foam scaffolds with antibacterial properties," J Mater Sci Mater Med, vol. 17, pp. 989-996, 2006.

[19] J. Jones and A. Clare, Bio-glasses: an introduction, New York: John Wiley and Sons, Ltd, 2012. 
[20] N. Gargiulo, A. Cusano, F. Causa, D. Caputo and P. Netti, "Silver-containing mesoporous bioactive glass with improved antibacterial properties," J Mater Sci Mater Med, vol. 24, no. 9, pp. 2129-2135, 2013.

[21] K. Magyari, C. Gruian, B. Varga, R. Ciceo-Lucacel, T. Radu, H. Steinhoff, G. Váró, V. Simon and L. Baia, "Addressing the optimal silver content in bioactive glass system in terms of BSA adsorption," J Mater Chem B, vol. 2, no. 35, pp. 5799-5808, 2014.

[22] J. Blaker, S. Nazhat and A. Boccaccini, "Development and characterisation of silver-doped bioactive glass-coated sutures for tissue engineeing and wound healing applications," Biomaterials, vol. 25, no. 7-8, pp. 1319-1329, 2004.

[23] M. Bellantone, H. Williams and H. Hench, "Broad-spectrum bactericidal activity of Ag2Odoped bioactive glass," Antimicrob Agents Chemother, vol. 46, no. 6, pp. 1940-1945, 2002.

[24] D. Boyd, H. Li, D. Tanner, M. Towler and J. Wall, "The antibacterial effects of zinc ion migration from zinc-based glass polyalkenoate cements," J Mater Sci Mater Med, vol. 17, no. 6, pp. 489-494, 2006.

[25] J. Pasquet, Y. Chevalier, J. Pelletier, E. Couval, D. Bouvier and M. Bolzinger, "The contribution of zinc ions to the antimicrobial activity of zinc oxide," Colloids Surf A, vol. 457, pp. 263-274, 2014.

[26] C. Lang, C. Murgia, M. Leong, L. Tan, G. Perozzi, D. Knight, R. Ruffin and P. Zalewski, "anti-inflammatory effects of zinc and alterations in zinc transporter mRNA in mouse models of allergic inflammation," Am J Physiol Lung Cell Mol Physiol, vol. 292, no. 2, pp. 577-584, 2007.

[27] O. Clarkin, A. Wren, R. Thornton, J. Cooney and M. Towler, "Antibacterial analysis of a zinc-based glass polyalkenoate cement," J Biomater Appl, vol. 26, no. 3, pp. 277-292, 2011.

[28] M. Yamaguchi, "Role of zinc in bone formation and bone resorption," J Trace Elem Exp 
Med, vol. 11, no. 2-3, pp. 119-135, 1998.

[29] H. Seo, Y. Cho, T. Kim, H. Shin and I. Kwun, "Zinc may increase bone formation through stimulating cell proliferation, alkaline phosphatase activity and collagen synthesis in osteoblastic MC3T3-E1 cells," Nutr Res Pract, vol. 4, no. 5, pp. 356-361, 2010.

[30] P. Melnikov, A. Malzac and M. Coelho, "Gallium and bone pathology," Acta Ortop Bras, vol. 16, no. 1, pp. 54-57, 2008.

[31] A. Salinas, S. Shruti, G. Malavasi, L. Menabue and M. Vallet-Regi, "Substitutions of cerium, gallium, and zinc in ordered mesoporous bioactive glasses," Acta Biomater, vol. 7, pp. 3452-3458, 2011.

[32] M. Hart and R. Adamson, "Antitumor activity and toxicity of salts of inorganic group IIIa metals: aluminum, gallium, indium, and thallium," Proc Nat Acad Sci USA, vol. 68, no. 7, pp. 1623-1626, 1971.

[33] A. Deliormanli, "Synthesis and characterization of cerium- and gallium-containing borate bioactive glass scaffold for bone tissue engineering," J Mater Sci: Mater Med, vol. 26, no. 67, pp. 1-13, 2015.

[34] A. Wren, A. Coughlan, L. Placek and M. Towler, "Gallium containing glass polyalkenoate anti-cancerous bone cements: glass characterization and physical properties," J Mater Sci: Mater Med, vol. 23, pp. 1823-1833, 2012.

[35] E. Zeimaran, S. Pourshahrestani, B. Pingguan-Murphy, N. Kadri, H. Rothan and R. Yusof, "Fabrication and characterization of poly (octanediol citrate)/gallium-containing bioglass microcomposite scaffolds," J Mater Sci, vol. 50, pp. 2189-2201, 2015.

[36] P. Collery, B. Keppler, C. Madoulet and B. Desoize, "Gallium in cancer treatment," Crit Rev Oncol Hematol, vol. 42, pp. 283-296, 2002.

[37] C. Chitambar, "Gallium-containing anticancer compounds," Future Med Chem, vol. 4, no. 10, pp. 1257-1272, 2012. 
[38] B. Leyland-Jones, "Treating cancer-related hypercalcemia with gallium nitrate," J Support Oncol, vol. 2, pp. 509-520, 2004.

[39] G. Malavasi, A. Pedone and M. Menziani, "Study of the structural role of gallium and aluminum in 45S5 bioactive glasses by molecular dynamic simulations," J Phys Chem B, vol. 117, pp. 4142-4150, 2013.

[40] M. Franchini, G. Lusvardi, G. Malavasi and L. Menabue, "Gallium-containing phosphosilicate glasses: synthesis and in vitro bioactivity," J Mat Sci Eng C, vol. 32, pp. 14011406, 2012.

[41] A. Alhalawani, D. Curran, B. Pingguan-Murphy, D. Boyd and M. Towler, "A novel glass polyalkenoate cement for fixation and stabilisation of the ribcage, post sternotomy surgery: an ex-vivo study," J Funct Biomater, vol. 4, pp. 329-357, 2013.

[42] R. Gunzburg, M. Szpalski and N. Passuti, The Use of Bone Substitutes in Spine Surgery: A State of the Art Review, Springer, 2002.

[43] S. Cho, K. Nakanishi, T. Kokubo, N. Soga, C. Ohtsuki, T. Nakamura, T. Kitsugi and T. Yamamuro, "Dependence of apatite formation on silica gel on its structure: effect of heat treatment," J Am Ceram Soc, vol. 78, p. 1769-1774, 1995.

[44] J. R. Jones, L. M. Ehrenfried and L. L. Hench, "Optimising bioactive glass scaffolds for bone tissue engineering," Biomaterials, vol. 27, no. 7, pp. 964-973, 2006.

[45] J. Lemaitre and M. Bohner, "Can bioactivity be tested in vitro with SBF solution?," Biomaterials, vol. 30, p. 2175-2179, 2009.

[46] T. Matsuda and J. Davies, "The in vitro response of osteoblasts to bioactive glass," Biomaterials, vol. 8, no. 4, p. 275-284, 1987.

[47] L. L. Hench, R. J. Splinter, W. C. Allen and T. K. Greenlee, "Bonding mechanisms at the interface of ceramic prosthetic materials," Journal of Biomedical Materials Research, vol. 5, no. 6, pp. 117-141, 1971. 
[48] Q. Chen, I. Thompson and A. Boccaccini, "45S5 Bioglass ®-derived glass-ceramic scaffolds for bone tissue engineering," Biomaterials, vol. 27, no. 11, pp. 2414-2425, 2006.

[49] H. Fu, M. Rahaman, D. Day and W. Huang, "Effect of pyrophosphate ions on the conversion of calcium-lithium-borate glass to hydroxyapatite in aqueous phosphate solution," J Mater Sci Mater Med, vol. 21, no. 10, p. 2733-2741, 2010.

[50] M. Ogino, F. Ohuchi and L. Hench, "Compositional Dependence of the Formation of Calcium Phosphate Films on Bioglass," J Biomed Mat Res, vol. 14, no. 1, pp. 55-64, 1980.

[51] C. Pantano, A. Clark and L. Hench, "Multilayer corrosion films on glass surfaces," J Am Ceram Soc, vol. 57, no. 9, pp. 412-413, 1974.

[52] L. Hench, "Bioceramics: From Concept to Clinic," J Am Ceram Soc, vol. 74, no. 7, pp. 1487-1510, 1991.

[53] M. Rahaman, D. Day, B. Bal, Q. Fu, S. Jung, L. Bonewald and A. Tomsia, "Bioactive glass in tissue engineering," Acta Biomaterialia, vol. 7, no. 6, pp. 2355-2373, 2011.

[54] N. Marion, W. Liang, G. Reilly, D. Day, M. Rahaman and J. Mao, "Bioactive borate glass supports the osteogenic potential of human mesenchymal stem cells," Mech Adv Mater Struct, vol. 12, pp. 239-246, 2005.

[55] H. Fu, Q. Fu, N. Zhou, W. Huang, M. Rahaman, D. Wang and X. Liu, "In vitro evaluation of borate-based bioactive glass scaffolds prepared by a polymer foam replication method," Mater Sci Eng C, vol. 29, pp. 2275-2281, 2009.

[56] X. Liu, Z. Xie, C. Zhang, H. Pan, M. Rahaman, X. Zhang, Q. Fu and W. Huang, "Bioactive borate glass scaffolds: in vitro and in vivo evaluation for use as a drug delivery system in the treatment of bone infection," J Mater Sci Mater Med, Vols. 575-582, p. 21, 2010.

[57] W. Jia, X. Zhang, S. Luo, W. Huang, M. Rahaman, D. Day, C. Zhang, Z. Xie and J. Wang, "Novel borate glass/chitosan composite as a delivery vehicle for teicoplanin in the 
treatment of chronic osteomyelitis," Acta Biomater, vol. 6, pp. 812-819, 2010.

[58] X. Zhang, W. Jia, Y. Gu, W. Xiao, X. Liu, D. Wang, C. Zhang, W. Huang, M. Rahaman, D. Day and N. Zhou, "Teicoplanin-loaded borate bioactive glass implants for treating chronic bone infection in a rabbit tibia osteomyelitis model," Biomaterials, vol. 31, no. 22, pp. 5865-5874, 2010.

[59] R. Martens, N. Miller, N. Cohen, J. Harrington and L. Bernstein, "Chemoprophylactic antimicrobial activity of gallium maltolate against intracellular Rhodococcus equi," $J$ Equine Vet Sci, vol. 27, no. 8, pp. 341-345, 2007.

[60] C. Bonchi, F. Imperi, F. Minandri, P. Visca and E. Frangipani, "Repurposing of galliumbased drugs for antibacterial therapy," BioFactors, vol. 40, pp. 303-312, 2014.

[61] S. Oh, S. Kim, J. Won, J. Kim, U. Shin and H. Kim, "Effects on growth and osteogenic differentiation of mesenchymal stem cells by the zinc-added sol-gel bioactive glass granules," J Tissue Eng, vol. 1, no. 1, pp. 1-10, 2010.

[62] M. Fang, J. Chen, X. Xu, P. Yang and H. Hildebrand, "Antibacterial activities of inorganic agents on six bacteria associated with oral infections by two susceptibility tests," Int J Antimicrob Agents, vol. 27, pp. 513-517, 2006.

[63] Y. Xie, Y. He, P. Irwin, T. Jin and X. Shi, "Antibacterial activity and mechanism of action of zinc oxide nanoparticles against campylobacter jejuni," Appl Environ Microbiol, vol. 77, no. 7, pp. 2325-2331, 2011.

[64] C. Chitambar, W. Matthaeus, W. Antholine, K. Graff and W. O'Brien, "Inhibition of leukemic HL60 cell growth by transferrin-gallium: effects on ribonucleotide reductase and demonstration of drug synergy with hydroxyurea," Blood, vol. 72, pp. 1930-1936, 1988.

[65] C. Chitambar, J. Narasimhan, J. Guy, D. Sem and W. O'Brien, "Inhibition of ribonucleotide reductase by gallium in murine leukemic L1210 cells," Cancer Res, vol. 51, pp. 6199-6201, 1991. 
[66] R. Rhaq, J. Wereley and C. Chitambar, "Induction of apoptosis by iron deprivation in human leukemic CCRF-CEM cells," Exp Hematol, vol. 23, pp. 428-432, 1995.

[67] R. Warrell, A. Skelos, N. Alcock and R. Bockman, "Gallium nitrate for acute treatment of cancer-related hypercalcemia: clinicopharmacological and dose response analysis," Cancer Res , vol. 46, pp. 4208-4212, 1986.

[68] R. Warrell, M. Issacs, N. Alcock and R. Bockman, "Gallium nitrate for treatment of refractory hypercalcemia from parathyroid carcinoma," Ann Intern Med, vol. 107, pp. 683-686, 1987.

[69] R. Warrell, R. Israel, M. Frisone, T. Snyder, J. Gaynor and R. Bockman, "Gallium nitrate for acute treatment of cancer-related hypercalcemia. A randomized, double-blind comparison to calcitonin," Ann Intern Med, vol. 108, pp. 669-674, 1988.

[70] R. Warrell and R. Bockman, "Gallium for bone loss in cancer and metabolic bone diseases," Metal ions in biology and medicine, Paris: John Libbey Eurotext, vol. 1, pp. 432-435, 1990.

[71] P. Todd and A. Fitton, "Gallium nitrate: A review of its pharmacological properties and therapeutic potential in cancer related hypercalcaemia," Drugs , vol. 42, pp. 261-273, 1991.

[72] M. Repo, R. Bockman, F. Betts, A. Boskey, N. Alcock and R. Warrell, "Effect of gallium on bone mineral properties," Calcif Tissue Int , vol. 43, pp. 300-306, 1988.

[73] C. Whitacre, G. Apseloff, K. Cox, V. Matkovic, S. Jewell and N. Gerber, "Suppression of experimental autoimmune encephalomyelitis by gallium nitrate," J Neuroimmunol, vol. 39, pp. 175-181, 1992.

[74] T. Hall and T. Chambers, "Gallium inhibits bone resorption by a direct effect on osteoclasts," Bone Miner, vol. 8, pp. 211-216, 1990.

[75] G. Cournot-Witmer, A. Bourdeau, M. Lieberherr, C. Thil, J. Plachot, G. Enault, R. 
Bourdon and S. Balsan, "Bone modeling in gallium nitrate-treated rats," Calcif Tissue Int, vol. 40, pp. 270-275, 1987.

[76] R. Bockman, A. Boskey, N. Blumenthal, N. Alcock and R. Warrell, "Gallium increases bone calcium and crystallite perfection of hydroxyapatite," Calcif Tissue Int, vol. 39, pp. 376-381, 1986.

[77] P. Guidon, R. Salvatori and R. Bockman, "Gallium nitrate regulates rat osteoblast expression of osteocalcin protein and mRNA levels," J Bone Miner Res , vol. 8, pp. 103$112,1993$.

[78] R. Bockman, P. Guidon, L. Pan, R. Salvatori and A. Kawaguchi, "Gallium nitrate increases type I collagen and fibronectin mRNA and collagen protein levels in bone and fibroblast cells," J Cell Biochem, vol. 52, no. 4, pp. 396-403, 1993.

[79] P. Collery, H. Millart, J. Simoneau and J. Etienne, "Selective uptake of gallium administered orally, as chloride, by tumor cells," New concepts in cancer chemotherapy, vol. 284, pp. 35-43, 1983.

[80] P. Collery, H. Millart, J. Simoneau, M. Pluot, S. Halpern, C. Pechery, H. Choisy and J. Etienne, "Experimental treatment of mammary carcinomas by Gallium chloride after oral administration: intratumor dosages of Gallium, anatomopathologic study and intracellular micro-analysis," Trace Elem Med, vol. 1, pp. 159-161, 1984.

[81] H. Otsuki, A. Brunetti, E. Owens, R. Finn and R. Blasberg, "Comparison of iron-59, indium-111, and gallium-69 transferrin as a macromolecular tracer of vascular permeability and the transferrin receptor," J Nucl Med, vol. 30, pp. 1676-1685, 1989.

[82] C. Edwards and R. Hayes, "Tumor scanning with 67Ga citrate," J Nucl Med, vol. 10, pp. 103-105, 1969.

[83] L. Bernstein, J. van der Hoeven and R. Boer, "Hepatocellular carcinoma detection by gallium scan and subsequent treatment by gallium maltolate: rationale and case study," 
Anticancer Agents Med Chem, vol. 11, pp. 585-590, 2011.

[84] J. Zhang, W. Liu, V. Schnitzler, F. Tancret and J. Bouler, "Calcium phosphate cements for bone substitution: Chemistry, handling and mechanical properties," Acta Biomater, vol. 10, no. 3, pp. 1035-1049, 2014.

[85] C. Finkemeier, "Bone-grafting and bone-graft substitutes," J Bone Joint Surg Am, vol. 84 A, pp. 454-564, 2002.

[86] G. Zimmermann and A. Moghaddam, "Allograft bonematrix versus synthetic bone graft substitutes," INJURY, vol. 42, pp. S16-S21, 2011.

[87] M. Putzier, P. Struble, J. Funk, C. Gross, H. Monig and C. Perka, "Allogenic versus autologous cancellous bone in lumbar segmental spondylodesis: a randomized prospective study," Eur Spine J, vol. 18, pp. 687-695, 2009.

[88] R. Warrel, R. Bockman, C. Coonley, M. Isaacs and H. Staszewski, "Gallium nitrate inhibits calcium resorption from bone and is effective treatment for cancer-related hypercalcemia," J Clin Invest, vol. 73, pp. 1487-1490, 1984.

[89] P. Melnikov, A. Teixeira, A. Malzac and M. Coelho, "Gallium-containing hydroxyapatite for potential use in orthopedics," Mater Chem Phys, vol. 117, pp. 86-90, 2009.

[90] M. Sanchez-Robles, P. Gamero-Melo and D. Cortes-Hernandez, "In vitro hydroxyapatite formation on the Ca doped surface of ZSM-5 [Ga] type zeolite," Ceram Int, vol. 39, pp. 7387-7390, 2013.

[91] C. Chitamber, "Medical applications and toxicities of gallium compounds," Int J Environ Res Public Health, vol. 7, no. 52, pp. 337-361, 2010.

[92] V. Mourino and P. B. A. Newby, "Preparation and characterization of gallium releasing 3$\mathrm{D}$ alginate coated 45S5 bioglass (R) based scaffolds for bone tissue engineering," Adv Eng Mater, vol. 12, no. 7, pp. B283-B291, 2010. 
[93] S. Shruti, A. Salinas, G. Lusvardi, G. Malavasi, L. Menabue and M. Vallet-Regi, "Mesoporous bioactive scaffolds prepared with cerium-, gallium- and zinc-containing glasses," Acta Biomater, vol. 9, pp. 4836-4844, 2012.

[94] S. Shruti, A. Salinas, G. Malavasi, G. Lusvardi, L. Menabue, C. Ferrara, P. Mustarelli and M. Vallet-Regì, "Structural and in vitro study of cerium, gallium and zinc containing solgel bioactive glasses," J Mater Chem, vol. 22, pp. 13698-13706, 2012.

[95] L. Palmer, C. Newcomb, S. Kaltz, R. Spoerke and S. Stupp, "Biomimetic Systems for Hydroxyapatite Mineralization Inspired By Bone and Enamel," Chem Rev, vol. 108, no. 11, pp. 4754-4783, 2008.

[96] D. Fourney, D. Schomer, R. Nader, J. Chlan-Fourney, D. Suki, K. Ahrar, L. Rhines and Z. Gokaslan, "Percutaneous vertebroplasty and kyphoplasty for painful vertebral body fractures in cancer patients," J Neurosurg, vol. 98, pp. 21-30, 2003.

[97] K. Hing, "Bone repair in the twenty-first century: Biology, chemistry or engineering?," Philos Trans A Math Phys Eng Sci, vol. 362, pp. 2821-2850, 2004.

[98] J. Regan, A. Russo and C. putte, Seeley's Anatomy \& Physiology, 9th Edition. New York, USA: Mc Graw Hill, New York, USA: Mc Graw Hill, 2011.

[99] "AS Applied Exercise Physiology," [Online]. Available: https://www.pinterest.com/rugby143/as-applied-exercise-physiology/. [Accessed 13 March 2017].

[100] E. Marieb, Human physiology and anatomy, sixth edition, Pearson Education, 2004.

[101] A. Waugh and A. Grant, Anatomy and physiology in health and illness, Churchill Livingstone, 2001.

[102] "Chapter 6: Bones And Skeletal Tissues," [Online]. Available: http://classes.midlandstech.edu/carterp/Courses/bio210/chap06/lecture1.html. [Accessed 13 March 2017]. 
[103] F. Martini, Fundamentals of anatomy and physiology, Fourth Edition, Upper Saddle River, NJ: Prentice Hall, 1998.

[104] "National Cancer Institude," [Online]. Available: http://training.seer.cancer.gov/anatomy/skeletal/tissue.html. [Accessed 13 March 2017].

[105] M. Abdelgawad, K. Søe and T. Andersen, "Does collagen trigger the recruitment of osteoblasts into vacated bone resorption lacunae during bone remodeling?," Bone , vol. 67, pp. 181-188, 2014.

[106] R. Ruimerman, "Modeling and remodeling in bone tissue. Doctoral dissertation," Eindhoven Technical University, Eindhoven, Netherland, 2005.

[107] S. Silverman and M. Maricic, "Recent Developments in Bisphosphonate Therapy," Semin Arthritis Rheum, vol. 37, no. 1, pp. 1-12, 2007.

[108] B. Toolan, "Current concepts review: Orthobiologics," Foot Ankle Int, vol. 27, no. 5, pp. 561-566, 2006.

[109] W. De Long, T. Einhorn, K. Koval, M. McKee, W. Smith, R. Sanders and T. Watson, "Bone grafts and bone graft substitutes in orthopaedic trauma surgery," J Bone Joint Surg Am, vol. 89, pp. 649-658, 2007.

[110] M. McKee, "Management of segmental bony defects: The role of osteoconductive orthobiologics," J Am Acad Orthop Surg, vol. 14, pp. S163-S167, 2006.

[111] G. Friedlaender, C. Perry, J. Cole, S. Cook, G. Cierny, G. Muschler, G. Zych, J. Calhoun, A. Laforte and S. Yin, "Osteogenic protein-1 (bone morphogenetic protein-7) in the treatment of tibialnonunions," J Bone Joint Surg Am, vol. 83A, no. 1, pp. S151-S158, 2001.

[112] "ThermoFisher SCIENTIFIC," [Online]. Available: https://www.thermofisher.com/antibody/product/Human-BMP-2-Carrier-FreeRecombinant-Protein/34-8507-82. [Accessed 13 March 2017]. 
[113] E. Erbe, J. Marx, T. Clineff and L. Bellincampi, "Potential of an ultraporous beta tricalcium phosphate synthetic cancellous bone void filler and bone marrowaspirate composite graft," Eur Spine J, vol. 10, no. 2, pp. S141-S146, 2001.

[114] S. Ghosh, S. Nandi, B. Kundu, S. Datta, D. De, S. Roy and D. Basu, "In vivo response of porous hydroxyapatite and beta-tricalcium phosphate prepared by aqueous solution combustion method and comparison with bioglass scaffolds," J Biomed Mater Res Part B Appl Biomater, vol. 86, no. 1, pp. 217-227, 2008.

[115] D. Hak, "The use of osteoconductive bone graft substitutes in orthopaedic trauma," J Am Acad Orthop Surg, vol. 15, pp. 525-536, 2007.

[116] L. Carey, H. Xu, C. Simon, S. Takagia and L. Chowa, "Premixed rapid-setting calcium phosphate composites forbonerepair," Biomaterials , vol. 26, pp. 5002-5014, 2005.

[117] C. Kasperk, J. Hillmeier, G. Noldge, I. Grafe, K. Dafonseca, D. Raupp, H. Bardenheuer, M. Libicher, U. Liegibel, U. Sommer, U. Hilscher, W. Pyerin, M. Vetter, H. Meinzer, P. Meeder, R. Taylor and P. Nawroth, "Treatment of painful vertebral fractures by kyphoplasty in patients with primary osteoporosis: a prospective nonrandomized controlledstudy," J Bone Miner Res, vol. 20, no. 4, pp. 604-612, 2005.

[118] C. Nich and M. Hamadouche, "Synthetic Bone Grafts: Clinical Use, Comprehensive," Biomaterials, vol. 1, pp. 335-347, 2011.

[119] J. Eldridge, J. Cunningham, A. Samuels, G. Blunn, T. Lawes, I. Learmonth and A. Goodship, "Glass ionomer as an expander of allograft in revision arthroplasty of the hip," Biomaterials, vol. 24, no. 3, pp. 499-508, 2003.

[120] D. Farrar, "Bone adhesives for trauma surgery: A review of challenges and developments," Int J Adhes Adhes, vol. 33, pp. 89-97, 2012.

[121] L. Hench, I. Xynos and J. Polak, "Bioactive glasses for in situ tissue regeneration," $J$ Biomater Sci Polym Ed, vol. 15, pp. 543-562, 2004. 
[122] A. Gorustovich, J. Roether and A. Boccaccini, "Effect of bioactive glasses on angiogenesis: a review of in vitro and in vivo evidences," Tissue Eng. Part B Rev, vol. 16, pp. 199-207, 2010.

[123] A. Hoppe, N. Güldal and A. Boccaccini, "A review of the biological response to ionic dissolution products from bioactive glasses and glass-ceramics," Biomaterials, vol. 32, no. 11, pp. 2757-2774, 2011.

[124] J. Jones, "Review of bioactive glass: From Hench to hybrids," Acta Biomater, vol. 9, pp. 4457-4486, 2013.

[125] "Drugs.com," [Online]. Available: http://www.drugs.com/monograph/gallium-nitrate.html. [Accessed 13 March 2017].

[126] P. Collery, H. Millart, D. Lamiable, R. Vistelle, P. Rinjard, G. Tran, B. Gourdier, C. Cossart, J. Bouana and C. Pechery, "Clinical pharmacology of gallium chloride after oral administration in lung cancer patients," Anticancer Research, vol. 9, pp. 353-356, 1989.

[127] L. Bernstein, T. Tanner, C. Godfrey and B. Noll, "Chemistry and pharmacokinetics of gallium maltolate, a compound with high oral gallium bioavailability," Metal-based Drugs , vol. 7, no. 1, pp. 33-47, 2000.

[128] S. Pourshahrestani, E. Zeimaran, N. A. Kadri, N. Gargiulo, S. Samuel, S. Naveen, T. Kamarul and M. Towler, "Gallium-containing mesoporous bioactive glass with potent hemostatic activity and antibacterial efficacy," J Mater Chem B, vol. 4, pp. 71-86, 2016.

[129] A. Deliormanlı and M. Y1ldırım, "Sol-gel synthesis of 13-93 bioactive glass powders containing therapeutic agents," J Aust Ceram Soc, vol. 52, no. 2, pp. 9-19, 2016.

[130] A. M. Deliormanli, "Electrospun cerium and gallium-containing silicate based 13-93 bioactive glass fibers for biomedical applications," Ceram Int, vol. 42, no. 1, pp. 897-906, 2016.

[131] A. Rahimnejad Yazdi and M. Towler, "The effect of the addition of gallium on the 
structure of zinc borate glass with controlled gallium ion release," Materials and design, vol. 92, pp. 1018-1027, 2016.

[132] J. Shelby, Introduction to glass science and technology. 2nd ed., Cambridge: The Royal Society of Chemistry, 2005.

[133] R. Ciceo-Lucacel and I. Ardelean, "FT-IR and Raman study of silver lead borate-based glasses," Journal of Non-Crystalline Solids, vol. 353, no. 18, pp. 2020-2024, 2007.

[134] G. Malinina, O. Stefanovsky and S. Stefanovsky, "Glass ceramics for incinerator ash immobilization," J Nucl Mater, vol. 416, pp. 230-235, 2011.

[135] D. Maniu, I. Ardelean, T. Iliescu, S. Cinta, V. Nagel and W. Kiefer, "Raman spectroscopic investigations on oxide glass system (1 - x) [3B2O3·K2O]. x TiO2," J Mol Struct, vol. 480, pp. 657-659, 1999.

[136] T. Iliescu, S. Simon and D. Calugar, "Raman spectroscopy of oxide glass system (1-x) (yB2O3.zLi2O) .xMO (MO = CuO, V2O5)," J Mol Struct, vol. 267, pp. 231-233, 1992.

[137] D. Manara, A. Grandjean and D. Neuville, "Advances in understanding the structure of borosilicate glasses: A Raman spectroscopy study," Am Mineral, vol. 94, pp. 777-784, 2009.

[138] R. Christensen, G. Olsen and S. Martin, "Structural studies of mixed glass former 0.35 $\mathrm{Na} 2 \mathrm{O}+0.65$ [x B2O3 + (1-x) P2O5] glasses by Raman and 11B and 31P Magic angle spinning nuclear magnetic resonance spectroscopies," J Phys Chem B , vol. 117, pp. 2169$2179,2013$.

[139] J. F. Stebbins, P. Zhao and S. Kroeker, "Non-bridging oxygens in borate glasses: characterization by 11 B and 17 O MAS and 3QMAS NMR.," Solid State Muclear Magnetic Resonance, vol. 16, no. 1, pp. 9-19, 2000.

[140] H. Eckert, "Structural characterization of noncrystalline solids and glasses using solid state NMR," Prog Nucl Magn Reson Spectrosc, vol. 24, pp. 159-293, 1992. 
[141] E. H. Rinke MT, "The mixed network former effect in glasses: solid state NMR and XPS structural studies of the glass system (Na2O)x(BPO4)1-x," Phys Chem Chem Phys, vol. 13, pp. 6552-6565, 2011.

[142] A. Rahimnejad Yazdi, L. Torkan, W. Stone and M. Towler, "The impact of gallium content on degradation, bioactivity and antibacterial potency of zinc borate bioactive glass," J Biomed Mater Res Part B Appl Biomater, 2017.

[143] X. Yang, L. Zhang, X. Chen, X. Sun, G. Yang, X. Guo, H. Yang, C. Gao and Z. Gou, "Incorporation of $\mathrm{B} 2 \mathrm{O} 3$ in $\mathrm{CaO}-\mathrm{SiO} 2-\mathrm{P} 2 \mathrm{O} 5$ bioactive glass system for improving strength of low-temperature co-fired porous glass ceramics," J Non-Cryst Solids, vol. 358, no. 9, pp. 1171-1179, 2012.

[144] N. Heatley, "A method for the assay of penicillin," Biochem J, vol. 38, pp. 61-65, 1944.

[145] Q. Fu, M. Rahaman, H. Fu and X. Liu, "Silicate, borosilicate, and borate bioactive glass scaffolds with controllable degradation rate for bone tissue engineering applications.I. Preparation and in vitro degradation," J Biomed Mater Res, vol. 95A, no. 1, pp. 164-171, 2010.

[146] Y. Li, L. Placek, A. Coughlan, F. Laffir, D. Pradhan, N. Mellott and W. AW., "Investigating the influence of $\mathrm{Na}+$ and $\mathrm{Sr} 2+$ on the structure and solubility of $\mathrm{SiO} 2-\mathrm{TiO} 2-$ CaO-Na2O/SrO bioactive glass," J Mater Sci: Meter Med, vol. 26, pp. 1-12, 2015.

[147] A. Wren, N. Cummins, F. Laffir, S. Hudson and M. Towler, "The bioactivity and ion release of titanium-containing glass polyalkenoate cements for medical applications," $J$ Mater Sci: Mater Med, vol. 22, pp. 19-28, 2011.

[148] D. Boyd and M. Towler, "The processing, mechanical properties and bioactivity of zinc based glass ionomer cements," J Mater Sci: Mater Med, vol. 16, pp. 843-850, 2005.

[149] D. Boyd, M. Towler, A. Wren, O. Clarkin and D. Tanner, "TEM analysis of apatite surface layers observed on zinc basedglass polyalkenoate cements," J Mater Sci, vol. 19, pp. 1170- 
$1173,2008$.

[150] A. Wren, D. Boyd and M. Towler, "The processing, mechanical properties and bioactivity of strontium based glass polyalkenoate cements," J Mater Sci: Mater Med, vol. 19, pp. 1737-1743, 2008.

[151] A. Bigi, E. Foresti, M. Gandolfi, M. Gazzano and N. Roveri, "Inhibiting effect of zinc on hydroxylapatite crystallization," J Inorg Biochem, vol. 58, pp. 49-58, 1995.

[152] N. Kanzaki, K. Onuma, G. Treboux, S. Tsutsumi and A. Ito, "Inhibitory effect of magnesium and zinc on crystallization kinetics of hydroxyapatite (0001) face," J Phys Chem B, vol. 104, no. , pp. 4189-4194, 2000.

[153] A. Yao, D. Wang, W. Huang, Q. Fu, M. Rahaman and D. Day, "In Vitro Bioactive Characteristics of Borate-Based Glasses with Controllable Degradation Behavior," Journal of the American Ceramic Society, vol. 90, no. 1, pp. 303-306, 2007.

[154] A. Haider, K. Gupta and I. Kang, "Morphological effects of HA on the cell compatibility of electrospun HA/PLGA composite nanofiber scaffolds," BioMed Res Int, vol. 2014, pp. $1-11,2014$.

[155] J. Jones, P. Sepulveda and L. Hench, "Dose-dependent behavior of bioactive glass dissolution," J Biomed Mater Res A, vol. 58, pp. 720-726, 2001.

[156] H. Lu, S. Pollack and P. Ducheyne, "45S5 Bioactive glass surface charge variations and the formation of a surface calcium phosphate layer in a solution containing fibronectin," $J$ Biomed Mater Res, vol. 54, pp. 454-461, 2001.

[157] H. Morgan, R. Wilson, J. Elliott, S. Dowker and P. Anderson, "Preparation and characterization of monoclinic hydroxyapatite and its precipitated carbonate apatite imtermediate," Biomaterials, vol. 21, pp. 617-627, 2000.

[158] W. Huang, M. Rahaman, D. Day and Y. Li, "Mechanisms for converting bioactive silicate, borate, and borosilicate glasses to hydroxyapatite in dilute phosphate solutions," Phys 
Chem Glasses: Eur J Glass Sci Technol B, vol. 47, no. 6, pp. 647-658, 2006.

[159] B. Sugarman, "Zinc and infection," Rev Infect Dis, vol. 5, no. 1, pp. 138-147, 1983.

[160] T. Södeberg, B. Sunze, S. Holm, T. Elmro, G. Hallmans and S. Sjöberg, "Antibacterial effect of zinc oxide in vitro," Scand J Plast Reconstr Hand Surg, vol. 24, pp. 193-197, 1990.

[161] T. Södeberg, S. Holm, R. Gref and G. Hallmans, "Antibacterial effect of zinc oxide, rosin and resin acids with special reference to their interactions," Scand J Plast Reconstr Hand Surg, vol. 25, pp. 19-24, 1991.

[162] S. Atmaca, K. Gül and R. Çiçek, "The Effect of zinc on microbial growth," Tr J Med Sci, vol. 28, pp. 595-597, 1998.

[163] J. Bullen, H. Roger, P. Spalding and C. Ward, "Iron and infection: the heart of the matter," FEMS Immunol Med Microbiol, vol. 43, pp. 325-330, 2005.

[164] O. Rzhepishevska, B. Ekstrand-Hammarström, M. Popp, E. Björn, A. Bucht, A. Sjöstedt, H. Antti and M. Ramstedt, "The Antibacterial activity of Ga3+ ions influenced by ligand complexation as well as the bacterial carbon source," Antimicrob Agents Chemother, vol. 55, no. 12, pp. 5568-5580, 2011.

[165] Y. Kaneko, M. Thoendel, O. Olakanmi, B. Britigan and P. Singh, "The transition metal gallium disrupts Pseudomonas aeruginosa iron metabolism and has antimicrobial and antibiofilm activity," J Clin Invest, vol. 117, no. 4, pp. 877-888, 2007.

[166] A. Rahimnejad Yazdi, L. Torkan, S. Waldman and M. Towler, "Development of a novel bioactive glass suitable for osteosarcoma-related bone grafts," J Biomed Mater Res Part B Appl Biomater, 2017.

[167] P. Schlesinger, S. Teitelbaum and H. Blair, "Osteoclast inhibition by Ga3+ contrasts with bisphosphonate metabolic suppression Competitive inhibition of H+ ATPase by bonebound gallium," J Bone Min Res, vol. 6, p. S127, 1991. 
[168] P. Price, "Vitamin K-dependent formation of bone gla protein (osteocalcin) and its function," Vitarn Horm, vol. 42, pp. 65-108, 1985.

[169] P. Price, M. Williamson, T. Haba, R. Dell and W. Jee, "Excessive mineralization with growth plate closure in rats on chronic warfarin treatment," Proc Natl Acad Sci USA, vol. 79, pp. 7734-7738, 1982.

[170] G. Mundy and J. Poser, "Chemotactic activity of y-carboxyglutamic acid containing protein in bone," Calcif Tissue Int, vol. 3, pp. 164-168, 1983.

[171] J. Malone, S. Teitelbaum, G. Griffin, R. Senio and A. Kahn, "Recruitment of osteoclasts precursors by purified bone matrix constituents," J Cell Biol, vol. 92, pp. 227-230, 1982.

[172] M. Yamaguchi and R. Yamaguchi, "Action of zinc on bone metabolism in rats: Increases in alkaline phosphatase activity and DNA content," Biochem Pharmacol, vol. 35, pp. 773$777,1986$.

[173] A. Ito, H. Kawamura, M. Otsuka, M. Ikeuchi, H. Ohgushi, K. Ishikawa, K. Onuma, N. Kanzaki, Y. Sogoa and N. Ichinose, "Zinc-releasing calcium phosphate for stimulating bone formation," Mater Sci Eng C, vol. 22, pp. 21-25, 2002.

[174] S. Haumont, "Distribution of zinc in bone tissue," J Histochem Cytochem, vol. 9, pp. 141$145,1961$.

[175] P. Balasubramanian, L. Strobel, U. Kneser and A. Boccaccini, "Zinc-containing bioactive glasses for bone regeneration, dental and orthopedic applications," Biomed Glasses, vol. 1, p. 51-69, 2015.

[176] K. Hadley, S. Newman and J. Hunt, "Dietary zinc reduces osteoclast resorption activities and increases markers of osteoblast differentiation, matrix maturation, and mineralization in the long bones of growing rats," J Nutr Biochem, vol. 21, pp. 297-303, 2010.

[177] M. Yamaguchi, "Role of nutritional zinc in the prevention of osteoporosis," Mol Cell Biochem, vol. 338, pp. 241-254, 2010. 
[178] M. Nagata and B. Lonnerdal, "Role of zinc in cellular zinc trafficking and mineralization in a murine osteoblast-like cell line," J Nutr Biochem, vol. 22, pp. 172-178, 2011.

[179] M. Yamaguchi and M. Weitzmann, "Zinc stimulates osteoblastogenesis and suppresses osteoclastogenesis by antagonizing NF-kB activation," Mol Cell Biochem, vol. 355, pp. 179-186, 2011.

[180] I. Kwun, Y. Cho, R. Lomeda, H. Shin, J. Choi, Y. Kang and J. Beattie, "Zinc deficiency suppresses matrix mineralization and retards osteogenesis transiently with catch-up possibly through Runx 2 modulation," Bone, vol. 46, no. 3, pp. 732-741, 2010.

[181] S. Maeno, Y. Niki, H. Matsumoto, H. Morioka, T. Yatabe, A. Funayama, Y. Toyama, T. Taguchi and J. Tanaka, "The effect of calcium ion concentration on osteoblast viability, proliferation and differentiation in monolayer and 3D culture," Biomaterials, vol. 26, no. 23, pp. 4847-4855, 2005.

[182] P. Marie, "The calcium-sensing receptor in bone cells: a potential therapeutic target in osteoporosis," Bone, vol. 46, no. 3, pp. 571-576, 2010.

[183] P. Valerio, M. Pereira, A. Goes and M. Leite, "Effects of extracellular calcium concentration on the glutamate release by bioactive glass (BG60S) preincubated osteoblasts," Biomed Mater, vol. 4, no. 4, p. 045011, 2009.

[184] A. Camargo, A. Baptista, R. Natalino and O. Camargo, "Bioactive glass in cavitary bone defects: a comparative experimental study in rabbits," Acta Ortop Bras, vol. 23, no. 4, pp. 202-207, 2015.

[185] K. Sato, H. Nukaga, T. Horikoshi and I. Iwasaki, "Difference in the induction of osteosarcoma in rabbit bone with single administration of three kinds of chemical carcinogens," Gan, vol. 69, no. 4, pp. 579-583, 1978. 